\title{
The Role of VET Colleges in Stimulating Teachers' Engagement in Team Learning
}

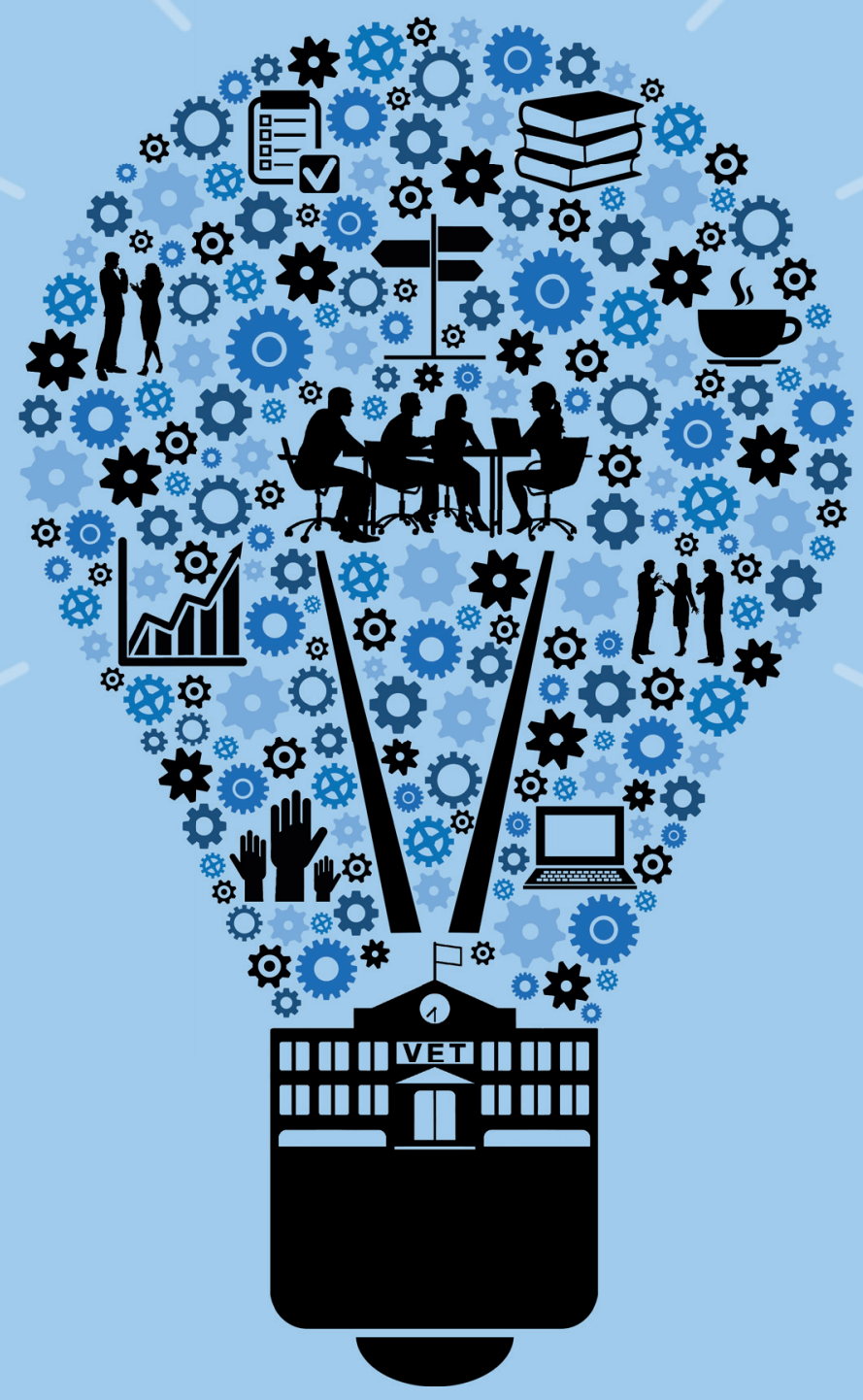

Machiel Bouwmans 



\section{The Role of VET Colleges in Stimulating Teachers' Engagement in Team Learning}

Machiel Bouwmans 


\section{Thesis committee}

\section{Promotor}

Prof. Dr M. Mulder

Emeritus Professor of Education and Competence Studies

Wageningen University \& Research

\section{Co-promotors}

Dr P. Runhaar

Associate professor, Education and Competence Studies Group

Wageningen University \& Research

Dr R. Wesselink

Associate professor, Education and Competence Studies Group

Wageningen University \& Research

\section{Other members}

Prof. Dr M.A.J.S. van Boekel, Wageningen University \& Research

Prof. Dr T.V. Bondarouk, University of Twente

Prof. Dr M.L.L. Volman, University of Amsterdam

Dr P.G.C. van den Bossche, Maastricht University and University of Antwerp

This research was conducted under the auspices of the Wageningen School of Social Sciences (WASS). 


\title{
The Role of VET Colleges in Stimulating Teachers' Engagement in Team Learning
}

\author{
Machiel Bouwmans
}

\section{Thesis}

submitted in fulfilment of the requirements for the degree of doctor at Wageningen University by the authority of the Rector Magnificus,

Prof. Dr A.P.J. Mol, in the presence of the

Thesis Committee appointed by the Academic Board to be defended in public on Friday 12 January 2018 at 1.30 p.m. in the Aula. 
Machiel Bouwmans

The Role of VET Colleges in Stimulating Teachers' Engagement in Team Learning 166 pages.

$\mathrm{PhD}$ thesis, Wageningen University, Wageningen, NL (2018)

With references, with summaries in English and Dutch

ISBN: 978-94-6343-706-6

DOI: $10.18174 / 425366$ 


\section{Table of contents}

$\begin{array}{lll}\text { Chapter } 1 & \text { General introduction } & 7\end{array}$

Chapter 2 Stimulating teachers' team performance through team- 29 oriented HR practices: the roles of affective team commitment and team learning

Chapter 3 Leadership ambidexterity: key to stimulating team learning through team-oriented HRM? An explorative study among teacher teams in VET colleges

Chapter 4 Fostering teachers' team learning: an interplay between transformational leadership and participative decisionmaking?

Chapter 5 Towards distributed leadership in VET colleges: the interplay between formal leaders and team members

(1)




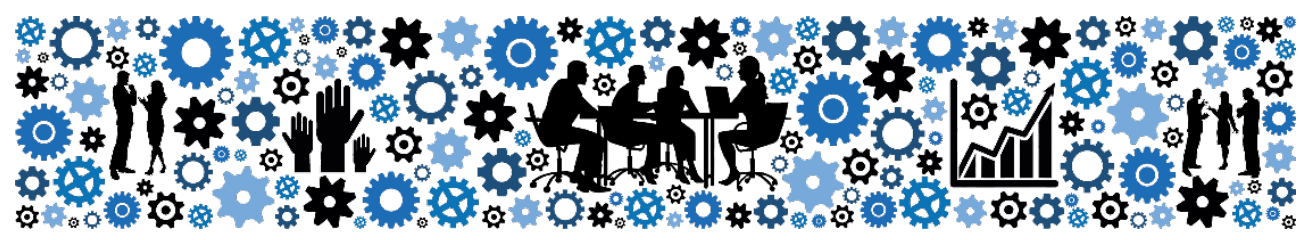

Chapter 1

General introduction 


\section{Introduction}

Teacher teams in secondary vocational education and training (VET) colleges in the Netherlands are responsible for the quality of their education. To maintain, or even increase, the educational quality, they work on designing, redesigning and implementing educational innovations. Developing these innovations is a complex task that requires teachers to cooperate and engage in team learning. Through engagement in team learning, teachers can achieve agreement on how to develop and implement an innovation. This agreement is needed to formulate concrete actions that teacher teams need to take in order to develop high-quality innovations. Team learning implies that teachers need to share knowledge and information with each other, construct new knowledge and information into collective knowledge and discuss opposing ideas. However, engagement in team learning is not always self-evident in VET teacher teams, as teachers tend to be preoccupied with individual teaching responsibilities and because they need to get used to intensive collaboration with other teachers. The expected benefits of engagement in team learning are however promising and it is therefore considered relevant to examine how VET teachers can be stimulated to engage in team learning.

It is assumed that VET colleges can play an important role in stimulating teachers' engagement in team learning. This dissertation therefore examines to what extent and how VET colleges can create a supportive organisational context that stimulates teachers to engage in team learning, by focusing on three organisational characteristics that have the potential to foster team learning: team-oriented human resource management (HRM), team leaders' leadership style, and the creation of opportunities for distributed leadership.

In this introduction chapter, background information about Dutch VET is first provided, and it is explained why teacher teams play a central role in VET colleges (Section 1.1). Second, it is explained why engagement in team learning is not always self-evident in teacher teams (Section 1.2). Third, the focus on a supportive organisational context is explained in more detail and the central research question is provided (Section 1.3). Fourth, the core concepts of this dissertation are explained in more detail (Section 1.4). Fifth, the outline of this dissertation and the sub-research questions for the upcoming chapters are provided (Section 1.5).

\subsection{Setting the scene: teacher teams in Dutch VET}

The research for this dissertation was conducted in secondary vocational education and training, which is abbreviated throughout the dissertation as VET. In this section, the position of VET in the Netherlands is described, followed by an elaboration on competence-based education in VET and the central role of teacher teams in VET colleges. 


\subsubsection{VET in the Netherlands}

In the Netherlands, students follow either pre-vocational education and training or junior general education after completing primary education. Students who have completed pre-vocational education and training can continue education in VET, and those who have finished junior general education may choose either VET or senior secondary general education (see Figure 1.1, in which VET is highlighted in grey) (De Bruijn, Billett, \& Onstenk, 2017).

Although Dutch VET is expected to deliver a triple qualification - for 1) work and career, 2) citizenship and social participation, and 3) further learning and personal growth - qualifying for a profession is its key target (De Bruijn et al., 2017). Students can choose between four main sectors, in which they specialise in a specific profession. These sectors are: 1) health, welfare, culture and sport, 2) engineering and construction, 3) environmental studies and food, and 4) economics, business, ICT and hospitality (Association of VET Colleges, 2017). In each sector, one- to four-year programmes are available at four qualification levels, with level 1 being the entrance level and level 4 leading to both work and higher professional education (De Bruijn et al., 2017). Depending on the sector they choose, students can work in various professions after graduation, for example as a hairdresser, construction worker, administrative assistant, host or hostess, mechanic or consultant.

Educational programmes are organised in 65 multidisciplinary VET colleges (ROCs in Dutch), agricultural VET colleges (AOCs in Dutch), and specialised vocational colleges across the Netherlands (Association of VET Colleges, 2017).

\begin{tabular}{|c|c|c|}
\hline $\begin{array}{l}\text { Higher professional education } \\
\qquad(\mathrm{HBO})\end{array}$ & \multicolumn{2}{|c|}{$\begin{array}{c}\text { Academic education } \\
\text { (WO) }\end{array}$} \\
\hline$\uparrow$ & \multicolumn{2}{|r|}{$\uparrow$} \\
\hline $\begin{array}{l}\text { VET: Secondary vocational } \\
\text { education and training (MBO) }\end{array}$ & $\begin{array}{l}\text { Secondary } \\
\text { general } \\
\text { education } \\
\text { (HAVO) }\end{array}$ & $\begin{array}{l}\text { Secondary } \\
\text { general } \\
\text { education } \\
\text { (VWO) }\end{array}$ \\
\hline$\uparrow$ & $\uparrow$ & $\uparrow$ \\
\hline $\begin{array}{l}\text { Pre-vocational education and } \\
\text { training }(\mathrm{VMBO})\end{array}$ & \multicolumn{2}{|c|}{$\begin{array}{l}\text { Junior general education } \\
\text { (HAVO \& VWO) }\end{array}$} \\
\hline$\uparrow$ & \multicolumn{2}{|c|}{$\uparrow$} \\
\hline \multicolumn{3}{|c|}{ Primary education } \\
\hline
\end{tabular}

Figure 1.1. The Dutch education system with Dutch abbreviations between brackets (based on De Bruijn et al., 2017) 
Participants in VET are mainly aged 16-20 years, and a small number are young working adults. Recent numbers show that 492,700 students attended a VET college in the 2015-2016 school year (Association of VET Colleges, 2017). Although student numbers have shown a downward trend for several years (CBS, 2017), 40-50\% of all Dutch students still follow education in a VET college (Ministry of Education, 2017), making VET the second largest educational sector in the Netherlands after primary education (De Bruijn et al., 2017). Such high student numbers are needed to meet the large demand for VET graduates from the labour market; a demand that is reflected in the 26\% increase in VET-level vacancies between 2015 and 2016 (UWV, 2017).

\subsubsection{Competence-based education}

A specific characteristic of Dutch VET is its connection with the labour market. VET colleges and the labour market need each other to effectively enact vocational education and to decide on the educational aims of programmes (De Bruijn et al., 2017). As professions change due to changing society and innovations, VET colleges and the labour market have the complex task of formulating professional competencies that are relevant today but also in the future. To fulfil this task, educational programmes are being designed or redesigned to increase alignment with the labour market. One way in which the gap between educational programmes and the labour market has been bridged is the implementation of competence-based education (CBE), which has been mandatory since 2012 in the Netherlands. CBE strengthens the linkages between educational programmes and labour market demands, so that students are better prepared for their professions when they start work. This implies that professional competencies that are needed in the labour market and realistic vocational problems are at the core of newly developed or redesigned courses and curricula (Mulder, 2017; Wesselink, de Jong, \& Biemans, 2010). VET colleges are continuing to work on increasing the quality of their CBE programmes. For example, to meet government demands regarding revision of the qualification structure, VET colleges have decreased the number of qualifications and developed broader qualifications, while increasing teaching time and the career orientation component in curricula (Ministry of Education, 2011). All this is done with the aim to provide students with a smooth transition to the labour market.

\subsubsection{Teacher teams at the centre of VET colleges}

Teacher teams play a central role in VET colleges, as is stipulated in the Professional Statute (Association of VET Colleges, 2009) and the collective labour agreement 20162017 (Association of VET Colleges, 2016b). In these documents, teacher teams are regarded as the basic organisational unit and are held responsible for the quality of their education. Teacher teams have the authority to make decisions about their 
educational process, didactics and pedagogy, as long as they adhere to legal requirements and the VET college's policy framework.

One implication of this central role of teacher teams is that they are responsible for designing, or redesigning, and implementing CBE programmes. In practice, this means for instance that teacher teams work on integrating existing courses that are mostly based on distinct disciplines such as mathematics and biology into new interdisciplinary courses, and on revising and updating courses so that they continue to be aligned with developments in society and the labour market. Within these teams, teachers from different disciplines and with different roles need to collaborate on designing, redesigning and implementing CBE (Runhaar \& Sanders, 2016; Truijen, 2012; Wesselink, 2010). Different vocational teachers therefore need to work with each other and with language and maths teachers, for example, and teachers with roles such as internship coordinator and coach also need to collaborate. For instance, to prepare ICT students for writing advisory reports about updating computer systems, vocational teachers and language teachers need to integrate language skills into vocational courses so that students can practice writing a concise advisory report. To give another example, an internship coordinator may receive information from an internship company about a new business innovation such as the use of drones. This innovation may require competencies from students that are not yet covered by the current curriculum. The internship coordinator then has to discuss with the relevant teachers to what extent and how these competencies can be accommodated in courses. In these examples, teachers' engagement in team learning is needed to achieve consensus on concrete actions to be taken.

\subsection{Teachers' engagement in team learning}

As explained in the previous section, engagement in team learning is needed to design, redesign and implement CBE programmes. Team learning is defined as teachers' collective engagement in processes that contribute to building and maintaining mutually shared cognition, leading to increased team performance (based on Van den Bossche, Gijselaers, Segers, \& Kirschner, 2006).

Because teachers have different roles and backgrounds in different disciplines, it is likely that they will have different ideas and information on how to design or redesign and implement CBE programmes. This multidisciplinarity provides challenges for their collaboration (Rainey, 2014), the effectiveness of which will therefore depend on the extent to which teachers are collectively able to create shared conceptions of their task through their engagement in team learning. It is not enough that different ideas and information are clarified and that there is mutual understanding: ideas and information also need to be accepted in the team before actions can be taken. If this is the case, teacher teams have reached a mutually shared cognition (Van den Bossche et al., 2006; Vangrieken, Dochy, \& Raes, 2016). 
Studies on team learning in the VET context have confirmed that team learning contributes to reaching a mutually shared cognition. For instance, it has been shown that VET teachers' team learning contributes to achieving a shared understanding of the principles of CBE (Runhaar, Ten Brinke, Kuijpers, Wesselink, \& Mulder, 2014), and that it is positively related to agreement on the CBE level of the educational programmes (Wijnia, Kunst, Van Woerkom, \& Poell, 2016).

Although team learning seems important for VET teacher teams, simply combining individual teachers in groups such as the formal teacher teams in VET colleges is no guarantee that team learning will occur (Van den Bossche et al., 2006; Vangrieken et al., 2016). For team learning to take place, it seems crucial that teacher teams are not only a formal team in an organisation, but also a real team (Vangrieken et al., 2016). Cohen and Bailey (1997) define a real team as 'a collection of individuals who are interdependent in their task, who share responsibility for outcomes, who see themselves and who are seen by others as an intact social entity embedded in one or more larger social systems' (p. 241).

The literature gives at least three reasons why formal teacher teams cannot always be characterised as real teams (Oude Groote Beverborg, Sleegers, \& van Veen, 2015; Vangrieken, Dochy, Raes, \& Kyndt, 2015). First, despite the central role and responsibility of teacher teams in VET colleges, teachers traditionally have a high degree of autonomy in their work, as teaching largely involves working alone in a classroom. They are therefore not used to engaging in frequent collaboration and interaction with other teachers, such as sharing and discussing information. Second, engagement in team learning would imply critical evaluation and requesting and providing feedback. This means that teachers would have to expose themselves to possible criticism, which could lead to disagreement and conflict, something that teachers tend to avoid by restricting collaboration to less exposing topics so that their privacy and autonomy are retained. Third, teachers find it difficult to make time for interaction with colleagues as they are generally occupied with the issues of the day.

For these reasons, teachers mainly collaborate on practical matters, such as work schedules and existing materials, and are less likely to engage in deeper levels of collaboration such as team learning (Vangrieken et al., 2016; Vangrieken et al., 2015). However, as teachers engage more in team learning if they feel and act more as a real team (Vangrieken et al., 2016), it is important to examine to what extent and how teachers can be stimulated to feel and act as a real team.

\subsection{Fostering VET teachers' team learning: a focus on team-oriented HRM, leadership style and distributed leadership}

As grouping teachers in formal teams does not automatically lead to engagement in team learning, this dissertation examines to what extent and how VET colleges, which are the teachers' organisational context, can foster team learning. Johns (2001) defines 
the organisational context as any stimulus or phenomenon, usually at a higher level of the organisation, that has an impact on a phenomenon at a lower level of the organisation. For VET teacher teams, the context is therefore regarded as stimuli or phenomena at higher organisational levels than the team itself. Because this context can provide constraints or opportunities for attitudes and behaviours (Johns, 2001), it can constrain or foster team learning.

While Johns (2001) emphasises the importance of including the context in research on organisational behaviour in general, workplace learning literature also increasingly acknowledges the organisational context as a possible antecedent of all workplace learning, including team learning. This is because these learning activities are contextually embedded in and influenced by the context in which they occur (Decuyper, Dochy, \& Van den Bossche, 2010; Ellinger, 2005; Fuller \& Unwin, 2011; Tynjälä, 2013). Despite this acknowledgement, team learning research both within and outside the educational context tends to focus primarily on the influence of team-level antecedents, such as psychological safety, group potency (or group efficacy) and group development, and not on organisation-level antecedents (e.g. Edmondson, 1999; Leicher \& Mulder, 2016; Raes, Decuyper, Van den Bossche, \& Dochy, 2015; Van den Bossche et al., 2006; Vangrieken et al., 2016). This focus on team-level antecedents is also notable in related research that examines predictors of creativity and innovation in the workplace (Hülsheger, Anderson, \& Salgado, 2009).

It is however important to take the organisational context into consideration, because organisations can differ in the extent to which they offer a supportive learning environment. Expansive environments, which are characterised as recognising and supporting workers' learning and participation in different communities of practice, foster workplace learning more than restrictive environments, which are characterised as regarding workers as productive units and focusing on short-term goals (Fuller \& Unwin, 2004).

HRM, which is the system of practices in an organisation that attempts to influence employees' abilities, motivation and opportunity to perform in desired ways, with the goal to increase the organisation's performance (Jiang, Lepak, Hu, \& Baer, 2012; Runhaar, 2016), is viewed as a tool to create these expansive environments. However, the specific HR practices needed to achieve these environments remain unexplored (Fuller \& Unwin, 2011). Consequently, it also remains largely unknown how organisations can provide a supportive environment for team learning.

It is therefore interesting to examine to what extent VET colleges are expansive, in the sense that they implement HR practices that foster teachers' engagement in team learning. VET colleges increasingly implement HRM to professionalise individual teachers and teacher teams, for example through formal training. However, even though VET colleges also recognise the importance of workplace learning, including team learning (Association of VET Colleges, 2016a; 
MB015, 2015), they are often unsure how to foster learning (and team learning) in the workplace. Moreover, research on HRM in the VET context is limited (Runhaar, 2016), so that many questions on the effectiveness of HRM in VET colleges for fostering workplace learning, including team learning, remain unanswered. Research on the extent to which and how VET colleges' HRM influences teachers' engagement in team learning is therefore needed.

To examine the possible influence of HRM on teachers' team learning, a behavioural perspective on HRM is adopted. This behavioural perspective suggests that HR practices affect organisational outcomes through employee behaviour: if employees act in desired ways that are aligned with organisational goals, the organisation's performance should improve (Jiang et al., 2012). For VET colleges' performance to improve, it is important, for example, that teachers feel and act as part of a real team and engage in team learning, as is explained in Section 1.2. VET colleges therefore need to invest in teams through HRM. To examine how they do this, this dissertation specifically focuses on VET colleges' HRM that is geared towards supporting teams and team learning, which is termed team-oriented HRM. In Chapters 2 and 3, the content of team-oriented HRM is determined based on the Ability-Motivation-Opportunity (AMO) model that is often central to HRM research (Boselie, Dietz, \& Boon, 2005; Jiang et al., 2012), and is also relevant in the educational context (Runhaar, 2016).

Following the process model of HRM (Purcell \& Hutchinson, 2007; Wright \& Nishii, 2013), which is explained in Text box 1.1, it is argued that a focus on HRM also implies a focus on managers' behaviour. The implementation of HR practices is often the responsibility of line managers (Purcell \& Hutchinson, 2007), or team leaders in VET colleges.

Although the HRM system is usually developed by the organisation's decision makers, it is the line managers or team leaders who implement the system, although rarely as fully intended by the decision makers (Wright \& Nishii, 2013). There are several reasons why the line managers or team leaders deviate from the HRM strategy in their implementation, related to their motivation and ability, competing demands and time pressure (Nehles, van Riemsdijk, Kok, \& Looise, 2006). As the implementation of HR practices influences how employees perceive these practices and what employees believe are appropriate attitudinal and behavioural responses, the implementation of HRM is more closely related to employee behaviour than the intended HRM strategy (Bowen \& Ostroff, 2004; Purcell \& Hutchinson, 2007; Wright \& Nishii, 2013). VET team leaders' implementation of team-oriented HRM should therefore be taken into account as it might influence how teachers respond in terms of their engagement in team learning. 
Despite the centrality of the process model in many studies on HRM, only limited attention is paid to managers' leadership styles in the relationship between HRM and performance (Vermeeren, Kuipers, \& Steijn, 2014). The HRM process model merely regards managers as executors of HRM and therefore does not explicitly take into account their personal leadership styles. However, managers' leadership styles can influence how employees respond, as is shown by previous research that indicates that a manager's leadership style can foster team learning (e.g. Bucic, Robinson, \& Ramburuth, 2010; Koeslag-Kreunen, Van der Klink, Van den Bossche, \& Gijselaers, 2017; Raes et al., 2013). Therefore, to explain the relationship between VET colleges' supportive context and teachers' team learning, not only how team leaders implement team-oriented HRM should be taken into account, but also how they act as leaders.

\section{Text box 1.1 - A process model of HRM}

To explain how HRM affects organisational performance, a causal chain has been developed in the HRM literature (Purcell \& Hutchinson, 2007; Wright \& Nishii, 2013). This causal chain implies an indirect influence of HRM on organisational performance through employee responses, as visualised in the process model of Figure 1.2. The first step in this model is the development of an intended HRM strategy that the organisation's decision makers believe will be effective in increasing the organisation's performance. The second step is the implementation of the intended HRM strategy in practice, which results in actual HRM. Line managers (i.e. team leaders in VET) are often responsible for this implementation and therefore influence whether HR practices are implemented as intended. In the third step, employees subjectively perceive and interpret the actual HR practices and form an understanding of which attitudes and behaviours are expected of them. In the fourth step, employees respond based on their perceptions and interpretations. Such a response can consist of changes in attitudes and/or behaviours. The fifth step consists of changes in the organisation's performance. The idea is that, if employees respond in ways that were intended by decision makers, the organisation's performance will increase.

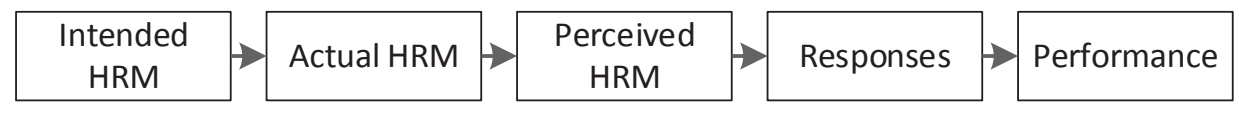

Figure 1.2. The process model of HRM (based on Wright \& Nishii, 2013)

Additionally, because designing, redesigning and implementing CBE is a complex task, it is likely that team leaders will be unable to single-handedly lead their teacher teams during this process. Such a complex task requires input from different 
perspectives and areas of expertise, and increases the need for distributed leadership (Pearce, 2004). Distributed leadership implies that teachers are enabled by their managers to exercise informal leadership tasks (Bolden, 2011; Tian, Risku, \& Collin, 2016). When leadership is distributed, the interdependence, coordination and interactions among team members increases, which encourages team members to engage in team learning ( $\mathrm{Liu}, \mathrm{Hu}, \mathrm{Li}, \mathrm{Wang}$, \& Lin, 2014). To what extent and how team leaders create opportunities for distributed leadership is therefore also taken into account in this dissertation. Subsequently, relationships between distributed leadership in teams and teachers' engagement in team learning are examined.

To recapitulate, this dissertation aims to provide new insights into the relationships between VET colleges' team-oriented HRM, team leaders' leadership styles, and opportunities for distributed leadership on the one hand, and teachers' engagement in team learning on the other. It does this by answering the following central research question:

To what extent and how does the organisational context, in terms of team-oriented HRM, team leaders' leadership style, and opportunities for distributed leadership, stimulate teachers' engagement in team learning?

\subsection{The core concepts of this dissertation}

The core concepts are explained in more detail in this section. First, team learning is conceptualised, followed by team-oriented HRM, team leaders' leadership style and distributed leadership.

\subsubsection{Team learning}

As previously mentioned, team learning is defined in this dissertation as the collective engagement of teachers in processes that contribute to building and maintaining mutually shared cognition, leading to increased team performance (based on Van den Bossche et al., 2006).

Team learning is regarded as a specific form of workplace learning, manifested in interactions between team members. Three forms of workplace learning are distinguished (Tynjälä, 2008): 1) incidental, unintentional and informal learning that occurs as a side effect of working, 2) intentional, yet informal, learning (e.g. mentoring, practising specific skills and tools), and 3) formal on-the-job and off-the-job training. Team learning is considered to largely represent the first form of workplace learning, because it is often a side effect of intensive collaboration between team members: through collaboration, team members share information and knowledge with each other and collectively construct meaning and discuss different perspectives to achieve agreement on actions they need to take. 
Although team learning is a distinct social phenomenon, it is often used interchangeably with related concepts such as collective learning (Knapp, 2010) and collaborative and cooperative learning (Dochy, Gijbels, Raes, \& Kyndt, 2014), and is considered to be similar to professional learning communities (PLCs). How team learning differs from these concepts is explained in Text box 1.2.

\section{Team learning processes}

Team learning can be recognised on the basis of specific processes that team members engage in during intensive collaboration. These processes occur in varying combinations, which makes team learning a dynamic process, often without a clear start and end (Decuyper et al., 2010).

At the basis of team learning lie the three processes of 'sharing', 'coconstruction' and 'constructive conflict', which describe what happens in teams when they learn. These three basic processes are responsible for the power of team learning (Decuyper et al., 2010) and reflect the crucial communicative processes that are at the core of team learning (Vangrieken et al., 2016). These processes are therefore central to this dissertation.

The first basic process, sharing, refers to team members sharing information, knowledge, creative ideas or perspectives with other team members who were previously unaware of the shared information. This implies that shared information is not necessarily new or recently developed, but previously unshared in the team (Decuyper et al., 2010). In VET colleges, vocational teachers and language teachers for instance have different knowledge that they may not have shared. By sharing information, these teachers create awareness of each other's knowledge.

The second basic process, co-construction, is the process by which team members develop collective knowledge and meaning based on the information that has been shared. Team members do this by engaging in repeating cycles of acknowledging, concretising, questioning and supplementing shared information (Decuyper et al., 2010; Van den Bossche et al., 2006). Vocational teachers and language teachers for instance can work on concretising how to integrate language skills into vocational courses, by questioning and supplementing these language skills and creating a collective meaning on how they should be integrated.

The third basic process, constructive conflict, is the process by which team members discuss different perspectives and conflicting ideas with one another. Team members do this in an open and constructive manner, meaning that they are open to each other's ideas and are willing to reach - possibly temporary - agreement (Decuyper et al., 2010; Van den Bossche et al., 2006). In VET teams, disagreement on how to integrate language skills into a vocational course could arise for instance if vocational teachers do not agree with the ideas of the language teacher. If the teachers openly 
discuss, explain and listen to different ideas and perspectives, more insight into different ideas and perspectives can be obtained and agreement on actions reached.

In practice, the processes of sharing, co-construction and constructive conflict are very much intertwined and reinforce each other. This makes these processes theoretically distinct but empirically difficult to disentangle (Decuyper et al., 2010; Van Woerkom \& Van Engen, 2009). Van Woerkom and Van Engen (2009) therefore used a broader term to describe the basic process of team learning, which they labelled information processing. Information processing refers to all the processes used to share information and apply shared interpretations to this information (Van Woerkom \& Croon, 2009). In this dissertation, information processing is therefore regarded as an umbrella term for the distinct processes of information sharing, co-construction and constructive conflict.

Two facilitative team learning processes are also central in Chapter 4: information acquisition and boundary crossing. These processes are regarded as facilitative because they enable team members to acquire new relevant information that they can share in their team. As such, these processes help teams learn in the 'right direction': they help make team learning more efficient and effective by providing context and focus (Decuyper et al., 2010).

The first facilitative process, information acquisition, refers to individual team members making focused inquiries in their environment to obtain new information, with the goal to strengthen existing knowledge or fill knowledge gaps, and is based on the study of Van Offenbeek (2001). Team members can do this by consulting different information sources, such as the internet and books, but also by participating in professional development activities or asking other team members for advice (Van Offenbeek, 2001; Wijnia et al., 2016).

The second facilitative process, boundary crossing, also refers to individual members acquiring new information, but specifically by asking people outside their team - such as experts, stakeholders or members of other teams - for feedback and advice on their own team's tasks and performance (Kasl, Marsick, \& Dechant, 1997; Wong, 2004). Although Decuyper et al. (2010) regard boundary crossing as a team activity, in this dissertation boundary crossing is considered an individual team member activity. This is because individual VET teachers fulfil different roles in their team and meet different outsiders in their own professional networks within these roles. As such, they may ask different outsiders for feedback and advice. For instance, a maths teacher will meet maths teachers in other teams, while an internship coordinator will meet professionals in internship companies. 


\section{Team learning outcomes}

The team learning definition of Van den Bossche et al. (2006) distinguishes between two types of team learning outcomes: mutually shared cognition and increased team performance. Research outside the VET context has shown that team learning is directly related to indicators of team performance, such as team effectiveness, efficiency and innovativeness (e.g. Edmondson, 1999; Leicher \& Mulder, 2016; Van der Vegt \& Bunderson, 2005; Van Woerkom \& Croon, 2009; Widmann, Messmann, \& Mulder, 2016). However, research on the relationship between VET teachers' team learning and their team performance seems to be largely missing. Previous research within the VET context has mainly focused on relationships between team learning and mutually shared cognitions. These studies have shown that team learning leads to a shared understanding of the principles of CBE (Runhaar et al., 2014) and to teachers' agreement on the CBE level of their educational programme (Wijnia et al., 2016). To

\section{Text box 1.2 - Team learning as a distinct theoretical concept}

Despite the fact that team learning, collective learning, collaborative and cooperative learning and professional learning communities (PLCs) all refer to social interactions that involve learning, there are some important differences. For instance, Knapp (2010) explains that team learning is a narrower term than collective learning because team learning refers to meso-level learning and outcomes, while collective learning can also refer to micro-level and macro-level learning. This distinction in learning levels is also made by Crossan, Lane, and White (1999), who distinguish between individual-, group- and organisational-level learning, in which the group level reflects the meso level referred to by Knapp (2010). This implies that team learning should be related to team outcomes, while collective learning can also be related to individual or organisational outcomes. This distinction in outcome level is what makes team learning different from collaborative or cooperative learning. According to Dochy et al. (2014), team learning is often theorised as processes that lead to team-level learning outcomes, while collaborative and cooperative learning are primarily theorised as processes that lead to individual-level learning outcomes. Nevertheless, this distinction is not always made in the team learning literature. For instance, Decuyper et al. (2010) consider team learning outcomes at the individual, team and organisational level. This makes the distinction between team learning and the related concepts somewhat cloudy. Moreover, PLCs clearly differ from the concept of team learning because PLCs can include the whole school or even teachers from different schools and, as such, cross the boundaries of a team. Another difference is that PLCs are characterised by intentional learning goals, while team learning is an emerging side effect of intensive collaboration rather than a starting point for reaching agreement (Vangrieken et al., 2015). 
obtain more insight into the relationship between VET teachers' team learning and team performance, this relationship is examined in Chapter 2.

\subsubsection{Team-oriented HRM}

HRM can generally be regarded as a system of practices that attempts to influence employees' abilities, motivation and opportunity to perform in desired ways, with the goal to increase the organisation's performance (Jiang et al., 2012; Runhaar, 2016). Team-oriented HRM is therefore defined as a set of HR practices aimed at increasing teams' abilities, motivation and opportunities to perform in desired ways, with the goal to increase team performance.

Research on the effects of HRM in the educational context shows that HR practices can have a positive impact on teachers. The implementation of HR practices has, for example, been shown to be positively related to teachers' work engagement (Runhaar, Sanders, \& Konermann, 2013), their professional development (Evers, Van der Heijden, Kreijns, \& Gerrichhauzen, 2011), and the compatibility between teachers and their job and organisation (Janssen, 2016). However, these studies only examined relationships between individual-oriented HR practices and individual teachers' attitudes and behaviours. It therefore remains unknown whether team-oriented HRM has a positive impact on teachers' engagement in team learning.

The relationship between team-oriented HRM and team learning also remains largely unexplored in other work contexts. There are however a few exceptions, such as the studies of Chuang, Jackson, and Jiang (2013) and Flinchbaugh, Li, Luth, and Chadwick (2016). These studies show positive relationships between the presence of team-oriented HRM and employees' engagement in knowledge acquisition and knowledge sharing. However, these studies only focus on knowledge acquisition and knowledge sharing, so that team learning is measured in restricted ways. Relationships with the team learning processes co-construction and constructive conflict or the umbrella process of information processing therefore remain unexamined. It is possible that different team learning processes are fostered by different team-oriented HR practices, and therefore examined how team-oriented HRM is related to a broader conceptualisation of team learning.

\subsubsection{Team leaders' leadership style}

A classic distinction in leadership style is that between a transformational leadership style and a transactional leadership style (Bass, 1997; Judge \& Piccolo, 2004). Transformational leaders offer purpose that surpasses short-term goals, and focus on the intrinsic needs of employees. A transformational leadership style is therefore characterised by committing teachers to the team's or the organisation's goals, by providing support, and by stimulating problem solving and out-of-the-box thinking. Transactional leaders, on the other hand, focus on the appropriate exchanges of 
resources. They do this by aiming to increase performance and prevent work avoidance.

Research on the relationship between the leadership style of school leaders or team leaders and workplace learning mostly focuses on transformational leadership. Findings show that a transformational leadership style can contribute to a school's innovative climate (Moolenaar, Daly, \& Sleegers, 2010) and individual teachers' engagement in informal learning activities, such as asking feedback and reflection (Geijsel, Sleegers, Stoel, \& Krüger, 2009; Oude Groote Beverborg et al., 2015; Runhaar, Sanders, \& Yang, 2010; Thoonen, Sleegers, Oort, Peetsma, \& Geijsel, 2011).

Literature on the relationship between leadership style and team learning both inside and outside the educational work context is more scarce (Raes et al., 2013). Outside the educational context, a transformational leadership style has been found to stimulate team learning (Raes et al., 2013). However, research conducted within the educational context (universities) found that both transformational and transactional leadership styles can encourage teachers' team learning (Bucic et al., 2010; KoeslagKreunen et al., 2017): which leadership style is most appropriate seems to depend on the team's needs, tasks and challenges.

Based on the context of VET teacher teams, this dissertation focuses on transformational leadership. As is explained in Section 1.2, the team structures in VET colleges do not automatically imply that formal teams act as real teams. VET teachers therefore need to be encouraged to feel and act as a team, so that their engagement in team learning increases. It is argued that a team leaders' transformational leadership style is more appropriate for this task than a transactional leadership style. This is because employee empowerment is a central component of a transformational leadership style. Empowerment implies that leaders try to increase their followers' participation in teams (De Hoogh, Den Hartog, \& Koopman, 2004), and try to move them beyond their self-interest by committing them to the good of their team (Raes et al., 2013). Transformational leaders can do this by delegating responsibilities to team members (Bass, 1997), which makes team members more dependent on each other. In this dissertation, therefore, it is examined whether this empowering aspect of a team leaders' transformational leadership style stimulates teachers' engagement in team learning.

\subsubsection{Distributed leadership}

Distributed leadership is a popular leadership perspective in the educational management literature and is advocated as necessary during complex tasks to increase performance (Bolden, 2011; Tian et al., 2016). Distributed leadership implies that leadership is the product of collective activity rather than being defined by the actions of individual formal leaders (Woods, Bennett, Harvey, \& Wise, 2004). This means that those individuals who are best equipped, skilled or positioned to lead in a certain 
situation do so, regardless of whether they are in formal leadership positions (Harris \& DeFlaminis, 2016). Distributed leadership is flexible and versatile (Hairon \& Goh, 2015; Harris, 2008), and the person who is best equipped, skilled or positioned can differ from situation to situation, and therefore who leads may also differ according to the situation. For instance, when improving the quality of CBE programmes, some teachers may be more skilled in developing new grading methods and therefore lead during this aspect of the improvement, while others may be more skilled in integrating courses and lead during that aspect.

Empirical evidence on antecedents and outcomes of distributed leadership is limited (Hairon \& Goh, 2015; Tian et al., 2016), which implies that its relationship with team learning is largely unknown. Only a few studies have examined relationships between shared leadership - a concept closely related to distributed leadership - and team learning, and these suggest that shared leadership supports team learning (Koeslag-Kreunen et al., 2017; Liu et al., 2014). However, whether distributed leadership stimulates engagement in team learning or whether the relationship is more complex - Day, Gronn, and Salas (2004) for instance suggest a reciprocal relationship remains unknown. The relationship between distributed leadership and teachers' team learning is therefore explored in this dissertation.

\subsection{Outline of this dissertation and sub-research questions}

In this section, the outline of the dissertation is explained by briefly describing the content and sub-research questions of the following chapters and the connection between the chapters.

\subsubsection{Chapter 2 - Team-oriented HRM}

Chapter 2 examines whether teachers' perceptions of a stronger presence of teamoriented HRM are related to higher levels of affective team commitment and engagement in information processing. Subsequently, it is examined whether these team-oriented HR practices are related to higher levels of team performance via teachers' affective team commitment and information processing. Hence, the subresearch question $(\mathrm{S}-\mathrm{RQ})$ in this chapter is:

To what extent is the relationship between team-oriented HR practices and team performance, in terms of team innovation and team efficiency, mediated by teachers' affective team commitment and their engagement in information processing (S-RQ1)?

This sub-research question is examined based on quantitative survey data from teachers, so that the complex process by which teachers' perceptions may affect their attitudinal and behavioural responses and their team performance can be statistically examined. 


\subsubsection{Chapter 3 - Team leaders' enactment of team-oriented HRM}

Chapter 3 builds on Chapter 2 by focusing on differences in team leaders' implementation of team-oriented HRM in practice. As was previously explained in Section 1.3, HRM implementation is often seen as the responsibility of managers, such as VET teachers' team leaders (Purcell \& Hutchinson, 2007; Wright \& Nishii, 2013). In this chapter, therefore, specific attention is paid to how team leaders differ in their enactment of team-oriented HRM and how this affects teachers' perceptions of teamoriented HRM and their response in terms of team learning. In this chapter, the second sub-research question is answered:

How does team leaders' enactment of team-oriented HRM affect teachers' perceptions of team-oriented HRM and their response in terms of team learning (S-RQ2)?

Given the more explorative nature of this sub-research question, in-depth qualitative face-to-face interview data and group interview data from team leaders and teachers are used to answer this question.

\subsubsection{Chapter 4 - Transformational leadership style}

Chapter 4 examines whether positive relationships exist between the extent to which teachers perceive that their team leaders have an empowering transformational leadership style and teachers' engagement in team learning processes. The focus is on examining whether teachers who perceive more empowerment from their team leader also perceive that they are given more opportunities to make decisions in their team, and whether this is related to the extent to which they feel they are (in terms of affective team commitment and perceived task interdependence) and act as (in terms of team member proactivity and team learning) part of a real team. The third and fourth subresearch questions are addressed in this chapter:

To what extent are there positive associations between transformational leadership and team learning processes (S-RQ3)?

To what extent are associations between transformational leadership and team learning processes mediated by participative decision-making, affective team commitment, perceived task interdependence and team member proactivity (S-RQ4)?

To answer these sub-research questions, quantitative survey data from teachers are used to statistically examine the complex relationship between transformational leadership and team learning. 


\subsubsection{Chapter 5 - Distributed leadership}

Chapter 5 explores how team leaders provide opportunities and constraints for establishing distributed leadership in teacher teams, and the role that team learning plays during the process of establishing distributed leadership. As such, the fifth and sixth research question are addressed:

In what ways do formal leaders create opportunities for distributed leadership, and how do they set boundaries for distributed leadership (S-RQ5)?

In what ways do teachers establish leader-follower relationships within their team, and what is the role of team learning in this process (S-RQ6)?

Like Chapter 3, Chapter 5 has a more explorative character. In-depth qualitative faceto-face interview data and group interview data from team leaders, coaches and teachers are therefore used in this chapter to answer the fifth and sixth sub-research questions.

\subsubsection{Chapter 6 - General conclusion and discussion}

This final chapter answers the central research question by integrating the findings of Chapters 2 to 5. The theoretical contributions and implications, methodological strengths and limitations and practical implications are also discussed.

\subsubsection{Connection between the chapters}

Figure 1.3 visualises the similarities and differences between Chapters 2 to 5 . Because team-oriented HRM and leadership style and the provision of opportunities for distributed leadership are contextual phenomena at a higher level in the organisation than teacher teams themselves, Figure 1.3 is presented in a top-down manner.

On the horizontal axis, a division is made between team-oriented HRM, team leaders' leadership style and distributed leadership, which shows that Chapters 2 and 3 focus on team-oriented HRM, Chapter 4 on leadership style and Chapter 5 on distributed leadership. On the vertical axis, three levels are distinguished: higher management and the HR department, team leaders, and the team and team members. As such, Figure 1.3 shows for instance that the role of team leaders is included in Chapters 3, 4 and 5. The team level is further specified as four aspects that are addressed in this dissertation: team members' leadership, attitudes and perceptions, behaviours, and outcomes. This specification shows for instance that team performance outcomes are addressed in Chapter 2, while establishing distributed leadership is discussed in Chapter 5. 
General Introduction

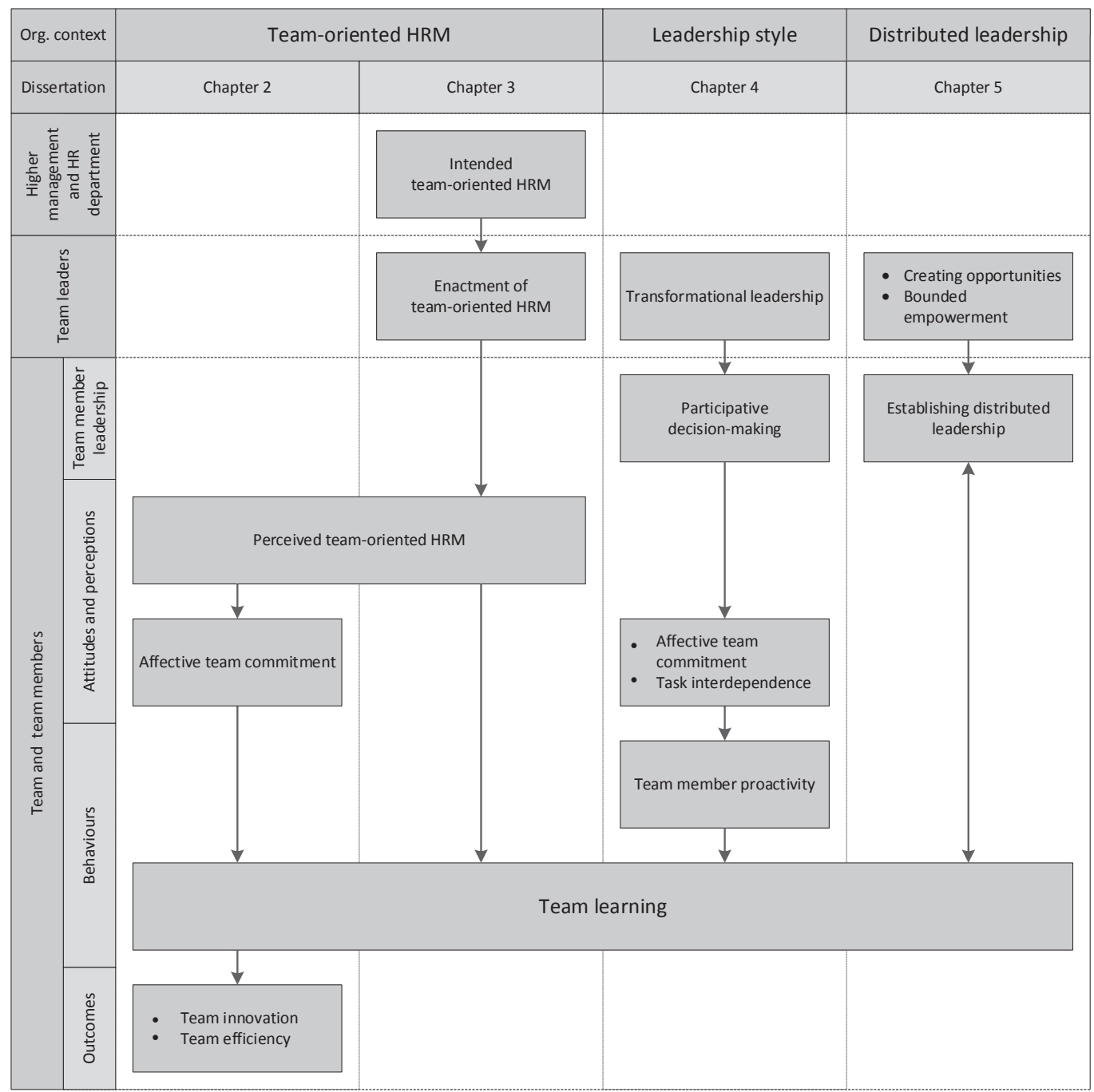

Figure 1.3. Similarities and differences between Chapters 2 to 5 


\section{Text box 1.3 - The interlinked research project on team learning}

This dissertation is part of an interlinked research project on VET teachers' team learning, executed by researchers from Wageningen University \& Research and Tilburg University in the period 2013-2018 and supported by the Dutch Organisation for Scientific Research (NWO). The central research question of that project is: 'To what extent and how do environmental, team and individual characteristics influence team learning and consequently CBE implementation and student outcomes?'. To answer this research question, the interlinked research project consists of four distinct research projects, each with its own focus. The research project that is at the basis of this dissertation examines to what extent the organisational context is associated with team learning in teacher teams, as is explained in this chapter. The goals of the other research projects are to examine: a) to what extent team member characteristics are associated with team learning, b) how team learning changes during the different stages of CBE implementation, and c) how organisational and educational sector-related characteristics interact with team characteristics to influence team learning and its team outcomes and student outcomes. Figure 1.4 provides the conceptual model of this interlinked research project, with the focus of the research project that is at the basis of this dissertation highlighted in grey.

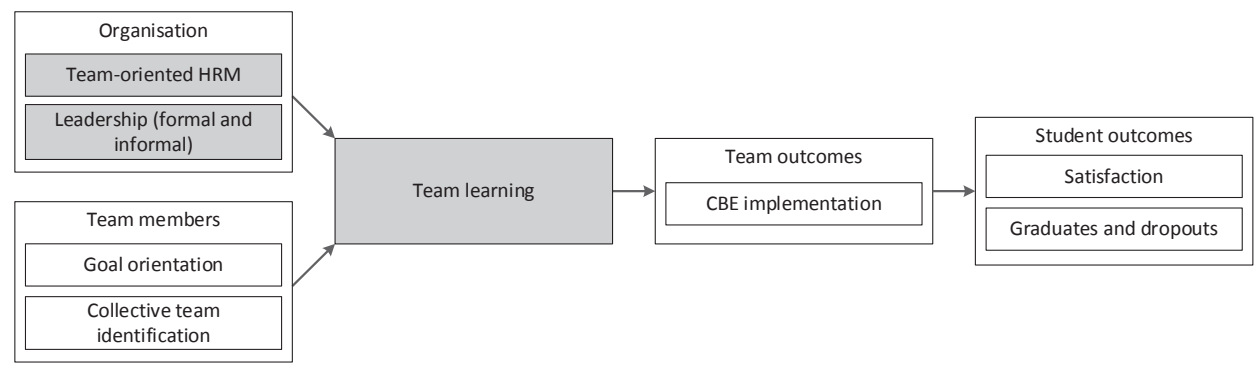

Figure 1.4. Conceptual model of the interlinked team learning project, with the focus of this dissertation highlighted in grey 


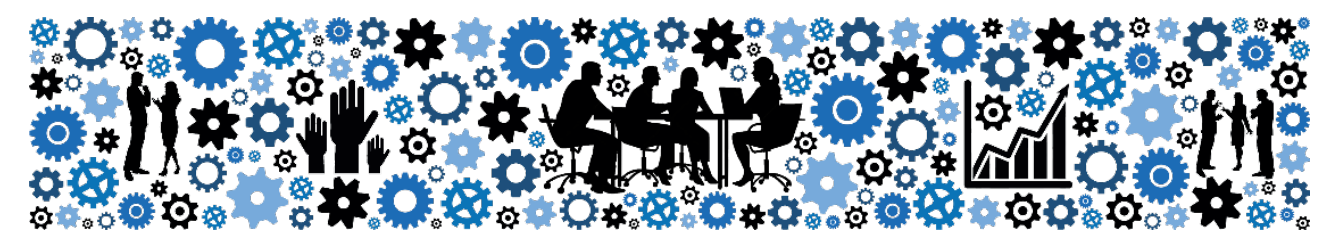

\section{Chapter 2}

\section{Stimulating teachers' team performance through team- oriented HR practices: the roles of affective team commitment and team learning ${ }^{1}$}

Teacher teams are increasingly held accountable for the quality of education and educational reforms in vocational education and training colleges. However, historically teachers have not been required to engage in deep-level collaboration, thus team-oriented HR practices are being used to promote teamworking in the sector. This paper examines the relationship between team-oriented HR practices and team performance in terms of innovation and efficiency via teachers' affective team commitment and engagement in team learning, in terms of information processing. To examine these associations, a team-oriented HRM research instrument was developed and validated based on the Ability-Motivation-Opportunity (AMO) model ( $\mathrm{N}=970,130$ teams) and hypothesised associations were examined using multilevel structural equation modelling ( $\mathrm{N}=704,70$ teams). The results show positive relationships between the team-oriented HR practices of recruitment, team development, team evaluation and teamwork facilitation, and team innovation. Additionally, all practices except team development were positively related to team efficiency. The relationships between team-oriented HR practices and these team performance indicators were often partially or fully mediated by affective team commitment and information processing. Because affective team commitment and information processing sometimes only partially mediated the links between team-oriented HR practices and team performance, other underlying mechanisms await identification.

\footnotetext{
1 This chapter is based on: Bouwmans, M., Runhaar, P., Wesselink, R., \& Mulder, M. (2017). Stimulating teachers' team performance through team-oriented HR practices: The roles of affective team commitment and information processing. International Journal of Human Resource Management. doi: 10.1080/09585192.2017.1322626
} 


\subsection{Introduction}

With the rise of new public management in the 1980s, a shift has taken place towards the greater accountability of public sector organisations (Hood, 1995). This implies that these organisations need to account for their actions, policies and products, which can be challenging for them. Simultaneously, team structures have been widely introduced in the public sector (Rainey, 2014). Teams offer advantages over individuals as more expertise and resources and different perspectives are available in teams. Because of this, teams often outperform individuals when it comes to challenging decision-making and problem-solving tasks (Decuyper et al., 2010; Rainey, 2014).

These developments are also seen in the vocational education and training (VET) sector worldwide, where teacher teams are increasingly held responsible for the development, execution and outcomes of educational programmes (Runhaar \& Sanders, 2013). In the Netherlands, where approximately $40 \%$ of all students follow education in VET colleges (Ministry of Education, 2017), increased government demands regarding the quality of education have encouraged VET colleges to develop and implement competence-based education (CBE) programmes. The effective development, implementation and execution of CBE have led to an increased focus on teams and teamwork in VET as teachers of different disciplines need to collaborate in teams on CBE (Truijen, 2012; Wesselink, 2010).

Although teacher teams are distinguishable social entities in VET colleges and teachers engage in collaboration with each other, their collaboration tends to be restricted to discussing practical matters, such as work schedules and existing materials used in classes, while more deep-level collaboration, which for instance contains discussing the didactics of teaching and developing new ideas for innovations, tends to be limited (Vangrieken et al., 2015). This appears to be a consequence of teachers' long tradition of focusing on their own work tasks and the relatively recent need for them to interact, share and discuss knowledge and ideas with others (Oude Groote Beverborg et al., 2015). Moreover, as in many other public and private sector teams, the multidisciplinary nature of VET teams presents challenges to teamworking (Rainey, 2014). Because of their different roles and expertise, teachers can have different opinions about CBE implementation (Wesselink, 2010). More specifically, given their different backgrounds, team members may have different perspectives on matters, and, consequently, conflicts between team members may arise (Rainey, 2014). Given this context, collaborating in teams is likely to pose a challenge for teachers.

To promote teamworking amongst teachers, Dutch VET colleges have developed and implemented team-oriented HR practices (Runhaar \& Sanders, 2013). However, whether these team-oriented HR practices promote teachers to act accordingly has yet to be empirically investigated. Specifically, the aim of this study is to examine associations between team-oriented HR practices and team performance. Given teachers' duty to implement the new curriculum we consider team innovation as 
one key performance outcome along with team efficiency. We use teachers' perceptions of team-oriented HR practices, and assess their responses to them in terms of affective commitment to the team and engagement in team learning. We also assess whether their responses are associated with higher levels of team performance. Our approach is consistent to that proposed by Bowen and Ostroff (2004) and Nishii and Wright (2008) in which perceptions of HR practices are used in assessing employees' (teachers') attitudinal and behavioural responses (Purcell \& Hutchinson, 2007). This study considers affective team commitment or teachers' emotional bond to the team as the attitudinal response to team-oriented HR practices (Van der Vegt \& Bunderson, 2005), and team learning or teachers' engagement in information processing, which refers to teachers sharing information and constructing shared interpretations of this information in their team, as the behavioural outcome (Van Woerkom \& Croon, 2009). We believe these two process measures are important in determining the performance of the team.

Hence, we aim to answer the following research question: To what extent is the relationship between team-oriented HR practices and team performance, in terms of team innovation and team efficiency, mediated by teachers' affective team commitment and their engagement in information processing?

In answering this question, we aim to make the following contributions to the literature. First, we aim to provide new insight into the potential effects of teamoriented HR practices in the educational context. This is needed because, although HR practices are increasingly implemented in schools (Runhaar \& Sanders, 2013), research on HRM in this context is still relatively limited, which has as a consequence that insight into the effectivity of HRM in schools is largely missing (DeArmond, Gross, \& Goldhaber, 2010). Second, we aim to identify the mechanisms that link team-oriented HR practices with team innovation and team efficiency. In this way we can begin to understand the processes involved in linking HR practices with team performance (Chuang et al., 2013; Jiang, Takeuchi, \& Lepak, 2013). This is an important contribution as even though previous studies have shown that both affective team commitment and engagement in team learning are positively related to the performance of multidisciplinary teams (Park, Henkin, \& Egley, 2005; Van der Vegt \& Bunderson, 2005; Van Woerkom \& Croon, 2009), it remains largely unexplored whether and how they are affected by teamoriented HR practices.

\subsection{Theoretical framework}

In this section, we first describe why we studied team innovation and team efficiency as indicators of teacher team performance. We then explain the hypothesised associations between team-oriented HR practices, affective team commitment, team learning (information processing) and team performance indicators. 


\subsubsection{Team performance: innovation and efficiency}

In order to achieve high performance organisations have to perform well in both innovation and efficiency (Sanders Jones \& Linderman, 2014). This is also true for VET colleges that need to be both innovative in the implementation of new CBE programmes and efficient in the execution of existing educational programmes. Because the responsibility for these innovative new programmes and efficient execution of existing programmes lies with teacher teams (Association of VET Colleges, 2009), team innovation and team efficiency are important indicators of teacher team performance.

Team innovation refers to intentionally introducing and applying new ideas, materials, procedures and products that are designed to improve team performance (Anderson \& West, 1998). To achieve team innovation, team members need to engage in activities together that foster creativity, flexibility and experimentation (Sanders Jones \& Linderman, 2014).

Team efficiency refers to the team's input-output ratio and to the extent in which teams avoid wasting effort and time and meet schedules during teamworking (Van Woerkom \& Croon, 2009). Team efficiency requires deep-level teacher collaboration so that teachers engage in discussing solutions for problems they meet in daily practice, which they then can implement in their work (Vangrieken et al., 2015).

Because both team innovation and team efficiency require deep-level collaboration, we expect that these performance indicators can be increased if teachers are stimulated to engage in teamworking through the mechanisms that we explain below.

\subsubsection{Team-oriented HR practices}

We used the Ability-Motivation-Opportunity (AMO) model to identify specific teamoriented HR practices. The AMO model states that by increasing employees' abilities (A), along with offering them motivational incentives (M) and opportunities to perform (0), organisations can increase performance (Appelbaum, Bailey, Berg, \& Kalleberg, 2001; Jiang et al., 2012). This implies that, to increase team performance, team-oriented ability-, motivation- and opportunity-enhancing HR practices are needed. Here, we elaborate on the content of these team-oriented HR practices.

The goal of ability-enhancing team-oriented HR practices is to create teams that consist of members who have and constantly improve their teamwork abilities, so that team performance can be stimulated (Chuang et al., 2013). This means that through recruitment HR practices teachers should be selected on the basis of their expertise, interpersonal skills and willingness to collaborate with colleagues. Also, VET colleges should invest in the further professional development of their teamworking abilities through team development $\mathrm{HR}$ practices.

Motivation-enhancing team-oriented HR practices aim to increase teachers' focus on the team and discretionary effort (Chuang et al., 2013). When teams are 
evaluated and rewarded through team evaluation HR practices on the basis of their collective performance, the importance of acting as a team is communicated clearly to team members. It then becomes apparent to individual teachers how they should perform their role (Gardner, Wright, \& Moynihan, 2011), and this can stimulate their involvement in the team and team performance.

Suitable environments for teamwork can be created through the opportunityenhancing team-oriented HR practices (Chuang et al., 2013). Designing and scheduling work through teamwork facilitation HR practices, so that team members who have the ability and motivation to engage in teamwork activities meet each other, can stimulate social interactions and team members' engagement in team learning processes (Chuang et al., 2013; Kaše, Paauwe, \& Zupan, 2009).

\subsubsection{Team-oriented HR practices, teachers' responses and team performance}

Consistent with the generic HRM literature, we anticipate that team-oriented HR practices will influence teachers' affective team commitment and team learning, in terms of information processing. This occurs as HR practices have been found to 'signal' employers' intentions to invest in employees, with employees (teachers) responding in ways they believe are appropriate (Bowen \& Ostroff, 2004). In terms of team-oriented HR practices, this implies that the ability-, motivation- and opportunity-enhancing practices all signal the importance of teams, teamworking and investment in team performance. Teachers will see that their commitment to the team and engagement in team learning, such as information processing, is valued by their VET college who have invested in these HR practices, and respond accordingly by displaying higher levels of affective team commitment and more engagement in information processing. This leads to the first hypothesis:

Hypothesis 1: Team-oriented HR practices are positively associated with affective team commitment and information processing.

Moreover, we propose that affective team commitment precedes information processing. An affective attachment to the team is likely to result in a willingness to engage in team learning with other team members. Affective team commitment implies that individuals identify with the team, form an emotional attachment to it and value their team membership (Van der Vegt \& Bunderson, 2005). Affective team commitment is particularly important for multidisciplinary teams, such as VET teacher teams, because the degree of team members' identification with their team affects the extent to which teams put their diversity to good use (Edmondson, Dillon, \& Roloff, 2007). Team members who identify with the team are more committed to team goals and more willing to participate in collective learning processes to achieve these goals (Van der Vegt \& Bunderson, 2005). This is confirmed by previous research in VET colleges that 
shows that more committed teachers with multidisciplinary backgrounds engage more in team learning processes such as information processing (Wijnia et al., 2016). This leads to our second hypothesis:

Hypothesis 2: Affective team commitment is positively associated with information processing.

In turn, we expect that when team members engage in information processing, that is, when they share information with each other, collectively construct shared interpretations of this information, and constructively discuss different perspectives to reach agreement (Decuyper et al., 2010; Van Woerkom \& Croon, 2009; Wijnia et al., 2016), the team's overall performance will increase.

Previous research within the VET context shows that information processing is associated with the successful implementation of CBE programmes (Wijnia et al., 2016). Moreover, research outside the educational context shows that information processing contributes to team innovation and efficiency (Van Woerkom \& Croon, 2009; Widmann et al., 2016). These findings indicate that information processing facilitates the sharing of team members' ideas, experimentation and alternative ways of doing things, and, as such, contributes to team innovation (Van Woerkom \& Croon, 2009). Additionally, these findings also indicate that engagement in information processing ensures that team members transfer their knowledge and skills to each other, and, as such, increase their efficiency in their work (Van Woerkom \& Croon, 2009). For instance teachers can share their knowledge on preparing lessons, so that other teachers' efficiency in preparing lessons increases (Egodawatte, McDougall, \& Stoilescu, 2011). On this basis we anticipate that information processing will be positively associated with teacher team innovation and efficiency. This leads to the third hypothesis:

Hypothesis 3: Information processing is positively associated with teacher team innovation and efficiency.

Combining these three hypotheses, we expect the positive associations between team-oriented HR practices and team innovation and efficiency to be mediated by teachers' affective commitment to the team and their engagement in information processing with other team members. This reasoning is consistent with findings presented in the generic HRM literature in which scholars have found employees' attitudes and behaviours mediate the relationship between HR practice and performance (e.g. Messersmith, Patel, Lepak, \& Gould-Williams, 2011; Nishii, Lepak, \& Schneider, 2008). Further, there is emerging context specific evidence which also suggests that teachers' attachment to the team and engagement in information 
processing leads to improved team performance (Vangrieken et al., 2016). This leads to the fourth hypothesis which, together with the other hypotheses, is depicted in the conceptual model of Figure 2.1:

Hypothesis 4: Team-oriented HR practices are positively associated with team innovation and efficiency via their positive associations with affective team commitment and information processing.

\subsection{Methods}

In this section, we describe the sample, measurements and data analysis. Because we have developed a new research instrument to measure team-oriented HR practices, the validation of this instrument is also explained.

\subsubsection{Sample and respondents}

Two datasets are used for this study. Dataset 1, which was used to validate the teamoriented HRM research instrument, was collected from April to December 2014. An online survey was sent to 1,650 teachers in 104 teams from 23 VET colleges in the Netherlands. Data on the HRM instrument were collected from 970 teachers (59\%) in 103 teams from 23 VET colleges. Dataset 2, which was used for hypothesis testing, was collected from April to December 2015. An online survey was sent to 1,376 teachers in 84 teams from 20 VET colleges. To obtain a good representation of each team, only those respondents were included in the analysis who answered all the relevant questions in the survey and who were members of a team with a minimum response rate of 33\%. This resulted in a sample of 704 (51\%) teachers in 70 teams from 19 VET colleges. Of these teachers, $46 \%$ were male with an average age of 48 years (SD $=11.01)$, which is representative of the Dutch VET teacher population (approximately 49\% male, average age 49 years; Lubberman, Van Rens, Hovius, \& Wester, 2013). On average, teachers had worked for 15.57 years in education (SD = 10.42). Most teachers had a bachelor's degree (74\%), 11\% had completed secondary vocational education, $9 \%$ had a master's degree, and $6 \%$ had completed other secondary education or post-higher education.

\subsubsection{Measurements}

All measurements were assessed using a five-point Likert scale, with 1 (never) to 5 (always) for team-oriented HR practices and information processing and 1 (completely disagree) to 5 (completely agree) for team innovation, team efficiency and affective team commitment.

Although the scales for team innovation, team efficiency and information processing focus on team-level processes, they are here measured through individual teachers' perceptions of these team-level processes. 


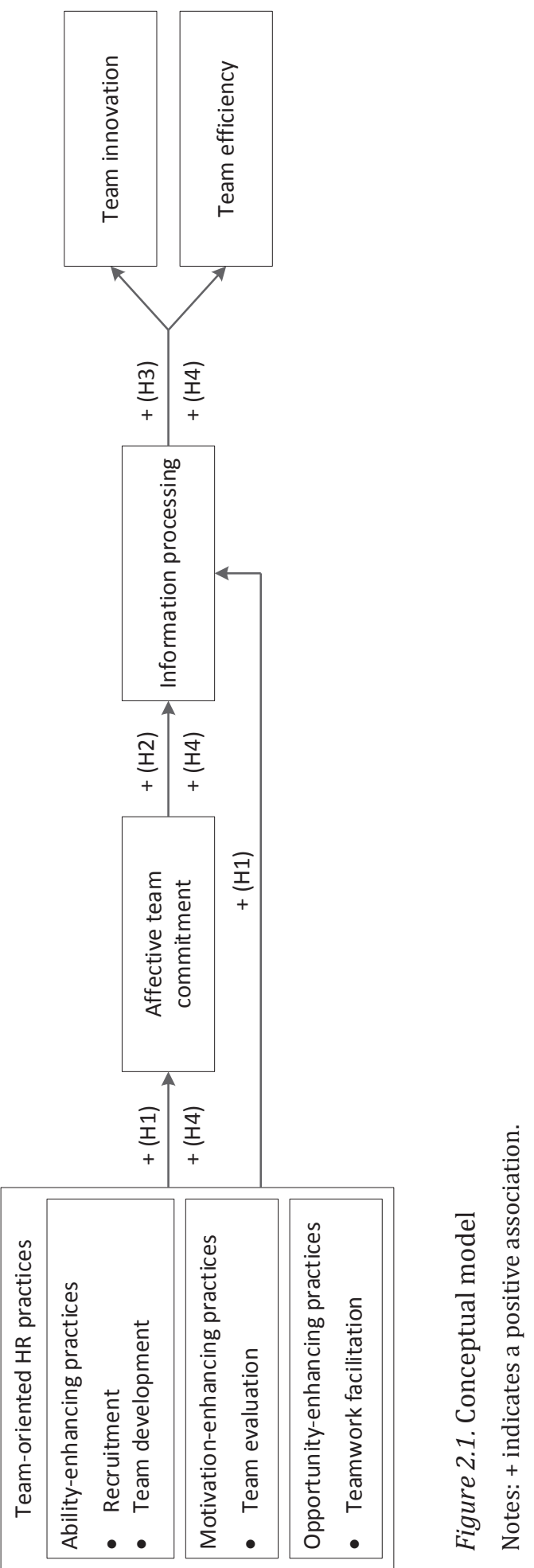


Team innovation. Team innovation was measured using the four-item scale developed by Van Woerkom and Croon (2009), although the formulation of the items was adjusted to fit the school context (Cronbach's alpha $=.89$ ). An example item is, 'Our team develops new materials and methods'.

Team efficiency. Team efficiency was measured using the three-item scale developed by Van Woerkom and Croon (2009) (Cronbach's alpha = .84). An example item is, 'Our team spends the available time well'.

Information processing. Information processing was measured using an adaptation of the team learning instrument of Van Offenbeek (2001) (Cronbach's alpha = .89). Based on Van Woerkom and Van Engen (2009), nine original Dutch items from this instrument were selected and combined into one scale for information processing. This scale was pilot tested among 128 teachers from one Dutch VET college who did not participate in the final data collection. Principal component analysis (PCA) on the pilot data showed a clear one-component structure. An example item is, 'In my team we developed a shared understanding about our work approach'.

Affective team commitment. Affective team commitment was measured using the collective team identification scale developed by Van der Vegt and Bunderson (2005) (Cronbach's alpha = .81). An example item is, 'I feel a strong sense of belonging to the team'.

Team-oriented HR practices. To measure team-oriented HR practices in Dutch VET colleges, a new instrument was developed, as previously mentioned. Our research instrument consisted of four, five-item scales that were developed based on teamoriented HR practices distinguished in previous studies (Chuang et al., 2013; Jackson, Chuang, Harden, \& Jiang, 2006). These HR practices were made context-specific based on knowledge of and information about HRM in Dutch education. Although Chuang et al. (2013) and Flinchbaugh et al. (2016) also measured team-oriented HR practices, their instruments were not suitable for the goal of this study and a new instrument was therefore required. First, like most HRM research (Knies, Boselie, Gould-Williams, \& Vandenabeele, 2014), the study of Chuang et al. (2013) was conducted in the private sector, which made their instrument unsuitable for the specific VET context of this study. For instance, multiple motivation-enhancing practices in their instrument focus on financial rewards, while VET colleges usually have little resources for such rewards. Second, although the study of Flinchbaugh et al. (2016) was conducted in the public sector, namely the health sector, their instrument does not focus on distinct AMO practices as we aimed to do here.

Our instrument was developed to measure the practices of recruitment, team development, team evaluation and teamwork facilitation. These practices are similar to HR practices measured in other studies (for an overview see Jiang et al., 2012), except that previous studies usually measured individual employee-oriented HR practices, while our instrument measured team-oriented HR practices. The research instrument 
was discussed with researchers in the field of HRM and team learning for readability and clarity, resulting in the reformulation or deletion of items and the creation of new ones. The instrument was also pilot tested among 123 respondents working in different organisations such as schools, municipalities and healthcare institutes, to test initial construct validity. Specifically, $47 \%$ of the respondents worked in an educational context. Construct validity was explored by PCA, which resulted in a four-component solution with four items per scale. This instrument was further tested for construct validity in the VET context using dataset 1 of this study (see the data analysis and results sections). Appendix A, at the end of this chapter, contains the final scales of the teamoriented HRM research instrument that were used in this chapter.

\subsubsection{Data analysis}

\section{Instrument validation}

To validate the team-oriented HRM research instrument, dataset 1 was randomly split into two subsamples. We used subsample $1(\mathrm{~N}=240)$ to explore the component structure of the instrument using PCA with oblique rotation in SPSS 21. Subsample 2 (N = 730) was used for cross-validation of the instrument using confirmatory factor analysis (CFA) in Mplus 7.4. Model fits were assessed using the following multiple fit indices: chi-square, the root mean square error of approximation (RMSEA), the TuckerLewis index (TLI), the comparative fit index (CFI) and the standardised root mean square residual (SRMR). A model fit is good when RMSEA $\leq .05$, TLI > .95, CFI $>95$ and SRMR $\leq .08$ (Hu \& Bentler, 1999), although RMSEA $\leq .08$, TLI > .90 and CFI > .90 are considered acceptable (Byrne, 2012). The average variance extracted (AVE) and the square root of the AVE were calculated as indicators for discriminant validity. Discriminant validity is good when all AVE values are above .50 and when the square root of the AVE value of each factor is larger than correlations of that factor with other factors (Zait \& Bertea, 2011).

\section{Hypothesis testing}

Dataset 2 was used for hypothesis testing. Because teachers are nested in teams, intraclass correlations (ICC(1) and ICC(2)) and average within-group agreement (rwG(J)) were calculated for all constructs. In education, ICC(1) values of .10 are considered to be medium and values of .15 or higher to be large (Hox, 2010). In general, ICC(2) values and $\mathrm{rWG}_{(\mathrm{J})}$ values should be .70 or higher to justify data aggregation to the team level (LeBreton \& Senter, 2007). All constructs of the conceptual model had ICC(1) values above .10, with three above .15, and one construct (information processing) had an ICC(2) value above .70. Four constructs had rwG(J) values above .70 (see Table 2.2). These results imply that aggregation of all constructs to the team level was not permitted, but that team membership affected the data and that the multilevel structure of the data needed to be taken into account. 
Multilevel structural equation modeling (MSEM) with complex structure analysis in Mplus was therefore used for hypothesis testing. MSEM with complex structure analysis takes into account the multilevel structure of the data, by assessing the conceptual model at the individual team member level while correcting the model for their team membership. As it includes the non-independence of the data by correctly computing standard errors and the chi-square test of the model fit (Muthén \& Muthén, 1998-2012), complex structure analysis reduces the chance of reporting type I errors (false positive results in the measurement model) (Oude Groote Beverborg et al., 2015).

The measurement model fit was assessed by the RMSEA, TLI, CFI and SRMR fit indices. The control variables gender, age and team size were included in the analyses by adding their regression coefficients on all mediating and dependent variables of the model.

\subsection{Results}

In this section, we first discuss the results of the validation of the team-oriented HRM research instrument then the results of the hypothesis testing.

\subsubsection{Instrument validation}

PCA on subsample 1 of dataset 1 showed a clear four-component structure corresponding to the proposed scales. CFA was used to further test the PCA structure on subsample 2 of dataset 1 , as well as two alternative models: a one-factor model that regarded all practices as an interdependent HRM system, and a three-factor model that only distinguished between ability-, motivation- and opportunity-enhancing practices. Analysis showed poor model fits for the one-factor structure $\left(\chi^{2}(104)=6749.765, \mathrm{p}<\right.$ $.001, \mathrm{TLI}=.365$, CFI $=.450, \mathrm{RMSEA}=.296, \mathrm{SRMR}=.157)$ and the three-factor structure $\left(\chi^{2}(101)=2991.758, \mathrm{p}<.001, \mathrm{TLI}=.716, \mathrm{CFI}=.761, \mathrm{RMSEA}=.198, \mathrm{SRMR}=.127\right)$. The four-factor structure showed a satisfactory model fit $\left(\chi^{2}(98)=530.967, \mathrm{p}<.001\right.$, TLI = $.956, \mathrm{CFI}=.964, \mathrm{RMSEA}=.078, \mathrm{SRMR}=.026$ ) and good discriminant validity because AVE values were greater than .50 and square roots of AVE values were larger than correlations between CFA factors (see Table 2.1 for PCA and CFA results). The fourfactor model was therefore used for hypothesis testing.

Additionally, a CFA on dataset 2 with all nine scales of the conceptual model showed an acceptable fit to the data, with $\chi^{2}(566)=1621.141, \mathrm{p}<.001$, TLI $=.942$, CFI $=.948, \mathrm{RMSEA}=.051$ and SRMR $=.038$.

\subsubsection{Hypothesis testing}

\section{Descriptive statistics}

Table 2.2 shows the descriptive statistics. All constructs of the conceptual model were positively correlated to one another. Correlations varied from small (e.g. between team 
development and affective team commitment; $r=.23$ ) to large (e.g. between information processing and team efficiency; $r=.56$ ).

\section{Model results}

The fit of the measurement model to the data was good, with $\chi^{2}(13)=21.941, p=.056$, TLI $=.972$, CFI $=.989$, RMSEA $=.031$ and SRMR $=.021$. The model was therefore used for hypothesis testing. Figure 2.2 presents the hypothesised total results of this model, and Table 2.3 presents all direct, indirect and total results.

The results show that Hypothesis 1, which expected that team-oriented HR practices had positive associations with affective team commitment and information processing, was partially confirmed, because different results for the separate HR practices were found. Recruitment, team evaluation and teamwork facilitation were positively associated with affective team commitment and information processing, while team development had no significant associations with affective team commitment and information processing. Results showed that Hypothesis 2, which expected that affective team commitment was positively associated with information processing, was confirmed. Hypothesis 3, which expected a direct positive association between information processing and team innovation and efficiency, was also confirmed. This implies that teachers who reported more information processing also reported higher levels of team innovation and efficiency. Hypothesis 4, which expected that team-oriented HR practices were indirectly and positively associated with team innovation and efficiency through affective team commitment and information processing, was partially confirmed. Recruitment, team evaluation and teamwork facilitation were indirectly associated with team innovation and efficiency, while team development had no significant indirect associations.

Additionally, non-hypothesised direct associations were found. Team development, teamwork facilitation and affective team commitment were directly and positively associated with team innovation. Moreover, teamwork facilitation and affective team commitment were directly and positively associated with team efficiency. Lastly, female team members reported less information processing than males, and older team members reported higher levels of team efficiency. 


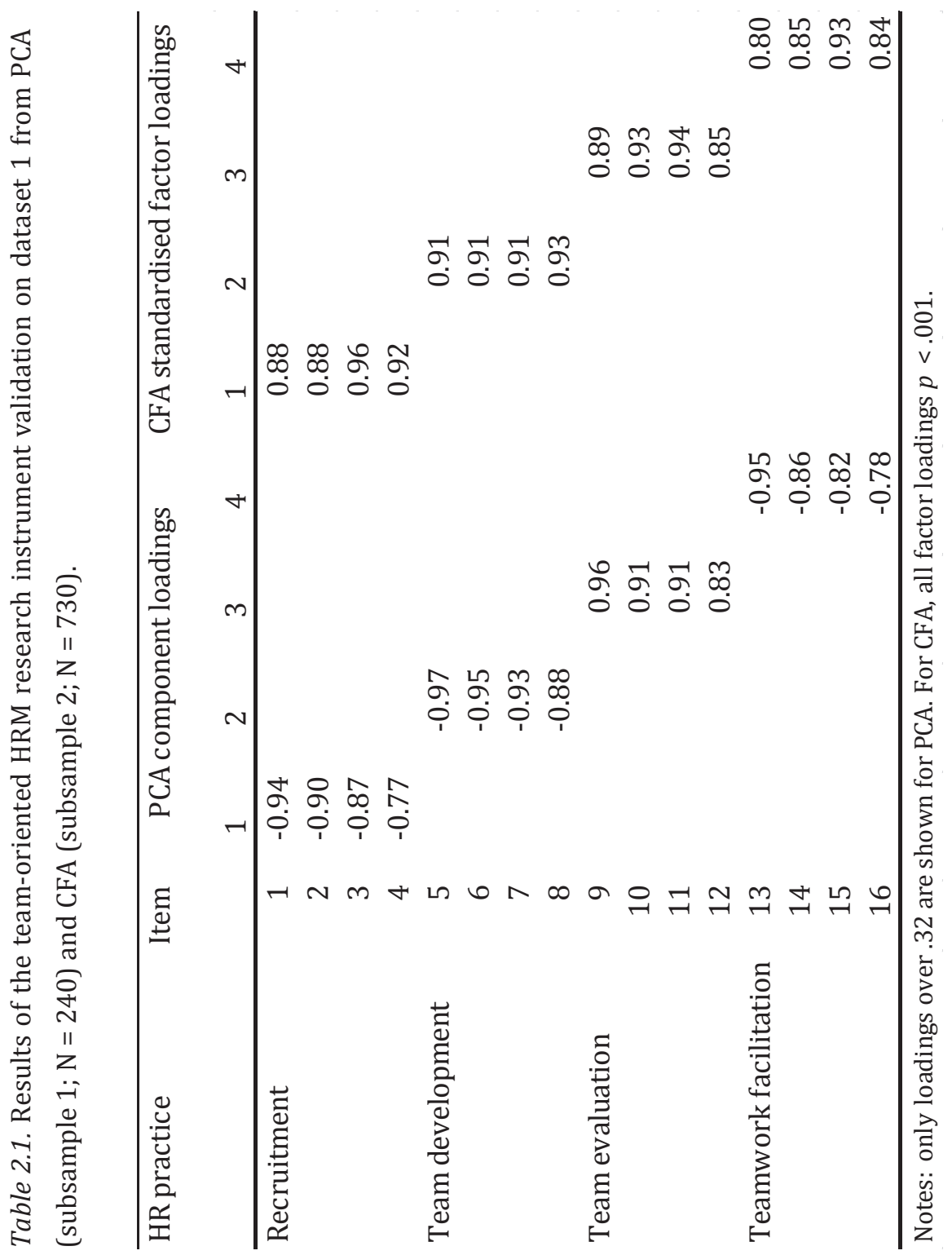




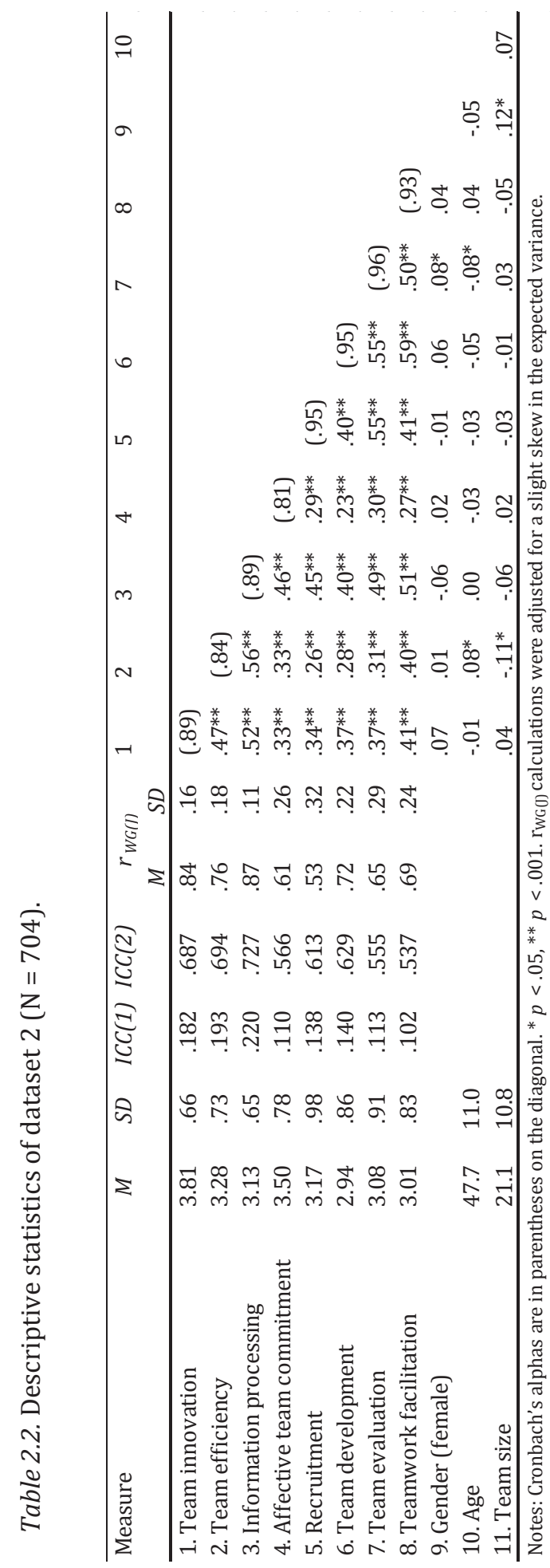




\subsection{Conclusion and discussion}

This study focuses on explaining how team-oriented HR practices are associated with VET teacher team performance in terms of innovation and efficiency. We predicted that team-oriented HR practices would be positively and indirectly associated with team innovation and efficiency, through positive associations with teachers' affective team commitment and engagement in team learning, in terms of information processing. Our results generally supported this line of reasoning. We found that all team-oriented HR practices, with the exception of team development, were positively associated with teachers' affective team commitment and their engagement in information processing. In turn, affective team commitment and information processing were positively associated with both team innovation and efficiency. Consequently, the team-oriented HR practices of recruitment, team evaluation and teamwork facilitation were indirectly associated with team innovation and efficiency.

As noted above, the team-oriented HR practice of team development was not associated with affective commitment and information processing. However, team development was directly associated with team innovation. A possible explanation for this finding is that team development is more often used to instruct teams on how to implement innovations such as CBE than to improve team-oriented attitudes and behaviours such as affective team commitment and information processing. Furthermore, teamwork facilitation was not only indirectly, but also directly associated with higher levels of team innovation and efficiency, which stresses the importance of offering teachers the opportunity to meet in practice.

Overall, these findings offer several new insights and possibilities for future research. We elaborate on these contributions below by discussing our findings.

\subsubsection{HRM research in the educational context}

As explained in the introduction, teacher teams have historically not had to engage in deep-level collaboration. However, VET colleges are now promoting teamworking so that teachers can develop new ideas, be more innovative and discuss didactics, all of which are needed to implement and execute CBE. Our study suggests that teamoriented HR practices play a crucial role in stimulating such collaboration as our results show that these HR practices are positively associated with teachers' affective team commitment and their engagement in information processing. By stimulating teachers to become committed to the team and engage in information processing, the teamoriented HR practices also appear to affect team performance, in terms of innovation and efficiency. 


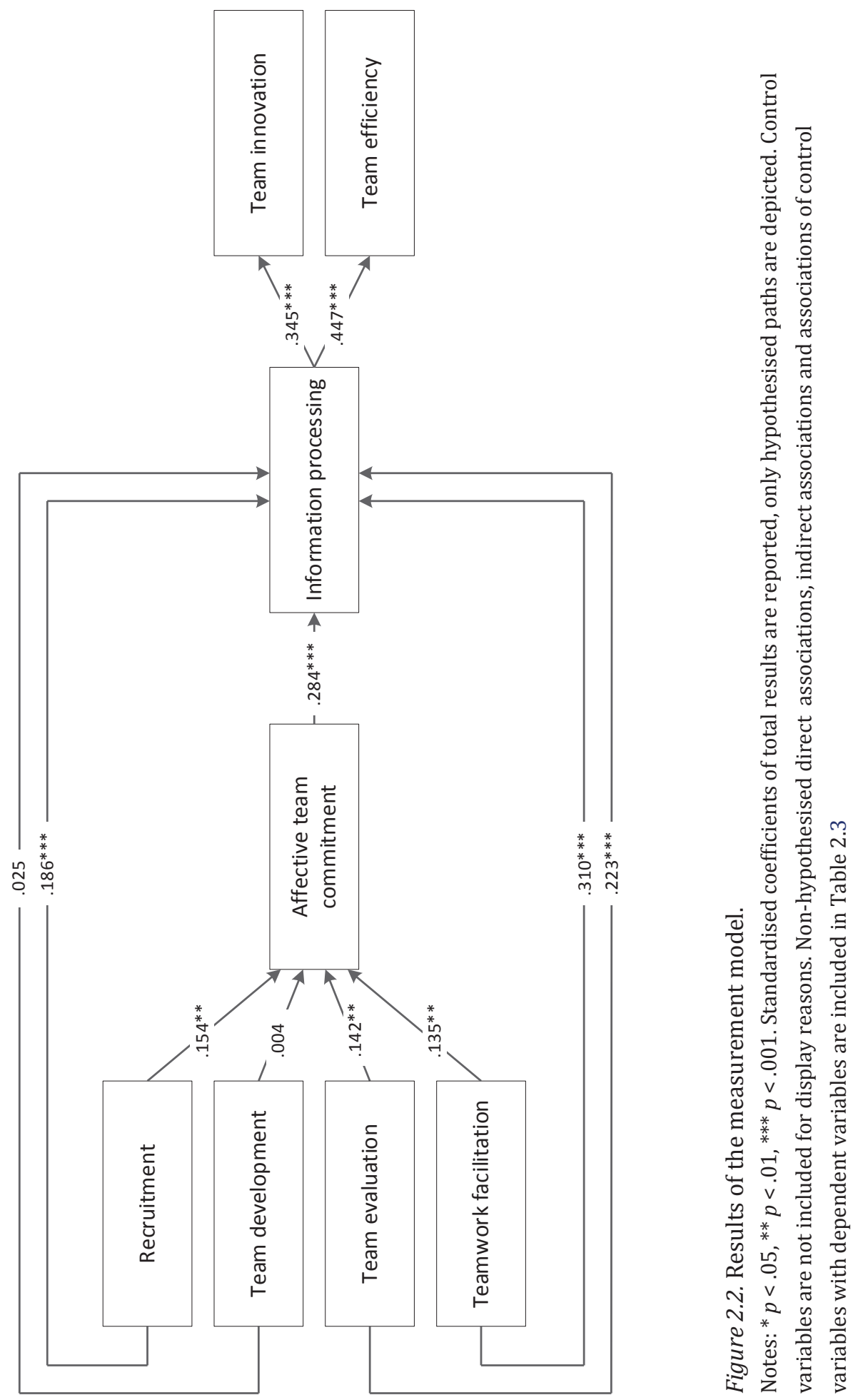




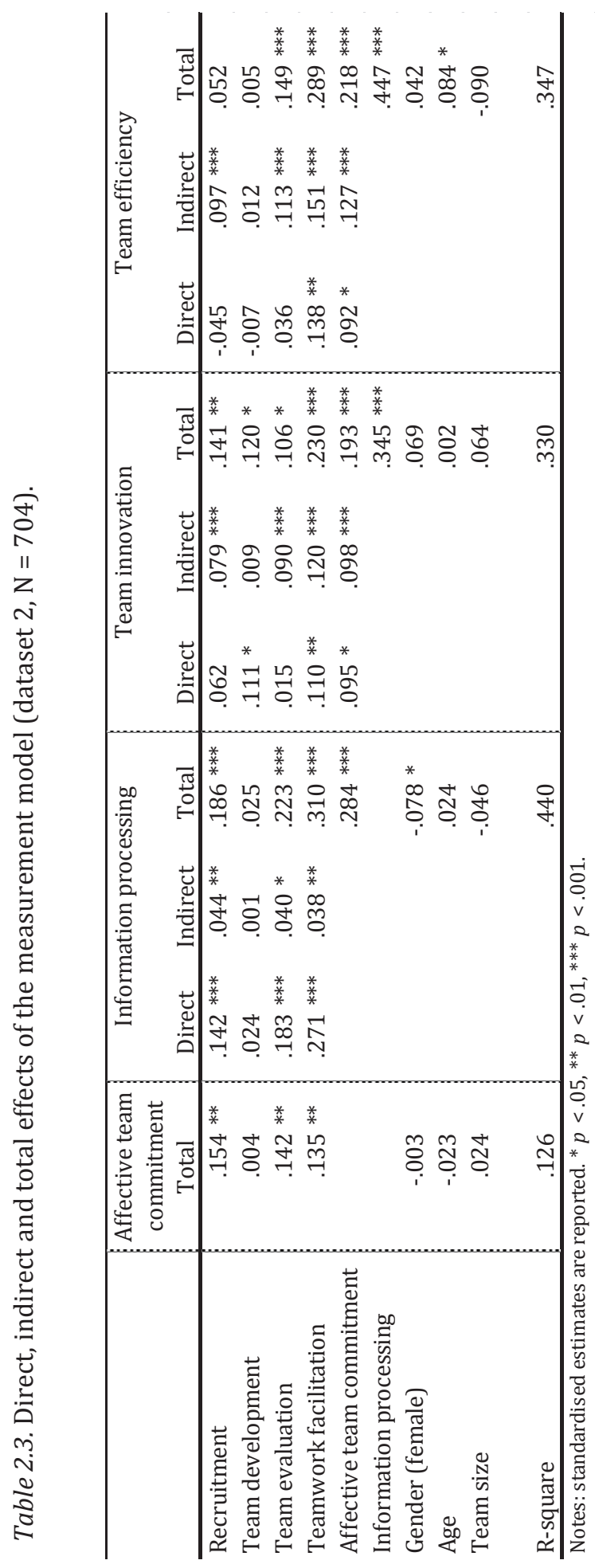


The link between team-oriented HR practices, affective team commitment, information processing and team performance varied by HR practice. For instance, on the one hand, recruitment, team evaluation and teamwork facilitation all seemed important team-oriented HR practices for taking teachers out of their isolation and making them feel part of a real team and behave in the interest of the team, and, as such, increase team performance indirectly. On the other hand, only teamwork facilitation also directly stimulated team performance. Despite these differences, each HR practice was found to make a unique contribution to team performance. To stimulate teacher team performance, therefore, a combination of ability-, motivation- and opportunityenhancing team-oriented HR practices is needed. Consequently, we propose that it is important to study associations between multiple HR practices and team performance simultaneously instead of examining the impact of single HR practices, as is usually done in studies on HRM in the educational context (DeArmond et al., 2010; Runhaar \& Sanders, 2016). This would enable the distinct effects of HR practices and possible interactions between these practices to be examined, which would help researchers to further understand the complex relationship between team-oriented HR practices and team performance.

\subsubsection{Focus on teams in the HRM-performance link}

The findings also underline the importance of further examining the link between HR practices and performance at the team level. While many studies have already focused on associations between HR practices, individual employee responses and outcomes such as organisational commitment, job satisfaction, empowerment and organisational citizenship behaviour (e.g. Kehoe \& Wright, 2013; Messersmith et al., 2011) and organisational outcomes such as financial outcomes (e.g. Jiang et al., 2012), our results suggest that employee perceptions of HR practices also affect team responses and outcomes. This insight is relatively new, because although the need to examine the team level is regularly stressed, there is still very little research on teams in the HRM literature (Chuang et al., 2013; Jiang et al., 2013). Because team structures have been widely introduced in many organisations and teams are better at dealing with changing environments and complex tasks than individuals (Decuyper et al., 2010), we believe future studies on the HRM-performance link should focus on teams so that our understanding of how HR practices can stimulate teamworking increases.

\subsubsection{Unravelling the HRM-performance link: the mediating role of information processing}

When examining associations between HR practices and team performance, we argue that relevant team-level mediating variables should also be included. In this study, we did this by researching the mediating effects of engagement in information processing. This shed new light on the associations between team-oriented HR practices and team 
performance, because so far only a few other studies have addressed associations between team-oriented HR practices and information processing in teams (Chuang et al., 2013; Flinchbaugh et al., 2016). We have contributed to these studies by broadening the concept of information processing by not only focusing on information sharing in teams, but by also including the processes of co-constructing shared interpretations and discussing different perspectives in teams into our conceptualisation of information processing. This broader conceptualisation of information processing is based on the team learning literature (e.g. Decuyper et al., 2010; Van Woerkom \& Van Engen, 2009). As such, we have tried to bridge the gap between HRM literature and team learning literature. This gap could be further bridged by including other team learning processes as possible mediating variables in future studies, to increase our understanding of associations between team-oriented HRM practices and team performance. The team learning literature would also benefit from bridging this gap, because although associations between team learning processes and team performance have been quite thoroughly examined (e.g. Leicher \& Mulder, 2016; Van Woerkom \& Croon, 2009; Wijnia et al., 2016), the role of HRM is largely underexposed.

\subsubsection{Limitations and future research}

This study is based on self-report data because attitudes and perceptions can only be measured by self-reports (Chan, 2009). A consequence of this is that the results could be influenced by common method bias. For future research, we therefore suggest combining reports from different sources, such as teachers and team leaders, to obtain more reliable data (Podsakoff, MacKenzie, Lee, \& Podsakoff, 2003).

Additionally, this study made use of cross-sectional data. Although it is plausible to assume that organisations implement team-oriented HR practices to stimulate team performance, instead of the reverse causal order (Chuang et al., 2013), the data make it impossible to draw this causal conclusion. Additional longitudinal research should be conducted to make stronger causal claims.

Moreover, when examining team processes such as information processing, analysis at the team level is often recommended (e.g. Van den Bossche et al., 2006). We used MSEM with complex structure analysis to analyse the research model at the individual teacher level, corrected for the team level. This was needed because data aggregation was not permitted. Consequently, we could only offer insights into individual teachers' perceptions of the team-level processes of information processing, team innovation and efficiency.

\subsubsection{Practical implications}

As teacher teams are responsible for educational improvements and innovations, it is important to invest in HRM practices that encourage teachers to engage in collaboration. VET colleges can do this through team-oriented HR practices such as 
selecting new team members based on their interpersonal skills and willingness to collaborate, evaluating teams by recognising and stimulating the attitudes and behaviours needed to reach team goals, and providing teams with the opportunity to collaborate which, according to our research, increases commitment and engagement in information processing. In doing so, teachers' focus shifts from individual tasks to team goals. If this kind of transformation is achieved, then team performance, in terms of innovation and efficiency will improve. 


\section{Appendix A. Team-oriented HRM research instrument}

\section{Ability-enhancing practices}

\section{Recruitment}

When recruiting new members for my team (from inside or outside the organisation), the following is taken into account:

1 the degree to which they are willing to commit themselves to the team interest.

2 the degree to which they have the potential to contribute to team performance.

3 their ability to work in a team.

4 the degree to which they are team players.

Team development

This organisation offers my team development opportunities (inside or outside our organisation), aimed at:

5 the learning needs of my team.

6 topics my team needs for further professionalisation.

7 enhancing the qualities of my team.

8 increasing team results.

\section{Motivation-enhancing practices}

\section{Team evaluation}

During the evaluation of my team, the following is taken into account:

9 the performance of my team.

10 the initiatives taken by my team.

11 how the team works on professionalisation.

12 the extent to which the team is functioning properly.

\section{Opportunity-enhancing practices}

\section{Teamwork facilitation}

This organisation makes it possible for my team to:

13 work together on our team tasks.

14 meet to discuss the team's functioning.

15 think about solutions for problems/challenges together.

16 apply innovations/changes together. 


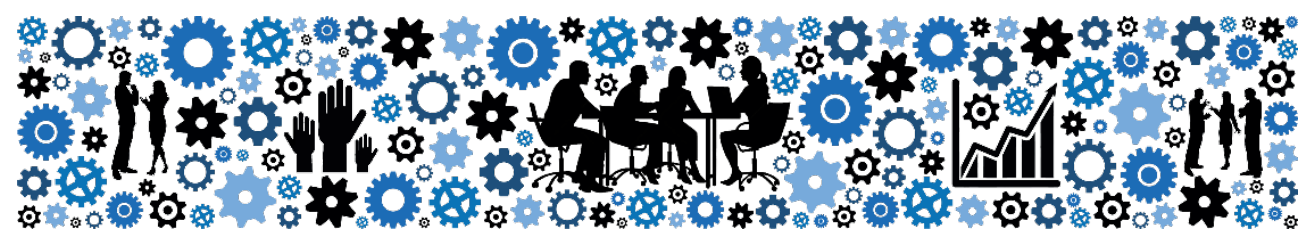

\section{Chapter 3}

\section{Leadership ambidexterity: key to stimulating team learning through team-oriented HRM? An explorative study among teacher teams in VET colleges ${ }^{2}$}

In vocational education and training (VET) colleges worldwide teacher teams work on innovations to improve their educational quality. To foster this process, teams benefit from team-oriented HRM aimed at stimulating teachers' engagement in team learning. This qualitative study explores in-depth how team leaders enact team-oriented HR practices and how this affects teachers' perceptions of these practices and their engagement in team learning. Interviews with four team leaders and group interviews with eleven teachers from their four teams were conducted in one VET college in the Netherlands. The results showed that team leaders were both controlling and stimulating in their enactment. To foster team learning, it appears not just necessary that team leaders' enactment and teachers' perceptions of this enactment are aligned, but that team leaders' enactment also is geared towards the team's needs. This study therefore shows team leaders' crucial role in the effective implementation of teamoriented HRM in VET colleges.

\footnotetext{
2 This chapter is based on: Bouwmans, M., Runhaar, P., Wesselink, R., \& Mulder, M. (In press). Leadership ambidexterity: Key to stimulating team learning through team-oriented HRM? An explorative study among teacher teams in VET colleges. Educational Management Administration \& Leadership
} 


\subsection{Introduction}

With the rise of new public management, accountability now plays a central role in public sector organisations (Hood, 1995). This development is also seen in the vocational education and training (VET) sector worldwide, where government and labour market demands regarding the quality of education have urged the VET sector to implement and improve competence-based education (CBE) (Mulder \& Winterton, 2017).

The success of educational organisations in implementing and executing adaptations and innovations such as CBE depends to a large extent on teachers' willingness to put extra effort into their work (Somech \& Ron, 2007). More specifically, engagement in team learning is considered to be necessary during complex educational adaptations and innovations (Dochy et al., 2014). This implies that teachers need to go beyond their primary tasks of teaching, and collaborate in teams to learn from and with each other and help each other improve (Barber \& Mourshed, 2007). In the case of CBE, teachers' engagement in team learning is shown to contribute to the successful implementation of CBE (Wijnia et al., 2016). However, teachers' engagement in team learning is not always a matter of course. This is because their primary task of teaching involves a high degree of autonomy, with the result that they are not always used to engaging in team learning (Vangrieken et al., 2016), as is also explained in Chapter 1

Because of the central role of teacher teams in successful CBE implementation, VET managers have invested in the development and implementation of human resource management (HRM) to support teams and stimulate team processes such as team learning (Runhaar \& Sanders, 2013). In Chapter 2 it was explained that this teamoriented HRM covers all HR practices such as recruitment, team development, team evaluation and teamwork facilitation, targeted at enhancing teams' abilities, motivation and opportunities to collaborate, learn and perform. Team-oriented HRM has recently gained attention in HRM literature in both the public and private sector context (e.g. Chuang et al., 2013). Although these studies show the potential of team-oriented HRM in stimulating team learning, they measure team-oriented HRM through employee perceptions and in merely abstract and quantitative terms. Furthermore, these studies largely neglect the role of line managers (i.e. team leaders in VET colleges), who are important executors of HRM and thus play an important role in the relationship between HRM and performance outcomes (e.g. Knies \& Leisink, 2013; Purcell \& Hutchinson, 2007). In this study, therefore, a qualitative approach is taken to explore in-depth how VET team leaders' enactment of team-oriented HRM affects teachers' perceptions of these HR practices, and their responses in terms of team learning.

Hence, this study aims to answer the following research question: How does team leaders' enactment of team-oriented HRM affect teachers' perceptions of teamoriented HRM and their responses in terms of team learning? 
In answering this research question, this study aims to provide insights into the relationship between HRM and team behaviour. This insight is needed because, although the importance of teams is acknowledged in HRM literature, very few studies actually include teams in their research (Jiang et al., 2013). First, by focusing on team learning as a specific team behaviour, new insights can be provided into how team learning processes can be stimulated, which is a topic that remains largely unexplored (Chuang et al., 2013). Second, by specifically focusing on the role of team leaders' enactment of team-oriented HRM, this study aims to provide insights into the process by which HRM can be effective in stimulating team learning. Third, by exploring this process within Dutch VET, this study provides new insights into the process of how HRM can be effectively enacted in VET.

\subsection{Theoretical framework}

\subsubsection{Team-oriented HRM}

To understand the relationship between team-oriented HRM and team learning, it is first explained which practices are regarded as team-oriented HR practices (the content), before it is explained how these HR practices may affect team learning (the process).

In Chapter 2 the content of team-oriented HR practices is described based on the Ability-Motivation-Opportunity (AMO) model. The AMO model argues that an organisation's performance is best served by an HRM system that contributes to employees' performance by increasing their abilities (A), creating motivational incentives (M) and providing opportunities to perform (0) (Boselie et al., 2005). As far as the content of team-oriented HRM is concerned, this implies that HR practices should be aimed at developing team performance by investing in the teams' abilities, motivation and opportunities. In Chapter 2 four HR practices were distinguished that were positively associated with teachers' team learning and/or team performance, namely the practices of recruitment, team development, team evaluation and teamwork facilitation. These HR practices are summarized in Table 3.1 and are the starting point for this study.

If a VET college values team performance, it is likely that a team-oriented HRM strategy will be developed that aims to stimulate team processes that increase performance, such as collaboration and team learning. Whether this intended strategy actually leads to team learning depends on a) how these practices are enacted, and b) how teachers perceive these practices and respond based on their perceptions (Wright \& Nishii, 2013). 


\subsubsection{Team leaders' enactment of team-oriented HRM}

In practice, not all intended HR practices that are described in an HRM strategy are enacted, or they are enacted in ways other than intended (Wright \& Nishii, 2013). This is because the enactment of HR practices is often devolved to line managers (Hailey, Farndale, \& Truss, 2005), or team leaders in the case of VET. There are various reasons why line managers deviate from HRM strategy in their enactment, such as line managers' motivation and ability, competing demands, and time pressure (McGovern, Gratton, Hope-Hailey, Stiles, \& Truss, 1997; Nehles et al., 2006). McGovern et al. (1997) found that line managers' motivation was the most important reason for their involvement in enacting HR practices, and that the quality of HR practices depended on their involvement and behaviour. This finding supports the assumed symbiotic relationship between HR practices and line managers' behaviour (Purcell \& Hutchinson, 2007). On the one hand, line managers need well-designed HR practices to have the opportunity to stimulate and reward employees and to foster performance. On the other hand, the way in which HR practices are enacted depends on these managers' behaviour. In the case of VET, this implies that team leaders' attitudes and behaviours are important factors in determining their enactment of team-oriented HRM and, as such, might influence the quality of team support provided through these practices.

Table 3.1. The content of team-oriented HRM

Recruitment: new team members are not solely recruited based on their expertise, but also based on their interpersonal skills and willingness and ability to collaborate.

Team development: team development is aimed at the learning needs of the team, so that teams can professionalise on topics that are relevant to them, such as on specific content knowledge and skills, or on improving teamwork and team processes.

Team evaluation: teams and team members are evaluated based on their collective performance and contributions to the team's goals, so that they understand what is expected of them and that team involvement is valued.

Teamwork facilitation: team members are facilitated in time and space to collaborate, so that they can discuss team tasks and the team's functioning, and can work on educational innovations and problems together. 


\subsubsection{Teachers' perceptions of team-oriented HRM}

Following the line of reasoning of Purcell and Hutchinson (2007), it is argued that teachers' behaviour is influenced by how they experience both team-oriented HR practices and their team leaders' behaviour. Teachers form an understanding of appropriate behaviour by interpreting HR practices and by interpreting the signals that team leaders send out through their enactment (Bowen \& Ostroff, 2004; Purcell \& Hutchinson, 2007; Wright \& Nishii, 2013). The social exchange theory has proven its value in explaining how individuals' perceptions lead to certain behavioural responses (e.g. Alfes, Truss, Soane, Rees, \& Gatenby, 2013; Runhaar, 2016). It explains the reciprocity within social relationships (Blau, 1964): if teachers perceive the presence of team-oriented HR practices and their team leader's support through his/her enactment of these practices, teachers feel obliged to reciprocate with positive team behaviour, such as engagement in team learning.

\subsubsection{Teachers' team learning}

Team learning is regarded as positive team behaviour, because it is shown to be positively related to team performance and CBE implementation (Van Woerkom \& Croon, 2009; Wijnia et al., 2016). As explained in Chapter 1, team learning is defined as teachers' collective engagement in processes that contribute to building and maintaining mutually shared cognition, leading to increased team performance (Van den Bossche et al., 2006). To achieve this, teams need to engage in different team learning processes. The following three processes form the core of team learning: team members a) share previously unshared information with each other, b) co-construct this information into shared interpretations by questioning, concretizing, and refining this information, and c) engage in constructive conflict to openly discuss and negotiate about different opinions so that they can reach consensus (Decuyper et al., 2010). When mutual understanding and shared cognition are achieved through engagement in these processes, teams perform more effectively (Van den Bossche et al., 2006; Vangrieken et al., 2016).

In Figure 3.1 the process through which intended team-oriented HRM may lead to increased engagement in team learning is visualised.

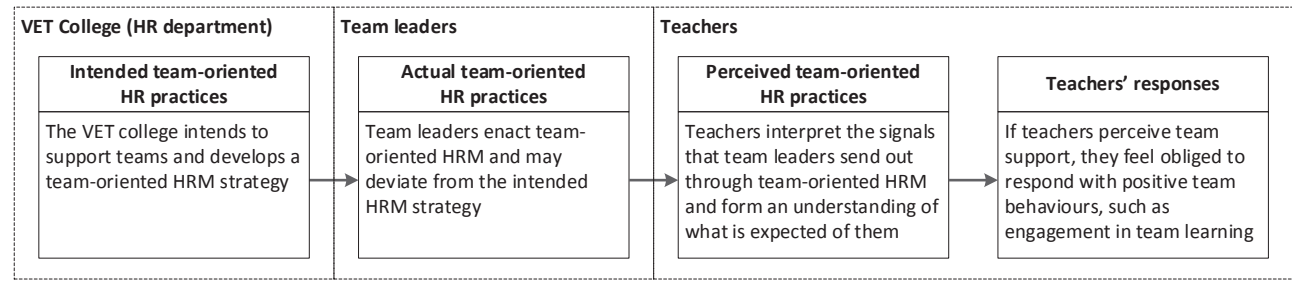

Figure 3.1. Conceptual model. 


\subsection{Methods}

A small-scale qualitative study was executed to make in-depth comparisons between how team leaders enacted team-oriented HRM, and how their enactment affected teachers' perceptions of appropriate behaviour and their engagement in team learning.

\subsubsection{Sample and research context}

Purposive sampling with two steps was used to select one Dutch VET college with a team-oriented HRM strategy in which the responsibility for enacting team-oriented HRM was devolved to team leaders. First, based on the large-scale quantitative analysis of team-oriented HRM and team learning presented in Chapter 2, one VET college was selected in which teachers recognized the presence of team-oriented HR practices and team leaders were responsible for enacting these HR practices. Second, a group interview was conducted with the HRM and educational development department heads to determine the content of the team-oriented HRM strategy. The results are described in Table 3.2.

The VET college selected focused on teams in their HRM strategy because these were held responsible for implementing a renewed vision on CBE in their educational programs. The main goal of the teams was to increase linkages between the courses in their curricula. Project groups were established within each team to increase these linkages, and worked for instance on standardizing grading methods for all courses or developing project-based education.

\subsubsection{Participants and study design}

Team leaders from all seven teams in the VET college were requested to participate and to let their teachers participate in interviews. Three team leaders declined because of practical reasons (e.g. time constraints). The remaining four team leaders participated with a total of eleven teachers: three teachers from teams 1 to 3 and two teachers from team 4 . These teachers were the driving forces behind the educational projects in their teams and had a good overview of team processes. During the interviews, a topic list was used that addressed engagement in team learning, team-oriented HR practices, and team leaders' behaviour. The team leaders participated in face-to-face interviews of about one hour each and teachers from each team participated in group interviews of about one to one and a half hours each. Group interviews were conducted because of the expected snowball effect: by discussing their perceptions on the interview topics, teachers could reconstruct their team reality together (Barbour, 2007). To individually prepare these group interviews, teachers filled in a short questionnaire about team learning and perceived team support before the interview. Their answers were discussed during the group interviews. 
Table 3.2. The VET college's team-oriented HRM strategy per HR practice

Recruitment: new team members are recruited through a standard procedure: a recruitment committee that consists of the team leader, a few teachers, and sometimes a student and a member of the HRM department. The committee assesses candidates' expertise as well as their willingness and skills to collaborate.

Team development: the VET college supports team leaders in finding team development trajectories that fit the needs of their team, but it is the team leaders' responsibility to deploy these development trajectories. Additionally, the VET college offers organisation-wide development trajectories in which all teams participate.

Team evaluation: there are no organisation-wide guidelines on team evaluation, because this is the team leaders' responsibility. However, there are rules for individual team member evaluation: team leaders need to evaluate teachers yearly and their collaboration in the team is a specific aspect of this evaluation.

Teamwork facilitation: the VET college values teamwork and therefore facilitates team leaders in time and money to foster collaboration. Team leaders can use this time and money as they see fit for their team.

\subsubsection{Data analysis}

The interviews were transcribed and coded in Atlas.ti version 7.5, using thematic analysis as the coding process (Braun \& Clarke, 2006). First, initial ideas were noted during the transcribing process, followed by an initial round of coding relevant fragments. This initial round was both deductive and inductive: some codes were based on theory on team-oriented HRM and team learning, while other codes were created without a predetermined theory, such as the codes that described team leaders' enactment. Next, codes were sorted into themes related to the different team-oriented HR practices and team learning, and both codes and themes were refined. Reliability was taken into account by calculating interrater reliabilities for two transcripts that were coded by independent researchers. These researchers discussed codes on which they had an agreement of .60 or lower (moderate agreement or less). Codes were changed based on their consensus, resulting in an average Cohen's Kappa of .92 with a range of [.65;1], which indicated a high agreement (Viera \& Garrett, 2005). One researcher re-examined the remaining transcripts based on this consensus and consulted the second researcher in case of doubt. The final codes and themes were used for the results section.

Validity of the analysis was taken into account using data triangulation, which implied comparing team leaders' and teachers' responses per team, testing the consistency and accuracy of codes by comparing the content of codes within and 
between transcriptions, and providing evidence for the analysis through examples and quotes. Ethics were taken into account by obtaining verbal informal consent from all participants and by ensuring anonymity (Barbour, 2007; Gibbs, 2007).

\subsection{Results}

This section describes team leaders' enactment of team-oriented HRM, teachers' perceptions of this enactment, and their response in terms of team learning.

\subsubsection{Team leaders' enactment of team-oriented HRM}

\section{Recruitment}

Team leaders collaborated with teachers and sometimes students or members of the HRM department in recruitment committees. Because they had to collaborate with others, they explained that they had little discretionary room to differ in their enactment. Therefore, no differences between team leaders were found.

\section{Team development}

Based on team leaders' descriptions, it was determined that all team leaders enacted their teams' development based on their teams' needs. They all stimulated teamwork and teachers' engagement in the newly-established project groups. This was for instance done during education development days that they regularly organised for their teams. A difference was found regarding their investment in formal training. Only team leaders 2 and 3 invested in team development through training sessions on topics such as student coaching (team 2) and project-based education (team 3), while team leaders 1 and 4 had not invested in specific team training. Despite these differences, all team leaders wanted to increase teachers' content knowledge and abilities and their collaboration and engagement in team learning. They believed that increased collaboration and team learning were achieved through team development, as explained by team leader 3: "That is the nice thing about team development... Teachers find each other. Afterwards, they work better as a team. That is a positive result" (team leader 3).

\section{Team evaluation}

In their enactment of team evaluation, all team leaders evaluated a broad array of topics with their teams, such as team performance and teacher collaboration. However, the main purpose of team evaluation was to control team performance. Performance indicators such as student reports and student numbers were therefore central to these evaluations. Formal, individual teacher evaluations primarily focused on individual performance during lessons, for instance based on students' satisfaction with the lessons. During these formal teacher evaluations, all team leaders only discussed teachers' team involvement when problems had occurred. Only team leaders 3 and 4 
evaluated teachers' team involvement informally during daily practice and before problems had occurred as well.

Although the primary emphasis of team evaluation was on the team and teacher performance, team leader 3 organised additional peer coaching meetings to evaluate collaboration in projects: "I evaluate new projects. For instance, we developed a new intake procedure. We reviewed it and focused, among others things, on collaboration" (team leader 3).

\section{Teamwork facilitation}

All team leaders had in common that they facilitated collaboration in the newlyestablished project groups during time that was originally reserved for regular team meetings. For instance, instead of organising regular team meetings every week, team leader 4 switched to organising regular meetings biweekly and using the other weeks for collaboration in project groups. Team leader 3 reserved time during regular team meetings for collaboration in project groups.

However, team leaders clearly differed in the role they took during teamwork facilitation and in their reasons for this. Team leaders 1 and 2 granted their teachers autonomy, because they believed in the teachers' professional attitude and abilities to engage in collaboration and only intervened when they perceived that collaboration was not going well. On the contrary, team leaders 3 and 4 did not rely on teachers' professional attitude and abilities, as is explained by team leader 3: "If I had to wait for teachers to take the initiative to meet, it wouldn't happen. That is why I say, childish as it may sound: 'Your project group will meet at 9 a.m. and our regular meeting will start at 9.30'” (team leader 3). Team leaders 3 and 4 therefore granted less autonomy to project groups and showed a more directive style during teamwork facilitation. Team leader 4's directive style, for instance, became apparent in the setting of clear goals for her teachers: she made it clear that project groups were expected to present and discuss their progress and ideas during team meetings. To monitor and stimulate this, she participated in these meetings and fostered team learning, so that teachers generated new project ideas and tried to reach consensus on their projects. Team leader 3 also participated in these team meetings to stimulate collaboration in and between project groups, engagement in team learning, initiative-taking, and out-of-the-box thinking. Only when team leaders 3 and 4 perceived that the project groups collaborated well, engaged in team learning, and took initiative, did they grant the project groups more autonomy.

\section{Reflection on the findings}

It is notable that, although the team leaders worked in the same VET college, differences between their enactments were found. These differences were most prominent in their enactment of teamwork facilitation. Team leaders 3 and 4, for instance, were more 
directive than team leaders 1 and 2 during teamwork facilitation, to prevent the avoidance of responsibilities. Furthermore, all team leaders granted autonomy to project groups during teamwork facilitation, but team leaders 1 and 2 did this from the start, while team leaders 3 and 4 only did this when they were convinced that teachers would take their responsibility. Additionally, only team leaders 3 and 4 actively stimulated collaboration and team learning during team meetings.

\subsubsection{Teachers' perceptions of team-oriented HRM Recruitment}

All the teachers described similar recruitment procedures to those described by the team leaders, which indicates that recruitment followed standard procedures that were known to both team leaders and teachers.

\section{Team development}

Despite the fact that teachers perceived team development activities differently from the team leaders, teachers of teams 2, 3 and 4 perceived that their team leaders' enactment of team development was based on the team's needs: team leaders invited guest speakers from companies and organised training courses on topics such as grading methods to increase their knowledge and skills. In addition, the teachers of team 3 perceived that their team leader specifically invested in collaboration and outof-the-box thinking by organising workshops on curriculum development. Only the teachers of team 1 did not perceive that their team leader used team development to meet the team's needs. They perceived that the team leader only invested in team development to increase his control on performance, by investing in training on a student tracking system to ensure that teachers made no mistakes in using this software, while teachers would have preferred training on student feedback:

Teacher 1: It [team development] is often pragmatic... Such as training on a particular software program.

Teacher 2: Everything to make the organisation manageable. Control by means of tools.

Teacher 1: Yes, while we would rather have training on specific topics, such as giving feedback (teachers, team 1).

\section{Team evaluation}

All teachers described their team leaders' enactment of team evaluation very similarly to the description given by team leaders. Teachers of teams 1, 2 and 4 perceived that their team leaders primarily focused on controlling team performance by evaluating student results and employee satisfaction surveys, and did not clearly evaluate collaboration. According to the teachers, their individual engagement in the team was 
only evaluated when difficulties had occurred. Only teachers of team 3 perceived that collaboration and teachers' team involvement were explicitly evaluated during peer coaching meetings, which corresponds with how team leader 3 described her enactment of team evaluation.

\section{Teamwork facilitation}

All teachers perceived that team leaders made time available during regular team meetings for project groups to collaborate. They perceived their team leaders' roles similarly to how team leaders described their roles. This implies that teachers of team 1 and 2 perceived that their team leaders relied on teachers' initiative to engage in teamwork. However, these teachers explained that they missed their leaders' presence and support. For instance, in team 2 teachers missed their leader's direction and guidance:

Sometimes you miss targets. I have the feeling that targets are set at a higher level, but that these targets are not communicated to us [by the team leader]. Then I think: "Just tell us what you want. Then we can take that into consideration and maybe change our plans" (teacher, team 2).

In team 1, teachers perceived that their team leader only controlled team performance and did not stimulate team processes, and even inhibited collaboration between project groups and the entire team:

Teacher 1: Some of us take initiatives but do not make progress. We think about solutions... but need support.

Teacher 2: Sometimes we are also inhibited...

Teacher 1: Everybody sits on their own 'island' and creates all kinds of things... But we remain on our 'islands'...

Teacher 1: We have the desire, motivation and inspiration [to seek collaboration]... But we miss a step.

Teacher 2: It is often said [by the team leader]: "you are going too fast, take it slowly" (teachers, team 1).

On the contrary, teachers of teams 3 and 4 perceived that their team leaders were directive and stimulated collaboration in and between project groups and with the entire team. For instance, the teachers of team 4 perceived that their team leader was directive by setting clear goals for project groups: 
Teacher 1: I have the feeling that we [the project group] can no longer say that we never discuss our project during the school year. That possibility does not exist.

Teacher 2: You are given a task, and it is expected of you that you deliver results.

Teacher 1: Yes... if you want engagement in team learning in a team, you should point that out by saying: "Because we are here together, we are going to do things together" (teachers, team 4).

Additionally, teachers of team 3 agreed that their team leader stimulated outof-the-box thinking, initiative-taking, and engagement in team learning in project groups:

Teacher 1: She believes it is important that we collaborate on projects and consider these projects from different perspectives. She really stimulates that. Teacher 2: Yes, she also stimulates new initiatives... by saying "examine the possibilities" (teachers, team 3 ).

Similarly, the teachers of team 4 experienced that their team leader stimulated out-of-the-box thinking and steered processes towards team learning on new ideas during team meetings:

When the team leader heard too much description of the process [of a group's project], she asked how the project could be concretized... She steered on making things specific... By discussing this with everybody, we looked at how we could integrate assessments. Some teachers provided input and then it was done (teacher, team 4).

\section{Reflection on the findings}

It is notable that teachers of teams 2, 3 and 4 perceived team support from their team leader more in accordance with how the team leaders described their role. For instance, in teams 3 and 4, teachers perceived that their team leaders were both directive and stimulating to increase their involvement in the team. However, teachers of team $2 \mathrm{did}$ not find the role of the team leader fitting for the team's needs: they missed a directive team leader during teamwork facilitation and did not know what was expected of them. It is further notable that teachers of team 1 perceived their team leader's behaviour differently from how the team leader intended: they perceived that their team leader only exercised control to foster team performance and inhibited collaboration and team learning. 


\subsubsection{Teachers' team learning}

With regard to team learning, teams 1 and 2 were characterized by limited engagement in team learning, because teachers explained that they worked on different "islands" and did not exchange ideas (team 1 ) or only shared largely practical information with each other (team 2). They did not co-construct shared interpretations on innovative topics such as grading methods, nor did they engage in constructive conflict on different perspectives: "Teachers in our team have different perspectives on grading... We have not succeeded in reaching agreement on that... Everybody continues to use their own grading method" (teacher, team 2 ).

Teams 3 and 4 were characterized by much engagement in team learning, because teachers shared ideas and co-constructed shared interpretations in their project groups and with the entire team on innovative topics such as the integration of courses in their curriculum (team 3) and grading methods (team 4): "It goes like this: 'What should we do? What do you do, and what do I do? How are we going to do this?'... We try to connect aspects [of our courses] as much as possible" (teacher, team 3).

These differences between teams 1 and 2 on the one hand and teams 3 and 4 on the other can be explained by their team leaders' enactment of team-oriented HRM, and especially by their enactment of teamwork facilitation. As explained above, team leaders 1 and 2 relied on teachers' professional attitude and abilities to collaborate themselves, but their teachers missed direction from them (teams 1 and 2) or even felt inhibited in their collaboration (team 1). The absence of a directive and stimulating team leader resulted in teachers not making much effort to engage in team learning (team 1) and in teachers not preparing for team meetings, resulting in little progress (team 2):

Teacher 1: Many teachers are very hesitant [to engage in the team] and search for support. They say: "we cannot meet because of different schedules".

Teacher 2: They do not search for solutions themselves (teachers, team 1).

Teacher 1: Team meetings are often poorly prepared by everybody. This slows down our progress... Nobody has very strong opinions.

Teacher 2: Yes, we just sit and wait for what comes... Nobody is entirely prepared [and says to others]: "Come on, you should prepare as well!" (teachers, team 2).

On the contrary, team leaders 3 and 4 were directive and stimulating, participated during team meetings (teams 3 and 4), and made clear what was expected of teachers (team 4). This resulted in teachers engaging in team learning with their project groups and with the entire team: 
This week we had a meeting with teachers who were not involved in our project on the following questions: "How can we design these projects for years 1 and 2 of our educational program? What kind of projects can we work on? What are the implications? How can we collaborate in these projects?" It is not always easy ... but I do believe that this team really tries to collaborate (teacher, team 3).

We have seven projects on which teachers collaborate and develop things together. Effort is put into that... For instance, we designed a new grading method in a smaller meeting, and discussed this in the regular team meeting. Together we reach agreement, and then we bring it into practice (teacher, team 4).

\subsection{Conclusion and discussion}

The goal of this study was to explore how team leaders' different enactments of teamoriented HRM affected teachers' perceptions of team-oriented HRM and their response in terms of team learning. The small-scale qualitative approach allowed for in-depth comparisons between team leaders and their teams, and led to some insightful findings.

By showing a) that team leaders largely determined the enactment of teamoriented HR practices in their teacher teams, and b) that their enactment seemed to affect teachers' engagement in team learning, this study confirms that, in the educational context too, the role of team leaders (i.e. line managers) is crucial for the effective implementation of HRM. The findings therefore emphasize the importance of using a process perspective to study the effectiveness of HRM in the educational context, rather than only a content perspective, as is usually the case in HRM studies in this context (Runhaar \& Sanders, 2016).

This conclusion is based on several important findings that highlight the central role of team leaders. First, it was found that team leaders differed to some extent in their enactment of the four team-oriented HR practices central to this study: recruitment, team development, team evaluation, and teamwork facilitation. These differences seemed to be a result of the extent to which they wanted to control team performance, and of the extent to which they had different beliefs about teachers' involvement in teacher teams. The latter was most clearly demonstrated in their facilitation of teamwork. Team leaders 1 and 2 believed teachers will take their own responsibility in engaging in their team and therefore granted them autonomy. They did not actively participate in teams, while team leaders 3 and 4 believed that teachers needed to be actively stimulated to engage in their team and therefore actively had a directive and stimulating role in team meetings.

Second, differences were found in the degree of alignment between team leaders' enactment and teachers' perceptions of team-oriented HRM. More specifically, 
teachers in teams 2, 3 and 4 experienced the team leaders' support through teamoriented HRM as it was intended by the team leader, whereas in team 1 there was misalignment because teachers perceived their team leaders' enactment as controlling team performance, while the team leader wanted to stimulate team learning.

Third, this alignment, combined with a fit between the team leaders' enactment and teams' needs, seemed to result in a high level of engagement in team learning. That is, in teams 3 and 4 , team leaders knew that their active involvement was needed to ensure engagement in team learning. This is because teachers then knew why and how they needed to work on improving their CBE programs, and understood that they had no other option than to engage in team learning. Where the alignment was not accompanied by a fit between team leaders' enactment and the teams' needs, this resulted in limited engagement in team learning. More specifically, the team leader of team 2 granted autonomy, while teachers desired a more directive team leader so that they knew what was expected of them. The absence of direction led to teachers not taking their responsibility in engaging in team learning. In team 1, the misalignment was accompanied by a misfit between the team leaders' enactment and the team's needs; teachers felt inhibited by their team leader to engage in team learning, with limited engagement in team learning as a consequence.

These insights provide some important contributions to the HRM literature in the public sector. The main findings of this study are discussed in more detail below, and suggestions for future research are given.

\subsubsection{Team leaders' enactment of team-oriented HRM}

During their enactment of team-oriented HRM, the team leaders in this study exercised control and granted autonomy. This distinction between control and autonomy is widely recognized in HRM literature and known as the control-commitment distinction. It is necessary to take this control-commitment distinction into account when examining team-oriented HRM in the educational context. Governments in many Western countries have decentralized power, responsibilities and funding in an effort to enable educational organisations to pursue the highest possible quality of education. Because this decentralization is often accompanied by new standards and performance evaluation systems (Gewirtz \& Ball, 2000), educational organisations run the risk of viewing HRM as just another tool to control the effort of teachers instead of a way of boosting teachers' engagement with their work (Runhaar \& Runhaar, 2012).

Given this tension between control and commitment, it would be interesting for future research to examine how this tension is reflected in team leaders' enactment of HRM. This can be done by including transformational-transactional leadership theory in future research. That is, a transactional leadership style implies a focus on performance and preventing work avoidance by exercising control and being directive, and a transformational leadership style implies a focus on committing teachers to team 
goals by empowering them and stimulating out-of-the-box thinking (Judge \& Piccolo, 2004). One could say that the team leaders' behaviour in this study showed characteristics of both transactional and transformational leadership styles. This combination of leadership styles is common, because transformational leadership is regarded as an extension of transactional leadership (Bass, 1999). Which leadership style is most reflected in a manager's behaviour depends on his/her perception of which style is most suitable in a certain situation (Bucic et al., 2010). Rosing, Frese, and Bausch (2011) refer to this capacity of managers to flexibly switch between leadership styles as ambidextrous leadership. Depending on tasks or challenges their team is working on, ambidextrous leaders show opening or closing behaviours. Opening behaviours are similar to a transformational leadership style and involve leaders' stimulation of followers' exploration through experimentation and risk taking, while closing behaviours are similar to a transactional leadership style and involve followers' exploitation by stimulating their adherence to rules and risk avoidance. Consequently, team leaders' enactment of team-oriented HRM seemed to be ambidextrous. They exercised control in situations in which they thought control was needed, such as during team evaluations because of accountability demands. They also granted autonomy and stimulated out-of-the-box thinking in situations that they thought were suitable for this, such as during teamwork facilitation.

Given the similarities between team leaders' behaviour during their enactment of team-oriented HRM and transactional and transformational leadership styles, it is notable that these leadership styles have been largely overlooked so far in studies on effective HRM implementation. Only Vermeeren et al. (2014) and Zhu, Chew, and Spangler (2005) have related these leadership styles to HRM implementation. It is therefore suggested that these leadership styles should be included in future HRM research. Research on why and to what extent managers adapt their leadership style during their enactment of HRM and the influence of their adaptation on employee and team behaviour could provide new insights into how HRM can be effectively enacted.

\subsubsection{Teachers' perceptions and team learning}

As mentioned above, in teams 2,3 and 4 there was, to a large extent, alignment between how team leaders enacted HR practices and how teachers perceived these practices in their teams. According to Bowen and Ostroff (2004), this alignment increases the chance of achieving desired employee behaviour through HRM. This indeed seemed to be the case in the teams where there was much engagement in team learning (teams 3 and 4). However, based on the findings, it seems insufficient for team leaders to communicate their enactment in a consistent and unambiguous way, so that teachers know what is expected of them and alignment arises. To make HR practices effective, team leaders also need to adjust their enactment to their team's needs, as team leaders 3 and 4 seemed to have done but team leader 2 did not. 
Based on these findings, it is suggested that ambidextrous leadership is needed to stimulate teachers' team learning, which is confirmed by previous research (Bucic et al., 2010; Koeslag-Kreunen et al., 2017). This implies that during certain tasks and challenges teacher teams benefit from control and direction instead of autonomy, while during other tasks and challenges they benefit more from autonomy. There seems to be no blueprint for stimulating team learning by enacting team-oriented HRM. Instead, the team's needs should be the starting point for enacting HR practices and exercising leadership. As such, this study underlines the conclusion of Szczesiul and Huizenga (2014), who argued that not all schools or teacher teams may be ready to rely on a teacher teams' responsibility to work on educational improvements autonomously, and that teachers need direction and support from a manager during their work so that is clear to them why and how they should work on these improvements. Teams that are ready to take their responsibility are likely to benefit from being given autonomy, while teams that are not ready are more likely to benefit from a directive and stimulating team leader. For future research, it would therefore be interesting to focus more on this fit between the enactment of HRM and teacher teams' needs: to what extent do team leaders take the teams' needs into consideration and adapt their leadership style to these needs, and does a fit lead to desired team behaviour, such as team learning and better team performance?

\subsubsection{Limitations and future research}

A limitation of this study is that it is based on retrospective self-report data, which could lead to subjective and biased reports. This issue was partly addressed by collecting data from different perspectives and by comparing these perspectives. Nevertheless, all respondents may have been unaware of specific team processes or unfamiliar with specific team-oriented HR practices. We therefore suggest that future research combines in-depth self-report data with more objective data, such as HRM documents, team plans, and team observations.

Another limitation is the generalizability of the findings of this study, because it was conducted within one small Dutch VET college. As team leaders of larger colleges in other educational contexts and in colleges with different experiences in developing an HRM strategy may also have discretionary room to enact HR practices, we suggest that future research includes a broader array of colleges and schools.

\subsubsection{Practical implications}

VET colleges that try to implement effective team-oriented HRM systems should be aware of the crucial role that line managers, or team leaders, play in this process. It is often the line managers who enact HR practices in teams, and how they do this affects teachers' perceptions of these practices and their responses. When leaders give clear directions to teachers by pointing out the goal of teacher collaboration and stimulate 
teachers' collaboration during educational innovations, they seem to realize higher engagement in team learning. 


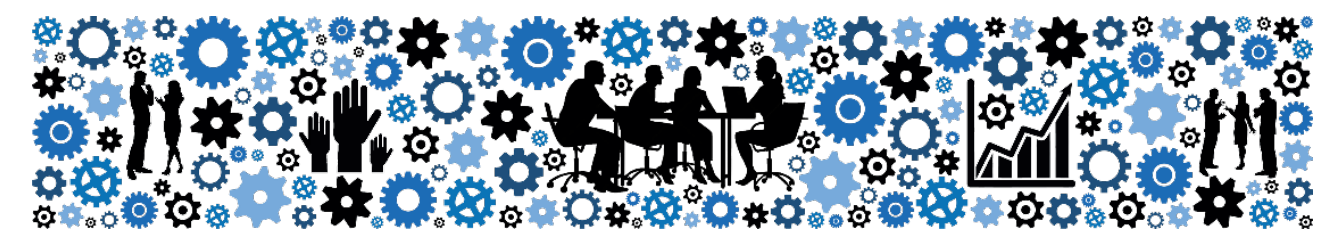

\section{Chapter 4}

\section{Fostering teachers' team learning: an interplay between transformational leadership and participative decision- making? ${ }^{3}$}

The implementation of educational innovations by teachers seems to benefit from a team approach and team learning. The study's goal is to examine to what extent transformational leadership is associated with teachers' engagement in team learning, and to investigate the mediating roles of participative decision-making, affective team commitment, perceived task interdependence and teachers' proactivity in this association. Data were analysed using multilevel structural equation modelling $(N=$ 992 teachers, 92 teams). Results show that transformational leadership had direct and indirect positive associations with the team learning processes of boundary crossing, information acquisition and information processing through all mediators. These results provide insights into how transformational leaders can have a positive influence on teachers' engagement in team learning.

3 This chapter is based on: Bouwmans, M., Runhaar, P., Wesselink, R., \& Mulder, M. (2017). Fostering teachers' team learning: An interplay between transformational leadership and participative decision-making? Teaching and Teacher Education, 65, 71-80. doi: 10.1016/j.tate.2017.03.010 


\subsection{Introduction}

Worldwide, governments and schoolboards initiate educational innovations to improve student attainment and the quality of educational programmes. As a result, schools constantly work on educational innovations (Runhaar, Konermann, \& Sanders, 2013). Teacher teams play a crucial role during these innovations, because it is only when teams change the way in which they work that effective change can be achieved at the organisational level (Edmondson, 2002). This implies that the success of school improvements depends, in part, on team performance (Park et al., 2005). Team learning is needed to increase team performance (Vangrieken et al., 2016). By engaging in team learning, teacher teams can better understand ideas behind educational innovations, reach agreement among team members on educational innovations, increase their innovativeness and make progress towards realising educational changes (DrachZahavy \& Somech, 2001; Runhaar et al., 2014; Wijnia et al., 2016).

Although team learning is important for realising educational innovations, simply putting people together in a team is no guarantee that team learning will occur (Van den Bossche et al., 2006). As is discussed in Chapter 1, teachers are often individually occupied with everyday issues, and may find it difficult to disengage themselves from these issues in order to collectively invest in team learning (Oude Groote Beverborg et al., 2015; Vangrieken et al., 2015). Consequently, teachers tend to engage in more superficial levels of collaboration, such as planning practical tasks and activities, and discussing existing course materials (Vangrieken et al., 2015). Therefore, Vangrieken et al. (2015) argue, teacher teams often resemble an aggregate of individuals who are not interdependent and who feel only limited team commitment, which hinders team learning.

Our study aims to examine how team learning can be fostered through the leadership style of team leaders, by focusing on transformational leadership. Previous studies reveal multiple positive research results. For example, a transformational leadership style of school leaders or team leaders enhances a school's innovative climate (Moolenaar et al., 2010), teachers' involvement in individual learning activities (Geijsel et al., 2009; Oude Groote Beverborg et al., 2015; Runhaar et al., 2010; Thoonen et al., 2011), and teachers' involvement in collective learning activities (Lodders, 2013; Silins \& Mulford, 2002; Vanblaere \& Devos, 2016). Additionally, research outside the educational context shows that transformational leadership is positively related to team learning (Raes et al., 2013).

Although these studies show the importance of transformational leadership in general and for teachers' team learning in particular, more research is needed to understand the underlying mechanisms and to unravel effective components. For instance, some studies show a direct association between transformational leadership and teachers' team learning processes (e.g. Lodders, 2013; Vanblaere \& Devos, 2016), while others suggest indirect associations (e.g. Raes et al., 2013; Silins \& Mulford, 2002). 
Therefore, in this study we identify and explore possible underlying mechanisms in the relationship between transformational leadership and team learning by examining the mediating roles of: 1) teachers' collective opportunities to participate in decisionmaking, defined as joint decision-making processes by leaders and teachers (Thoonen et al., 2011); 2) teachers' individual affective team commitment, defined as teachers' affective bond with the team (Van der Vegt \& Bunderson, 2005); 3) teachers' individually perceived task interdependence, defined as the extent to which teachers need support from their colleagues to fulfil their task (Van der Vegt, 2008); and 4) teachers' proactivity, defined as teachers' behaviour aimed at improving the team's performance (Griffin, Neal, \& Parker, 2007).

More specifically, we examine whether transformational leaders decentralise influence in teacher teams by giving teachers the opportunity to participate in decisionmaking (Avolio \& Gibbons, 1988; Mulford \& Silins, 2003; Thoonen et al., 2011), and whether this stimulates their engagement in team learning. Additionally, we examine whether participation in decision-making enhances teachers' team-oriented attitudes in terms of their affective team commitment and perceived task interdependence. Finally, we examine whether these team-oriented attitudes encourage proactive team behaviour and whether proactive teachers participate more in team learning. As such, the following research questions are answered: 'To what extent are there positive associations between transformational leadership and team learning processes?', and: 'To what extent are associations between transformational leadership and team learning processes mediated by participative decision-making, affective team commitment, perceived task interdependence and team member proactivity?'

\subsection{Theoretical framework}

In this section, the concept of team learning is first elaborated by explaining the core team learning processes that are central to this study. We then explain why we expect transformational leadership to stimulate team learning directly and indirectly through the aforementioned potential mediators.

\subsubsection{Teachers' team learning}

Team learning enables teams to respond to changing environments and to learn how to collaborate more effectively (Decuyper et al., 2010; Edmondson et al., 2007). In the literature, different team learning processes are identified, such as discussing errors, learning from mistakes, seeking feedback and integrating knowledge (Edmondson, 1999; Edmondson et al., 2007; Kostopoulos, Spanos, \& Prastacos, 2013; Tjosvold, Yu, \& Hui, 2004). In their review study, Decuyper et al. (2010) combine these different activities into three basic processes that they believe form the core of team learning. These basic processes are described in detail in Chapter 1, and are shortly repeated here: the first process is information sharing, which refers to team members sharing 
previously unshared information with other team members; the second process is coconstruction, which refers to team members collectively combining insights and information into shared interpretations through dialogue and reflective communication; and third process is constructive conflict, which refers to team members negotiating and discussing different perspectives of team members. These processes describe what happens in teams when they learn. In practice, these three processes do not occur linearly but are very much intertwined (Decuyper et al., 2010; Van Woerkom \& Van Engen, 2009). Van Woerkom and Van Engen (2009) therefore suggest combining these processes under the denominator information processing. In this chapter, we follow their suggestion and consider information processing as the central team learning process in teacher teams. Information processing is essential for enabling learning in teams because it helps teams to reduce ambiguous information and to define what actions teams need to take (Van Offenbeek, 2001).

Before team members can share information with each other and discuss, question and concretise information in such ways that necessary actions can be formulated and planned, it is important that new information flows into the team. Individual team members play a central role in this, because it is they who acquire relevant new information (Van Offenbeek, 2001). They can do this by engaging in information acquisition and boundary crossing. Both activities imply that team members search for new and relevant information, but the way in which they do this differs. Information acquisition involves consulting different information sources, for example collecting information from the Internet and books, participating in professional development activities or asking other team members for advice (Van Offenbeek, 2001; Wijnia et al., 2016). Boundary crossing implies that team members ask people outside the team, such as experts, stakeholders or members of other teams, for feedback and advice on team tasks and team performance (Wong, 2004). In other words, new information is gathered from people outside the mental, physical and organisational team borders (Kasl et al., 1997). Through boundary crossing, team members can acquire advice or feedback on ideas that the team has come up with or on the direction a team is heading in. Such feedback and advice may necessitate reconsidering plans and ideas to make them more efficient and effective. In this sense, boundary crossing helps to point team learning in the 'right' direction (Decuyper et al., 2010). One aspect that information acquisition and boundary crossing have in common is that they are both initiated by individual team members.

When combined, information acquisition and boundary crossing by individual team members and information processing in the team describe how new information flows into the team and how this information is interpreted and discussed in the team. 


\subsubsection{Transformational leadership and team learning}

Transformational leaders help organisations deal with changing environments by encouraging their followers to generate creative solutions for complex problems (Bass, 1997; Bass, Avolio, Jung, \& Berson, 2003) and to put extra effort into their performance by challenging their values, beliefs and attitudes (Podsakoff, MacKenzie, Moorman, \& Fetter, 1990). Transformational leadership has been widely studied in different work contexts (G. Wang, Oh, Courtright, \& Colbert, 2011), including the educational context (Leithwood \& Jantzi, 2005). Although most studies focus on how transformational leadership is related to individual employee outcomes, studies increasingly show that transformational leadership is positively related to team outcomes as well (Schaubroeck, Lam, \& Cha, 2007; G. Wang et al., 2011).

Within the educational context, scholars have suggested that transformational leadership consists of three dimensions (Geijsel, Sleegers, \& Van Den Berg, 1999; Leithwood \& Jantzi, 2006). First, by initiating and identifying a vision, transformational leaders contribute to vision development in schools, which can increase teachers' commitment to the organisation and may result in the greater willingness of teachers to put extra effort into realising organisational goals (Thoonen et al., 2011). Second, through individual support and consideration, transformational leaders focus on the development and mentoring of teachers by, for instance, delegating challenging tasks, providing feedback, and recognising and satisfying teachers' needs and concerns (Raes et al., 2013; Thoonen et al., 2011). Third, through intellectual stimulation, transformational leaders stimulate creativity and professionalisation by encouraging teachers to question their own beliefs and values and by enhancing their problemsolving abilities (Geijsel et al., 1999; Raes et al., 2013; Thoonen et al., 2011).

These three dimensions can be divided into a charismatic and an empowerment component. The charismatic component (initiating and identifying a vision) refers to inspiration and influence through the expression of ideals, and the empowerment component (individual support and consideration and intellectual stimulation) refers to the participative aspect of transformational leadership (De Hoogh et al., 2004): stimulating groups to be creative and enhancing their collective problemsolving abilities (Bass, 1997). This empowerment component is more explicitly aimed at stimulating interactions in groups or teams than the charismatic component. Through empowerment, transformational leaders can stimulate team members to move beyond their self-interest and to invest in their team (Raes et al., 2013), and can create a learning climate in teams that stimulates the team's development (Zaccaro, Ely, \& Shuffler, 2008). Therefore, we expect that when transformational leaders empower their teams, this is positively related to teachers' engagement in team learning processes, and we formulated our first hypothesis as follows: 
Hypothesis 1: Empowering transformational leadership is positively associated with teachers' engagement in information acquisition, boundary crossing and information processing.

\subsubsection{Unravelling possible mediators}

Participative decision-making

As mentioned in the introduction of this chapter, transformational leaders tend to decentralise influence within teams (Avolio \& Gibbons, 1988; Mulford \& Silins, 2003). For instance, research shows that transformational leaders encourage teachers to participate in decision-making (Geijsel et al., 2009; Thoonen et al., 2011). Participative decision-making implies that the decision-making process is not regulated by and reserved for team leaders and a few teachers, but that each team member has the opportunity to participate in decision-making. Such participation can increase teachers' support for educational change and contribute to school improvements (Harris, 2009; Scribner, Sawyer, Watson, \& Myers, 2007).

We expect participative decision-making to partially mediate the associations between transformational leadership and team learning because participative decisionmaking increases the mutual influence among team members. This mutual influence creates interaction between team members, encourages team members to share knowledge, and stimulates the further creation of a learning climate in teams (Liu et al., 2014). For example, teachers' involvement in team decisions may increase the need for information processing in terms of sharing information with each other and concretising shared information together in order to make informed and considered decisions. Teachers' involvement in decision-making may also increase their individual information acquisition and boundary crossing behaviour because they feel responsible for making considered decisions, and may therefore want to consult all the available and relevant information.

Although this association between participative decision-making and team learning lacks empirical evidence, previous research does confirm that empowering teams and distributing leadership among team members are positively associated with team learning (Liu et al., 2014). We expect a similar association between participative decision-making and team learning. Therefore, based on these concepts, the following hypothesis was formulated:

Hypothesis 2: Participative decision-making will partially mediate the positive associations between transformational leadership and information acquisition, boundary crossing and information processing. 
Affective team commitment, perceived task interdependence and team member proactivity

Empowering teachers with the opportunity to participate in decision-making processes may increase their team-oriented attitudes. Research shows that participative decisionmaking is positively associated with employees' affective commitment to the organisation (Scott-Ladd, Travaglione, \& Marshall, 2006; Seibert, Wang, \& Courtright, 2011), and similar associations are found at the team level. For instance, the study of Kirkman and Rosen (1999) shows that, when teams are empowered and team members share decision-making, team members feel collectively responsible for the team's performance and feel more committed to their team. Furthermore, because participative decision-making means that team members have a shared responsibility for the realisation of team tasks, they may feel that they need to interact more to complete their tasks. In other words, participative decision-making may be associated with increased levels of perceived task interdependence of team members. While this possible association misses a solid empirical base, research does show that task interdependence positively affects the positive association between team empowerment and team performance (Chen, Kirkman, Kanfer, Allen, \& Rosen, 2007; Liden, Wayne, \& Bradway, 1997), which indicates that there is an important association between empowerment and task interdependence. Therefore, we expect that participative decision-making will be positively associated with teachers' affective team commitment and their perceived task interdependence.

In turn, we expect that teachers' increased affective team commitment and perceived task interdependence (i.e. teachers have stronger team-oriented attitudes) will be positively associated with higher levels of proactive team member behaviour by teachers (i.e. they show more team-oriented behaviour). This mechanism can be explained by the role theory (Griffin et al., 2007; Katz \& Kahn, 1978): when individuals feel part of a team and recognise a bond of identity, they will act in ways to support their team by carrying out activities to increase the team's performance. Proactive individuals aim to change their work environment by taking control over the situation and trying to cause change at their own initiative. Their behaviour is future-oriented and involves risk-taking, because they anticipate future problems and needs (Griffin et al., 2007; Parker \& Collins, 2010). Proactive team behaviour is a specific form of proactive work behaviour, aimed at changing the team's situation, such as its performance (Griffin et al., 2007). For example, proactive team members try to improve team procedures and search for new ideas and methods to change team performance, and communicate their ideas with other team members (Parker \& Collins, 2010). Because of their search for new ideas and methods, we expect that proactive team members will engage more in information acquisition and boundary crossing. Furthermore, because proactive team members want to convince others of their ideas, 
we believe that they will also engage more in information processing than less proactive team members.

Combining our expectations, we first expect transformational leadership to be positively related to participative decision-making (Hypothesis 2). Second, we expect that 1) participative decision-making is positively associated with teachers' affective team commitment and perceived task interdependence, that 2) these team-oriented attitudes are positively associated with teachers' proactive team behaviour, and that 3 ) this proactive behaviour is positively associated with teachers' engagement in team learning. Based on this line of reasoning, we formulated the following hypothesis (all hypotheses are depicted in the conceptual model in Figure 4.1):

Hypothesis 3: The positive associations between transformational leadership and information acquisition, boundary crossing and information processing will, in addition to participative decision-making, be partially mediated by affective team commitment, perceived task interdependence and team member proactivity.

\subsection{Methods}

\subsubsection{Sample and respondents}

Data were collected as part of a study on vocational education and training (VET) teachers' team learning. The VET context was chosen for this study because VET colleges are currently implementing competence-based education (CBE) to better meet increased labour market demands such as employers' expectations regarding employees' lifelong learning skills and professional competencies (Mulder, Weigel, \& Collins, 2007). CBE involves revising existing curricula to increase the integration of theory and practice, and enhancing students' self-regulated learning (Mulder, 2017). VET teacher teams are regarded as the central organisational unit in the implementation of these reforms (Runhaar \& Sanders, 2016). These teacher teams are multidisciplinary and consist of teachers with different skills, areas of expertise and roles. For example, some teachers have expertise in specific courses, while others have additional tasks such as development or coaching tasks (Wesselink, 2010). To implement CBE in educational programmes, teachers within these teams need to combine their expertise and collaborate with each other (Truijen, 2012).

Data were collected through an online survey that was sent to 1,650 teachers in 104 teams in 23 VET colleges in the Netherlands, over the period April to December 2014. To obtain this sample, team leaders at every VET college in the Netherlands were contacted and asked to allow their teacher team to participate. Teachers were sent an email with a personal invitation to take part in the survey and were assured that data would be processed anonymously. 
Only those teams with a minimum response rate of 33\% were included to obtain a good representation of each team in the analysis. This resulted in a final sample of 92 teams with a total team size of 1,565 team members $(M=17.01, S D=9.61)$, of whom 992 completed the survey (63.4\%). These 992 team members were included in our analysis. $52 \%$ of these 992 teachers was female, and the mean age was 47.26 years old $(S D=$ 11.27), which is representative of the Dutch VET teacher population, in which approximately $51 \%$ is female and the average age is 49 years old (Lubberman et al., 2013). On average, these team members had worked as a teacher for 14.43 years ( $S D=$ 10.74). Most of the teachers had a Bachelor's degree (70.6\%), 10.1\% had a Master's degree, $11.9 \%$ had a senior secondary vocational education degree, and the remaining $7.5 \%$ was either following an educational programme or had received a post-education degree.

\subsubsection{Measurements}

The conceptual model was analysed primarily using existing and validated scales plus two adjusted and pilot-tested scales for information acquisition and information processing. For most scales, original Dutch items or existing translations were used. The scales for team member proactivity and boundary crossing were translated into Dutch using back-forward translation by a native English speaker.

For the team learning scales and the team member proactivity scale, a 5-point Likert scale with 1 (never) to 5 (always) was used; for the remaining scales, a 5-point Likert scale with 1 (completely disagree) to 5 (completely agree) was used, except for the perceived task interdependence scale, for which the original 7-point Likert scale with 1 (completely disagree) to 7 (completely agree) was used.

Team learning. Boundary crossing (four items) was measured using the translated scale of Wong (2004). A referent shift from 'our team' to 'I' was used on all items, because boundary crossing is regarded as an individual team member activity. An example item is, 'I seek feedback about the team's work from people external to the team' (Cronbach's alpha = .79). Information acquisition (five items; Cronbach's alpha = .65 ) and information processing (nine items; Cronbach's alpha $=.90$ ) were measured using an adaptation of the team learning instrument of Van Offenbeek (2001). These adapted scales were pilot tested among 128 VET teachers who did not participate in the current study. Explorative factor analysis with oblimin rotation in SPSS 21 showed a clear two-component structure, and the scales had acceptable to good reliabilities (in the pilot, the Cronbach's alpha for information acquisition $=.75$ and for information processing $=.89$ ). An example item of information acquisition is, 'I ask my team members for help and advice about my work', and for information processing, 'In my team we challenge each other to look at our work in new ways'. 


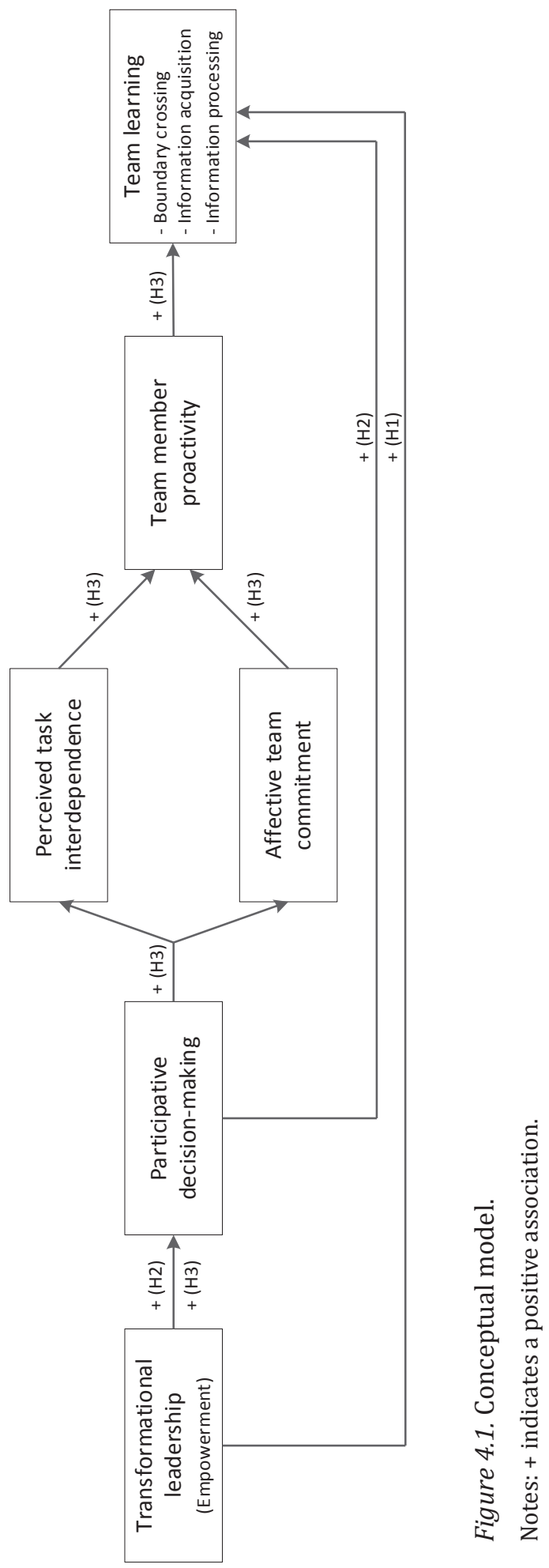


Transformational leadership. Transformational leadership was measured using the empowerment items of the transformational leadership scale developed by De Hoogh et al. (2004) (five items; Cronbach's alpha = .89). Example items are, 'My manager delegates challenging responsibilities to employees' and, 'My manager stimulated employees to think in new ways about problems'.

Participative decision-making. Participative decision-making was measured using the translated items of De Dreu and West (2001) of the scale developed by Campion, Medsker, and Higgs (1993) (three items; Cronbach's alpha = .84). An example item is, 'My team is designed to let everyone participate in decision-making'.

Affective team commitment. Affective team commitment was measured using the translated items of Jak and Evers (2010) of the collective team identification scale developed by Van der Vegt and Bunderson (2005) (four items; Cronbach's alpha = .81). An example item is, 'I feel a strong sense of belonging to the team'.

Perceived task interdependence. Perceived task interdependence was measured using the three-item scale of Van der Vegt (2008). The three-item scale had a low reliability (Cronbach's alpha $=.58$ ). Item statistics showed that the reliability of the scale could be improved to an acceptable level by removing the item 'In our team there is little need for collaboration, team members perform their task independently without help from others (reverse coded)' (Cronbach's alpha $=.70$ ). Consequently, task interdependence was measured using the remaining two items: 'The members of this team have to exchange information and advice in order to do their work properly' and, 'In our team, team members are dependent on each other to perform their tasks properly'.

Team member proactivity. Team member proactivity was measured using the translated scale of Griffin et al. (2007) (three items; Cronbach's alpha = .89). An example item is, 'I improved the way my team does things'.

Table 4.1 shows the reliabilities, means, standard deviations, intraclass correlations (ICC(1) and ICC(2)), average within-group agreements ( $\mathrm{r}_{\mathrm{WG}(J)}$ ), and correlations of all scales. A confirmative factor analysis (CFA) of the 8 scales and all 35 items in Mplus Version 7.4 was performed to assess the fit to the data using multiple fit indices: chi-square, the root mean square error of approximation (RMSEA), the TuckerLewis index (TLI), the comparative fit index (CFI), and the standardised root mean square residual (SRMR). A measurement model fit is good when RMSEA $\leq .05$, TLI >.95, CFI > .95 and SRMR $\leq .08$ (Hu \& Bentler, 1999), while RMSEA<.08, TLI>.90 and CFI >.90 are considered acceptable (Byrne, 2012). The CFA showed an acceptable fit to the data, with $\chi^{2}(532)=1666.362, p<.001$, TLI $=.922$, CFI $=.931$, RMSEA $=.046$ and SRMR $=$ .048 . 


\subsubsection{Data analysis}

The conceptual model of Figure 4.1 was assessed using multilevel structural equation modelling (MSEM) in Mplus Version 7.4 (Muthén \& Muthén, 1998-2012). Because teachers were nested within teams, we computed the intra-class correlations (ICC(1) and ICC(2) and average within-group agreement ( $\left.\mathrm{r}_{\mathrm{WG}(J)}\right)$ for all variables. In education, ICC(1) values of .10 are considered as medium and values of .15 or higher as large (Hox, 2010). In general, ICC(2) values and $\mathrm{rWG}_{\mathrm{W}()}$ values should be .70 or higher to justify data aggregation to the team level (LeBreton \& Senter, 2007). Table 4.1 shows that four of the eight scales had ICC(1) values above.10, that none of the scales had an ICC(2) above .70 , and that four scales had $\mathrm{r}_{\mathrm{WG}(\mathrm{J})}$ values above.70. These results imply that aggregation of all constructs to the team level was not permitted, but that team membership affected the data and that the multilevel structure of the data needed to be taken into account.

Therefore, to obtain correct model results, the nested structure of the data and the individual level constructs were taken into account using MSEM with complex structure analysis. MSEM with complex structure analysis implies that the conceptual model was assessed at the individual team member level, while controlling for their team membership. This complex structure analysis offers the possibility to correctly analyse models at the individual level, while controlling for the nested structure of the data by including the non-independence of the sample by correctly computing standard errors and the chi-square test of the model fit (Muthén \& Muthén, 1998-2012). This reduces the type I error rate (false positive results in the measurement model) (Oude Groote Beverborg et al., 2015).

The measurement model fit was assessed using the fit indices RMSEA, TLI, CFI and SRMR. Nested models were compared using the chi-square difference test (Satorra \& Bentler, 2001) and, when applicable, adjustments to the measurement model were made based on the modification indices given by Mplus.

The control variables gender, age and team size were included in the analyses by adding their regression coefficients on all variables of the model.

\subsection{Results}

The fit of the measurement model to the data was analysed. The first model fit (Model 1) was insufficient, with $\chi^{2}(13)=113.890, p<.001$, TLI $=.737$, CFI $=.930$, RMSEA $=.088$ and SRMR $=.041$. Based on the modification indices, one association was added to the model: the direct association between affective team commitment and information processing. This resulted in Model 2, with an acceptable fit $\left(\chi^{2}(12)=39.296, p<.001\right.$, $\mathrm{TLI}=.923, \mathrm{CFI}=.981$, RMSEA $=.048$, SRMR $=.025)$. The second model fitted the data significantly better than the first model $\left(\Delta \chi^{2}(1)=74.594, p<.001\right)$. Next, all nonsignificant associations were removed from Model 2. This resulted in Model 3, which also had an acceptable fit $\left(\chi^{2}(30)=77.573, p<.001\right.$, TLI $=.946$, CFI $=.967$, RMSEA $=$ .040 , SRMR $=.032$ ). However, Model 2 fitted the data significantly better than Model 3 


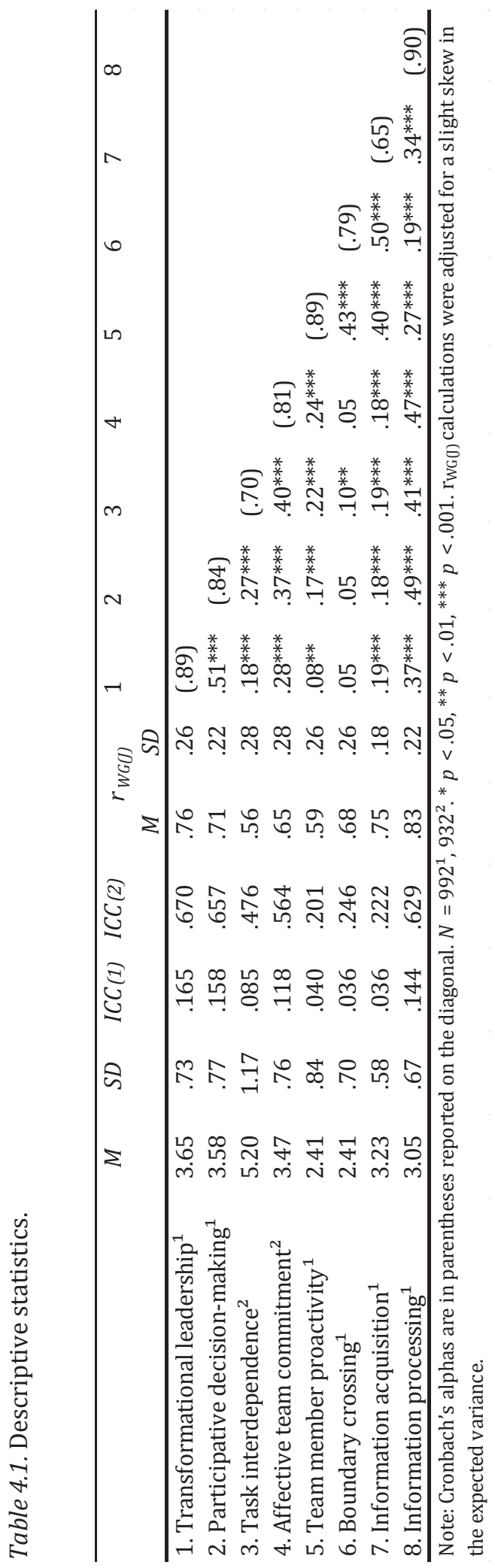


$\left(\Delta \chi^{2}(18)=38.277, p<.01\right)$. Model 2 was therefore retained and used for further analyses. Figure 4.2 presents the results of this model and the direct, indirect and total results are reported in Table 4.2 .

The results show that Hypothesis 1, which expected a direct positive association between transformational leadership and information acquisition, boundary crossing and information processing, was partially confirmed. Transformational leadership was significantly positively associated with information acquisition and information processing, but had no significant association with boundary crossing.

Hypothesis 2, which expected that the association between transformational leadership and the three team learning processes would be partially mediated by participative decision-making, was also partially confirmed. We found that transformational leadership had a significant positive association with participative decision-making, and that participative decision-making had a significant positive association with information processing and was not significantly associated with boundary crossing and information acquisition. Therefore, participative decisionmaking only partly mediated the association between transformational leadership and information processing, while participative decision-making did not mediate the associations between transformational leadership and boundary crossing and information acquisition. The significant mediation was complementary, which implies that both the direct and indirect associations between transformational leadership and information processing were positive.

Hypothesis 3, which expected that the association between transformational leadership and the three team learning activities would, in addition to participative decision-making, also be partially mediated by affective team commitment, perceived task interdependence and team member proactivity, was fully confirmed. Participative decision-making was significantly positively associated with affective team commitment and perceived task interdependence and these, in turn, were significantly positively associated with team member proactivity. Team member proactivity was significantly positively associated with boundary crossing, information acquisition and information processing. Therefore, all indirect paths from transformational leadership through these mediating variables for boundary crossing, information acquisition and information processing were significant: transformational leadership had small indirect positive associations with the three team learning processes. 

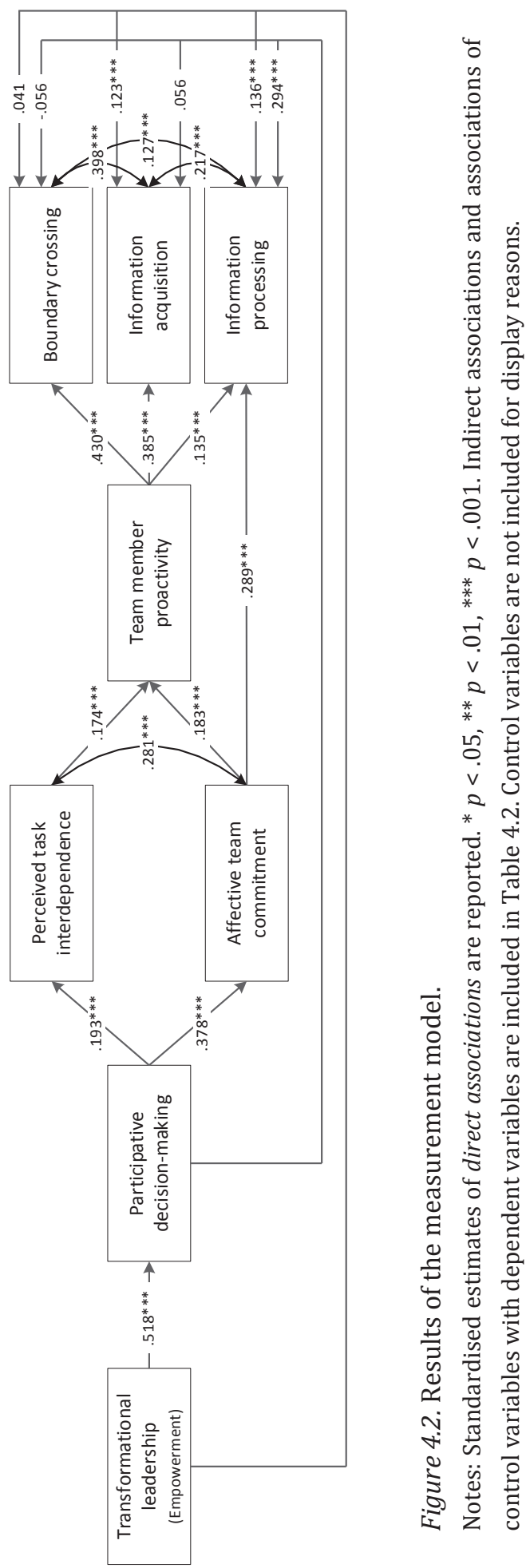


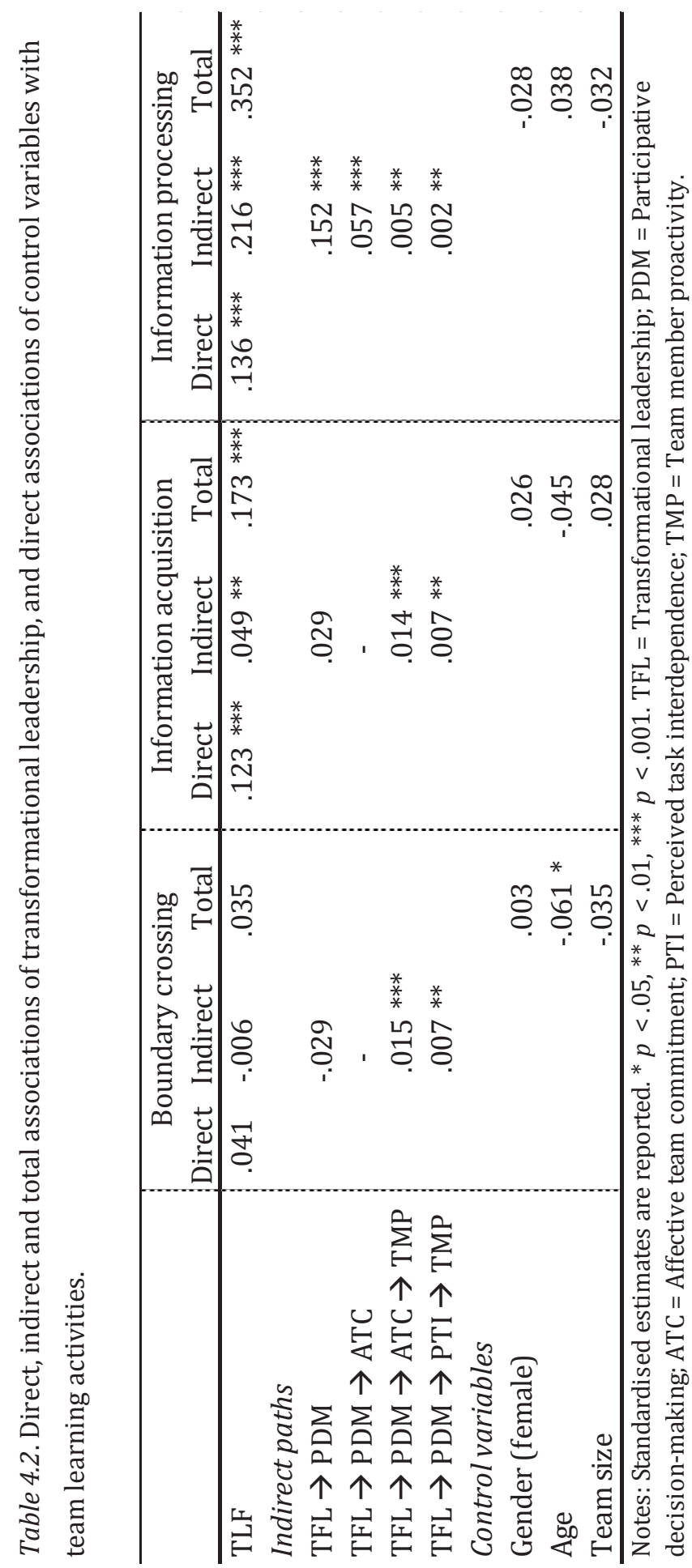




\subsection{Conclusion and discussion}

In this study, we examined to what extent a transformational leadership style of team leaders would be associated with engagement in team learning in VET teacher teams. More specifically, we examined the mediating roles of participative decision-making, affective team commitment, perceived task interdependence and team member proactivity in this association. Three main conclusions can be drawn from this study.

First, transformational leadership was positively associated with two team learning processes, namely individual teacher's information acquisition and teacher teams' information processing. In other words, the more teachers perceived the leadership style of their team leaders to be transformational, the more teachers reported engaging individually in information acquisition and engaging as a team in information processing. This finding can be explained by the empowerment characteristic of transformational leaders. On the one hand, transformational leaders focus on stimulating individual teachers to be creative and on enhancing their problem solving abilities. On the other hand, transformational leaders try to move these individual teachers beyond self-interest and delegate responsibilities to them, which creates a climate in which teachers need to interact with each other (Geijsel et al., 1999; Raes et al., 2013; Zaccaro et al., 2008). In that sense, it is noteworthy that transformational leadership was not associated with teachers' boundary crossing. One would expect that transformational leaders would also stimulate teachers to engage in boundary crossing so that teachers could obtain feedback and advice from outsiders, which is needed to increase their performance with regard to educational innovations. However, it is possible that transformational leaders primarily focus on stimulating teacher teams to act more as 'real teams'. This would imply an internal focus on their team and, consequently, less investment in stimulating teachers to cross their team's boundaries. Another possible explanation could be that transformational team leaders believe that the necessary expertise for the educational innovation is available within their team. Therefore, they may stimulate team learning within the team, but do not feel an urgency to stimulate teachers to engage in boundary crossing. Our data did not provide insights into these possible explanations. Future research on the motives of transformational team leaders for stimulating specific team learning processes, and on whether they are aware of stimulating specific team learning processes, could provide more in-depth insights into the association between transformational leadership and specific team learning processes.

Second, we delved deeper into the associations between transformational leadership and team learning by providing insights into how the opportunity to participate in decision-making mediated the associations between transformational leadership and team learning processes. Results showed a positive association between transformational leadership and participative decision-making, in line with previous research (Geijsel et al., 2009; Thoonen et al., 2011). Additionally, teachers who 
experienced more opportunities to participate in decision-making also reported higher levels of information processing in their team. Therefore, these findings support our assumption that participative decision-making mediates the association between transformational leadership and team learning. However, it is notable that participative decision-making was not associated with information acquisition and boundary crossing by individual team members and did not mediate between transformational leadership and these two team learning processes. A possible explanation for the absence of these mediations is that participative decision-making primarily influences what happens in the teams and between team members (e.g. by increasing the mutual influence among team members; Liu et al., 2014), and has less influence on the behaviour of individual team members. This would imply that behaviours for which other team members are not needed, such as engagement in boundary crossing and information acquisition, are not affected by the opportunity to participate in decisionmaking. So, while we expected that participative decision-making would be directly associated with individual team members' search for relevant information so that they could make informed and considered decisions in the team, the results rejected our assumption. However, we did find that participative decision-making was indirectly associated with information acquisition and boundary crossing, as explained in the third conclusion.

Third, we examined the associations between transformational leadership and team learning further, by assessing other possible underlying mechanisms. More specifically, we examined whether participative decision-making was positively associated with the team-oriented attitudes of teachers in terms of affective team commitment and perceived task interdependence, whether these team-oriented attitudes were positively associated with higher team member proactivity, and whether team member proactivity was positively associated with more engagement in team learning. The data led to some interesting findings.

To start, participative decision-making was positively associated with both affective team commitment and the perceived task interdependence of teachers. These findings support our assumption that empowering team members with the opportunity to participate in team decision-making increases teachers' team-oriented attitudes. This is important, because teachers have long been characterised as working in isolation and not feeling connected to their team (Runhaar \& Sanders, 2013). Through participative decision-making, teachers seem to come out of their isolation and feel more part of a real team.

In turn, these team-oriented attitudes were positively associated with more team-oriented behaviour in terms of team member proactivity. As such, the results suggest that when team members feel more connected to their team, they want to put extra effort into improving their team. 
Consequently, more proactive team members reported higher engagement in all three team learning processes. These findings therefore suggest that more team learning will occur if teams have more proactive team members. It is noteworthy that the associations between team member proactivity and information acquisition and boundary crossing were considerably stronger than the association between team member proactivity and information processing. A possible explanation for this difference is that proactive teachers feel individually responsible for the quality of the educational innovation, and therefore feel the urgency to collect relevant information through information acquisition and boundary crossing. Consequently, because information processing is a collective activity, it is less dependent on individual proactivity. Nonetheless, proactive teachers still reported more information processing than less proactive teachers. This finding can also be explained by the increased feeling of responsibility of the former: as a result of participative decision-making, all team members engage to some extent in information processing, but proactive team members engage in additional information processing because they want to communicate their ideas to others.

Throughout this set of mediating variables, transformational leadership had significant, yet small, positive associations with boundary crossing, information processing and information processing. As such, this study contributes to previous research on the association between transformational leadership and team learning (Lodders, 2013; Raes et al., 2013; Silins \& Mulford, 2002; Vanblaere \& Devos, 2016), by suggesting that transformational leaders do not only directly, but also indirectly, influence engagement in team learning processes.

\subsubsection{Limitations and future research}

Our research model suggests how transformational leaders can contribute to team learning through the identified underlying mechanisms, but we should not neglect the possibility of other underlying mechanisms. First, transformational leaders can empower teams in other ways, not just by giving teams the opportunity to participate in decision-making. For example, leaders can distribute leadership in teams and take a step back as visible leaders to promote the mutual influence between team members (e.g. MacBeath, 2005; Spillane, 2005), which could also influence team learning. Second, other individual team member characteristics, such as the willingness to work in teams, and other team characteristics, such as team culture and psychological safety, could play important roles as well (Raes et al., 2013; Vangrieken et al., 2015). Third, there may be explanatory variables for the team-oriented attitudes and behaviours that we did not include in our model. For example, we only examined whether team member proactivity was associated with affective team commitment and perceived task interdependence, while other variables - such as personality and the learning and performance orientations of individuals - can also be associated with proactive 
behaviour (Parker \& Collins, 2010). Therefore, we suggest that future research delves deeper into the associations between transformational leadership and team learning by including other mediating and explanatory variables.

A limitation of this study is the use of self-report data. Teachers were asked to rate their own attitudes and behaviour and their perceptions of leadership practices. The structure of the survey and the way in which scales were formulated could result in teachers unknowingly relating scales overly consistently with each other, leading to common method bias. Therefore, for future research it is recommended to combine survey data from different sources (Podsakoff et al., 2003). For example, combining data on leadership from teachers and team leaders could lead to less biased results and strengthen conclusions. Additionally, more in-depth studies, for example based on interviews or observations, may provide more detailed insights into how transformational leadership and the underlying mechanisms influence team learning.

Moreover, by using MSEM with a complex structure analysis, we analysed the research model at the individual teacher level while controlling for the team level. This implies that we did not analyse associations at the team level. Analysis at the team level is recommended by some authors when examining collective team learning processes (such as information processing) because these activities are team-level constructs (e.g. Van den Bossche et al., 2006). However, we chose to examine all variables at the individual level and controlled for the team level because analysis showed that only half of the variables in the research model had high enough ICCs for team-level analysis. It was therefore theoretically inconsequent and not statistically permitted to analyse variables such as team member proactivity and boundary crossing at the team level. This implies that an alternative MSEM with two-level analysis instead of complex structure analysis was not suitable here; if we had analysed at least one team learning variable at the team level, all indirect associations would need to be analysed at the team level as well (Preacher, Zyphur, \& Zhang, 2010). This would be undesirable, because the individual level constructs are only meaningful at the individual level. Consequently, in our study we only offered insights into individual teachers' reports on the team level activity of information processing, corrected for their team membership.

Lastly, cross-sectional data was used in this study, which makes it impossible to make causal claims. It would therefore be interesting to test similar measurement models on longitudinal data, for example to explore whether increased opportunities to participate in decision-making processes foster team learning.

\subsubsection{Practical implications}

This study offers team leaders some guidance for stimulating teachers' team learning. First, transformational leaders stimulate teachers to be creative, and they move them beyond self-interest. It is therefore suggested here that, by applying a transformational leadership style, team leaders can stimulate teachers to participate more in team 
learning. Additionally, we also suggest that transformational team leaders can stimulate team learning by involving teachers in decision-making processes. Participation in decision-making not only seems to increase the teachers' feeling of belonging to a real team, but also seems to make teachers behave in ways more beneficial to the team (i.e. team member proactivity). By enhancing these teachers' team-oriented attitudes and behaviours, participative decision-making can stimulate team learning. Overall, our results indicate that, in terms of stimulating team learning, it is worthwhile to actively stimulate teachers to come out of their comfort zone, to give them responsibilities and to give them the opportunity to express their creativity within their team. 


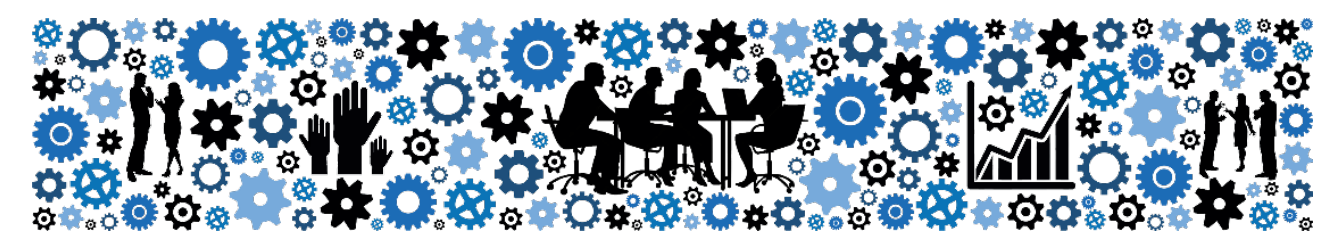

\section{Chapter 5}

\section{Towards distributed leadership in VET colleges: the interplay between formal leaders and team members ${ }^{4}$}

Complex educational innovations in vocational education and training (VET) colleges require teamwork and distributed leadership so that team members are enabled to contribute based on their expertise. The literature suggests that distributed leadership is affected by formal leaders' and teachers' actions, but how their actions affect distributed leadership remains largely unknown. Our study, examining what kind of actions affect distributed leadership within VET teacher design teams (TDTs) working on educational innovations, helps to fill this knowledge gap. Individual interviews and group interviews were conducted with three formal leaders (team leaders) and thirteen members of five TDTs from one VET college. These interviews were analysed using thematic analysis. Regarding formal leaders' actions, results showed that team leaders created opportunities for distributed leadership in TDTs, but also set boundaries by, for instance, limiting the scope and making decisions. Regarding teachers' actions, results indicated that TDT members established leader-follower relationships through team learning processes. Furthermore, it was found that distributed leadership in teams changed according to the different phases of the educational innovation. Overall, this study shows that hybrid leadership configurations existed, in which team leaders and teachers played a central role in establishing distributed leadership in teams, and the study indicates that distributed leadership in teams depends on team members' expertise, time and context.

\footnotetext{
4 This chapter is based on: Bouwmans, M., Runhaar, P., Wesselink, R., \& Mulder, M. (In press). Towards distributed leadership in VET schools: the interplay between formal leaders and team members. Educational Management Administration \& Leadership.
} 


\subsection{Introduction}

Schools are expected to continuously work on complex educational innovations, to retain or even to increase the quality of their educational programmes (Runhaar, et al., 2013). This is also true for the vocational education and training (VET) sector. As a response to increasing labour market demands that require employees to be skilled in lifelong learning and have specific competencies, VET colleges all over the world are redesigning their educational programmes to prepare students for these demands by implementing and improving competence-based education (CBE). In CBE the professional competencies that are needed in jobs and vocational core problems are the starting point for curriculum development, and teachers need to collaborate to develop multidisciplinary curricula that integrate theory and practice (Truijen, 2012; Wesselink et al., 2010). This is a complex task that puts high demands on leaders to guide their teachers effectively.

The distributed leadership literature argues that formal leaders cannot singlehandedly lead others when demands are high, because complex tasks involve many challenges that require input from different perspectives and areas of expertise (Gunter, Hall, \& Bragg, 2013). Therefore, distributed leadership in teacher teams which implies that leadership is the product of conjoint activity instead of individual actions (Woods et al., 2004) - is preferable during complex educational innovations such as CBE, if teams are to cope more effectively with these innovations. It is however unclear how distributed leadership can be effectively achieved, as there is no blueprint on how to establish distributed leadership (Harris \& DeFlaminis, 2016).

Distributed leadership in teacher teams depends on structures such as the organisational culture and values, and on the actions and interactions of those involved. Bolden (2011) suggested in his review study that research on distributed leadership should focus on these actions and interactions by examining how formal and informal leadership co-exist and interact with each other in so called 'hybrid leadership configurations'. The concept of hybrid leadership configurations was introduced by Gronn (2009) to take into account the role that formal leaders play in situations where leadership is distributed. More recently, Tian et al. (2016) argued in their review study that there still is a research gap on these formal and informal leaders' actions and interactions, and therefore suggested to examine distributed leadership from an agency perspective, which refers to 'the actions and interactions of people in taking initiatives, making choices and participating in leadership work' (Tian et al., 2016, p. 148). In this study, we follow their suggestions and use an agency perspective to examine how the actions and interactions of formal leaders (team leaders) and informal leaders (teachers) affect the establishment of distributed leadership in VET teacher teams working on the implementation of CBE. We are specifically interested in how formal leaders create opportunities for distributed leadership, and how teachers utilise these opportunities by taking on leader and follower roles within the team. 
Greater insight in formal and informal leaders' actions and interactions is needed for several reasons. First, although the influence of formal leaders' actions on distributed leadership is often emphasized, scholars such as Crawford (2012) and Tian et al. (2016) argue that only a few studies have actually examined formal leaders' actions. Formal leaders can create opportunities for distributed leadership (Tian et al., 2016), but can also put boundaries on distributed leadership (Hairon \& Goh, 2015). As such, they act as what Bush and Glover (2012) called 'gatekeepers' of distributed leadership. However, because empirical research on their actions is limited, it remains largely unknown how they create opportunities and put boundaries on distributed leadership and how this affects the establishment of distributed leadership in teacher teams. Second, regarding teachers' actions, Scribner et al. (2007) show that interactions in teacher teams need to be taken into account when examining how distributed leadership can be established. They show that collaborative dialogue, which refers to the construction and reconstruction of collective knowledge by team members (Loureiro \& Caria, 2013), plays a crucial role in establishing leader and follower roles within teams. However, research on distributed leadership within teams is scarce (Scribner et al., 2007), and much remains unknown about what activities collaborative dialogue actually encompasses and how these activities affect the establishment of leader-follower relationships in teams. Therefore, we use team learning literature to theoretically and empirically determine relevant collaborative dialogue activities in the establishment of distributed leadership.

Hence, we aim to answer to following research questions: 'In what ways do formal leaders create opportunities for distributed leadership, and how do they set boundaries for distributed leadership?', and: 'In what ways do teachers establish leaderfollower relationships within their team, and what is the role of team learning in this process?'

\subsection{Theoretical framework}

\subsubsection{Towards distributed leadership}

Although distributed leadership has gained much attention in educational management literature over the past decades (e.g. Gronn, 2002; Spillane, 2005), many scholars agree that different conceptualisations of distributed leadership have made the concept elusive (e.g. Hairon \& Goh, 2015; Harris \& Spillane, 2008; Tian et al., 2016), resulting in conceptual confusion and overlap with other concepts such as shared leadership, democratic leadership and collaborative leadership. For empirical studies on distributed leadership it is therefore important to determine characteristics of distributed leadership that scholars agree upon and to conceptualize these characteristics in measurable ways. 
Recently Hairon and Goh (2015) did this by developing a questionnaire measuring formal leaders' role in distributed leadership. They neglected however how teachers distribute leadership within their teams. Nevertheless, their attempt in combination with characteristics described by other scholars provide input for conceptualising distributed leadership in our study. The first characteristic that many scholars agree upon is that distributed leadership contains multiple levels of involvement in decision-making, such as formal leaders in hierarchical leadership positions and informal leaders (e.g. Bolden, 2011; Gronn, 2009; Harris, 2008; Tian et al., 2016). A second characteristic is that distributed leadership is dynamic with open boundaries of leadership, meaning that those who are best equipped and skilled to lead to achieve a certain goal do so, and that who leads depends on the goals that are being worked on (e.g. Harris \& DeFlaminis, 2016; Woods et al., 2004). This implies that multiple individuals can exercise leadership at some point, but not that everybody is a leader or always leads (Harris \& DeFlaminis, 2016). Third, interactions between individuals are needed to determine who leads and who follows (e.g. DeRue \& Ashford, 2010; Woods, 2016). Combined, these characteristics form the starting point for conceptualising formal and informal leaders' actions and interactions in establishing distributed leadership.

\subsubsection{Formal leaders' actions}

Teachers act within a complex power structure that creates, but also constrains their opportunities to lead (Lumby, 2013). This power structure is reflected in formal leaders' behaviour. On the one hand they create opportunities for distributed leadership by empowering teachers (Tian et al., 2016), but on the other hand, they also put boundaries on teachers' empowerment (Hairon \& Goh, 2015).

Creating opportunities for distributed leadership. Formal leaders can create opportunities for teachers to exercise influence in non-hierarchical networks of teachers that exist alongside prevailing formal leadership structures in schools (Tian et al., 2016). This implies that formal leaders encourage or discourage teachers to lead, and, as such decide on how distributed leadership is shaped (Hatcher, 2005). To conceptualise how team leaders can create these opportunities we use the framework of MacBeath (2005).

MacBeath (2005) distinguishes four ways in which formal leaders can create opportunities for distributed leadership. The first, formal distribution, implies that formal leaders delegate influence by describing leadership tasks in the job descriptions of teachers. The second, pragmatic distribution, implies that formal leaders delegate influence relatively ad hoc as a response to increased demands, such as the need to improve the quality of educational programmes. The third, strategic distribution, implies that formal leaders introduce new members with specific expertise and resources in teams to fulfil specific leadership tasks. The fourth, incremental 
distribution, implies a transition from formal leader's influence to teachers' informal influence. On the one hand, formal leaders give increased responsibilities to teachers as teachers demonstrate their ability to lead, and on the other hand, teachers show willingness to take on more responsibilities.

Bounded empowerment. Formal leaders also decide on the scope of distributed leadership by deciding what responsibilities are distributed and how this distribution is realised. Hairon and Goh (2015) refer to this as 'bounded empowerment', which means that teachers are only given a certain degree of influence. The authors give three reasons why distributed leadership is bounded. First, there will be certain areas of decision-making that cannot be given to teachers. For instance, teachers are only empowered to make decisions within their scope of work, and not on school-level aims. Second, distributed leadership is bounded insofar as formal leaders are kept informed about decisions made by teachers. Gronn (2009) adds to this that formal leaders also make final decisions based on information provided by informal leaders. Third, decisions made by teachers are bounded because these must be aligned with school goals and coordinated with decisions made by others (Hairon \& Goh, 2015). Overall, bounded empowerment implies that power in schools continues to be a characteristic of formal leaders, and that distributed leadership is merely a delegated and licensed form of influence under the formal leader's authority, which has also been emphasized by Hatcher (2005). Distributed leadership therefore does not imply that the boundaries of leadership are fully open or that everybody has equal opportunities to lead (Lumby, 2013). Instead, it are formal leaders who set the conditions for distributed leadership.

\subsubsection{Teachers' actions}

When the conditions are set by formal leaders, teachers can allocate influence within their team. Here the dynamic character of distributed leadership and the central role of interactions in determining leader and follower roles become apparent. To conceptualise the dynamics, we built on another part of the framework of MacBeath (2005), and distinguish two ways in which team members do this. And to conceptualise the interactions, we use team learning theory.

The first way of distributing leadership within teams, opportunistic distribution, implies that teachers willingly undertake and distribute additional responsibilities in an ad hoc manner. The second, cultural distribution, implies that influence is spontaneously and organically shared between teachers, and is expressed through activities rather than roles. Here, distributed leadership has become part of the team culture (MacBeath, 2005). In both opportunistic and cultural distributions, some individuals may be included in and others may be excluded from exercising influence.

Because Scribner et al. (2007) showed the importance of collaborative dialogue in establishing distributed leadership, we argue here that collaborative dialogue also plays an important role during these opportunistic and cultural 
distributions. As previously mentioned in the introduction, it however remains unclear what activities collaborative dialogue consists of and how these activities affect distributed leadership. Collaborative dialogue has much in common with the concept of team learning, because both refer to the co-construction and reconstruction of collective knowledge by team members (Decuyper et al., 2010; Loureiro \& Caria, 2013). In team learning literature distinct team learning processes are distinguished, and we therefore believe that this literature can help in conceptualising collaborative dialogue. Decuyper et al. (2010) identified three basic team learning processes that describe what happens when teams engage in team learning. These processes are described in detail in Chapter 1 and are central in this chapter as well. The first, information sharing, implies that team members share previously unshared information with each other. The second, co-construction, implies that team members develop shared knowledge by refining, adding to and changing shared information by questioning, concretising and completing this information. The third, constructive conflict, implies that team members discuss or negotiate about opposing ideas to reach agreement. As previously mentioned in the preceding chapters, in practice, these three processes are highly intertwined. For example, co-construction can lead to constructive conflict, and new information can be shared while team members engage in constructive conflict. Given this interconnectedness, these processes are also combined in literature under the denominator 'information processing' (Van Woerkom \& Van Engen, 2009).

As teacher teams are usually not internally hierarchically structured, meaning that no hierarchy exists between teachers within teams, their loose structure makes it possible for all members to engage in collaborative dialogue (Scribner et al., 2007), and therefore in team learning as well. We can imagine that, by engaging in different team learning processes, team members construct solutions to complex challenges and, as such, lead their team through these challenges. This implies that team learning contributes to the distribution of leadership in teams, as is also suggested by Day et al. (2004). Additionally, teacher teams can develop a mutually shared cognition on distributed leadership through engagement in team learning, such as an understanding of what leadership encompasses and who the leaders are. As such, we assume that team learning contributes to establishing leader-follower relationships in teams.

In turn, established leader-follower relationships can shape team learning. When leadership is distributed within a team, the mutual influence among team members increases, which requires frequent interactions between members, such as information sharing and co-construction (Liu et al., 2014). Moreover, teachers with leader roles may contradict or point out fallacies in other teacher's ideas, which can stimulate team learning (Leithwood, Steinbach, \& Ryan, 1997), and teachers with leader roles can create learning environments in their team (Chatalalsingh \& Reeves, 2014).

In line with what is theoretically proposed by Day et al. (2004), the aforementioned studies indicate a reciprocal relationship between distributed 
leadership and team learning: team learning processes shape leader-follower relationships in teams, and these relationships shape new team learning processes.

To recapitulate, in this study on the one hand we explore how formal leaders set conditions for distributed leadership in teams, and on the other hand, we explore the dynamic nature of distributed leadership by examining how teachers utilise these conditions by establishing leader-follower relationships within their team through engagement in team learning. This is visualised in Figure 5.1.

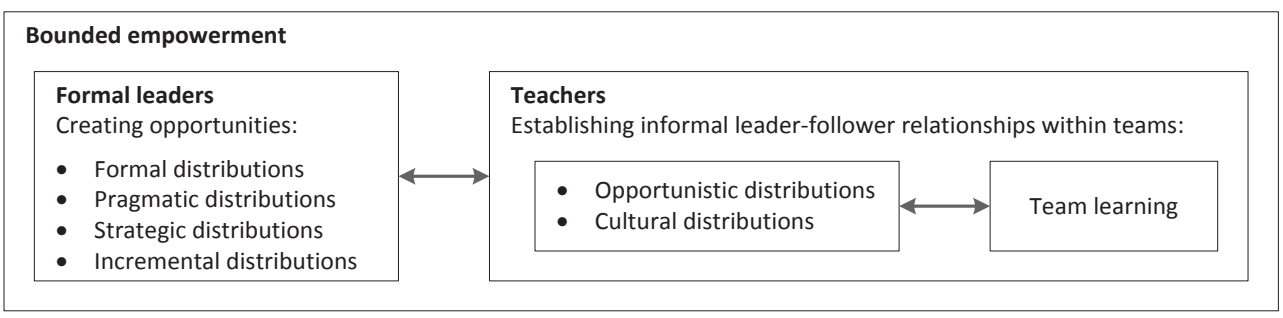

Figure 5.1. Conceptual model.

\subsection{Methods}

In this section we explain our choices regarding the research context, study and instrument design, and analysis, and elaborate on the quality of our research in terms of validity, reliability and ethics.

\subsubsection{Research context and sample}

The study was conducted in one VET college that had developed a policy for an educational innovation to increase the alignment between CBE programmes and the labour market. This policy required teacher teams to organise their teaching in blocks of five weeks, in which various professional competencies of students were to be developed and tested. These five-week blocks needed to be practice-based and tailormade in the sense that they contained both mandatory and elective learning activities.

Teacher teams' development of this innovation consisted of two consecutive phases. In the first phase, they had to develop a vision of the innovation. Teams could design their own vision, as long as they adhered to the policy regulations, such as organising education in blocks of five weeks. This implied that teams had to determine the core competencies for which they educate students, and specify which courses should be part of the five-week blocks. In the second phase, teacher teams had to develop these five-week blocks and experiment during class. To do this, teachers had to integrate courses into blocks, sometimes develop new courses, and create schedules.

In all teacher teams, a teacher design team (TDT) was set up to take responsibility for the innovation. A TDT is 'a group of at least two teachers, from the same or related subjects, working together on a regular basis, with the goal to 
(re)design and enact (a part of) their common curriculum' (Handelzalts, 2009, p. 7). TDTs consisted of teachers, here called design teachers - who were members of the larger teacher team - and a coach, who was not a member of the larger teacher team. There was no predetermined hierarchy between design teachers and coaches within the TDTs and they fell under the supervision of a team leader.

These TDTs were expected to yield interesting results on the establishment of distributed leadership. Through purposive sampling with two selection criteria, five TDTs were selected. The first criteria was that all TDTs be selected from a single VET college to ensure that the TDTs had similar structures and worked on the same innovation. This increased the TDTs' comparability. The second criteria was to only select TDTs that were developing innovations, to ensure that the TDTs worked on complex tasks during the data gathering and that it was possible to reconstruct their reality.

Based on these criteria, eight TDTs were selected and their team leaders were approached to participate in the study. Three team leaders declined because of practical reasons (e.g. time constraints), and the team leaders of the remaining five TDTs agreed to participate.

Table 5.1 shows the sizes of the participating TDTs and their larger teams. Teacher teams varied in size, which implies that the percentage of teachers involved in TDTs also differed.

Table 5.1. Sizes of TDTs and larger teacher teams.

\begin{tabular}{lccc}
\hline & $\begin{array}{c}\text { TDT size } \\
\text { design teachers } \\
\text { and one coach) }\end{array}$ & $\begin{array}{c}\text { Teacher team size } \\
\text { teachers, excluding the } \\
\text { coach) }\end{array}$ & $\begin{array}{c}\text { \% of teachers with a } \\
\text { design teacher role }\end{array}$ \\
\hline TDT 1 & 4 & 4 & $75 \%$ \\
TDT 2 & 4 & 15 & $20 \%$ \\
TDT 3 & 3 & 14 & $14 \%$ \\
TDT 4 & 3 & 4 & $50 \%$ \\
TDT 5 & 3 & 7 & $29 \%$ \\
\hline
\end{tabular}

Note: When calculating the percentage of teachers in TDTs, coaches were left out of the calculation.

\subsubsection{Study design}

Ten design teachers, three coaches and three team leaders were interviewed to gain insight into formal leaders' and TDT members' actions, and to obtain reconstructions of reality from different perspectives (see Table 5.2). All the interviews lasted about one hour. 
Design teachers participated in group interviews A, B, C and D because of the expected snowball effect: by discussing team processes together, design teachers could reconstruct team processes more accurately than individual teachers would be able to do in individual interviews (Barbour, 2007). One coach also participated in group interview $\mathrm{C}$ because the coach was only a member of that specific TDT (TDT 3). The other coaches participated in individual interviews because they were members of two TDTs: one coach was a member of TDTs 1 and 2, and the other coach was a member of TDTs 4 and 5. The interviews enabled us to discuss these TDTs separately. Team leaders participated in separate interviews to prevent power relations being exhibited during group interviews: because design teachers and coaches were asked to reflect on the team leader's role, we wanted to ensure that they could speak freely and uninhibited by the team leader's presence (Barbour, 2007).

For all interviews a similar topic list was used as a research instrument. Topics that were addressed included the actions of design teachers, coaches and team leaders during the innovation, the delegation of leadership, and engagement in team learning. The topic list was evaluated with a policy advisor of the participating VET college to ensure clarity and relevance.

Table 5.2. Overview of group interviews and face-to-face interviews per TDT.

\begin{tabular}{llll}
\hline TDT & Design teachers & Coach & Team leader \\
\hline 1 & Group interview A $(N=2)$ & Interview $\mathrm{A}^{1}$ & Interview $\mathrm{B}^{2}$ \\
2 & Group interview B $(N=2)$ & Interview $\mathrm{A}^{1}$ & Interview $\mathrm{B}^{2}$ \\
3 & Group interview $\mathrm{C}^{3}(N=3)$ & Group interview $\mathrm{C}^{3}$ & Interview C \\
4 & Group interview $\mathrm{D}^{4}(N=4)$ & Interview $\mathrm{D}^{1}$ & Interview $\mathrm{E}^{2}$ \\
5 & Group interview $\mathrm{D}^{4}(N=4)$ & Interview $\mathrm{D}^{1}$ & Interview $^{2}$ \\
\hline
\end{tabular}

${ }^{1}$ Same coach for TDT 1 and 2, and for TDT 4 and 5.

${ }^{2}$ Same team leader for TDT 1 and 2, and for TDT 4 and 5.

${ }^{3}$ The coach participated in the group interview because he was a member of TDT 3 only.

4 Two TDTs of one larger team participated in one group interview, with two design teachers of each TDT.

\subsubsection{Data analysis}

Transcripts were coded with Atlas.ti version 7.5 using thematic analysis (Braun \& Clarke, 2006), and data were processed and analysed in four phases. In the first phase, the one researcher made initial notes, coded transcripts in a theory-driven way, and combined codes into themes. In the second phase, the themes and codes of two transcripts were reviewed by another researcher and the two researchers discussed differences to reach agreement on the final codes. In the third phase, the first researcher refined codes and themes in the remaining transcripts based on the final codes, and in 
the fourth and final phase, the codes and themes were associated and quotations were abstracted from the data.

\subsubsection{Quality and ethics}

Based on Gibbs (2007) and Barbour (2007), the validity of the study was assessed in several ways. First, triangulation was used by combining data from group interviews and individual interviews to compare insights from different perspectives. Second, we used the idea of constant comparison, which implies checking the consistency and accuracy of codes by comparing the content of codes both within and between cases. Third, we provided evidence for our data interpretation through the examples and quotations in the results section.

Reliability was assessed by calculating the interrater reliability for the two transcripts that were coded and discussed by the two researchers. The average Cohen's kappa was .82, which indicates good agreement (Viera \& Garrett, 2005).

Ethics were taken into account in several ways. First, verbal informed consent was obtained from all participants. Second, anonymity was ensured by removing participant, team and organisation identifiers from the results, and by denying unauthorised people access to non-anonymised data (Gibbs, 2007).

\subsection{Results}

As mentioned above, two consecutive phases of the educational innovation were defined: vision development and content development. We have described how distributed leadership was established through the actions and interactions of formal leaders and TDT members for each phase. The results therefore provide insight into the dynamics of distributed leadership over time (i.e. the differences between the two phases), and during different tasks (i.e. developing a vision, or developing content and experimenting).

\subsubsection{Phase 1: Vision development}

\section{Formal leaders - Creating opportunities}

At the start of the educational innovation, team leaders delegated influence to TDTs through pragmatic and strategic distributions. First, based on teachers' expertise and motivation, team leaders appointed two or three teachers from the teacher team as design teachers in the TDT (pragmatic distribution). For example, the team leader selected one teacher with experience in the labour market, one teacher with experience in specific courses and one teacher with experience in innovation for TDT 2. Second, because one of the challenges that arose during the vision development phase was that design teachers did not have the appropriate expertise, team leaders introduced coaches with expertise in vision development in all TDTs to support the design teachers (strategic distribution). 


\section{Formal leaders - Bounded empowerment}

TDT members experienced boundaries set by team leaders in several ways. First, all team leaders regularly took part in TDT meetings to stay informed about decisions made by the TDT. Although TDT members generally welcomed the team leader's presence, in TDT 5 it caused tensions between the team leader and the design teachers. The design teachers thought that the team leader should only facilitate the TDT and not influence vision development through the meetings. At the time of data gathering, they had not yet found a solution to this problem. Second, in TDTs 2 and 3, team leaders made decisions on aspects of the innovation beyond the TDT members' scope of influence. For instance, in TDT 2, it was the team leader who decided whether other teachers could join TDT meetings. In TDT 3, the team leader decided on the innovation's scope, as this quote illustrates: 'I said: "Take it easy. Let us first look at developments in other teams, so we can use those... We will not change our examination yet ..." I outlined the main directions' (team leader, TDT 3).

\section{TDT members - Establishing informal leader-follower relationships}

TDT members established two different informal leader-follower relationships in a relatively ad hoc manner, within the conditions created by team leaders (opportunistic distributions). The first of these relationships, identified in TDTs 1, 2 and 5, implied that coaches claimed and were granted leader roles and design teachers claimed and were granted follower roles. Coaches claimed this leader role by sharing information on how to develop a vision. The design teachers granted this role to coaches and claimed follower roles themselves because they acknowledged their own lack of expertise in vision development. This quote illustrates this: 'Without the coach we would not have succeeded.... Possibly, we would still be at the start of vision design' (design teacher, TDT 1).

The second relationship, identified in TDTs 3 and 4, implied a leader-follower relationship in which both coaches and design teachers took on leader and follower roles. In TDT 3, design teachers and the coach had different perspectives on the educational innovation. Constructive conflict was needed to reach agreement on a leader-follower relationship, in which design teachers took the lead in the vision development, and the coach inspected whether the vision reflected the VET college's policy. The need for constructive conflict is illustrated by this quote:

'Design teachers focused on conditions of their current education, and I focused on conditions of the innovation. I am not implying that these conditions collided, but they did not always correspond. At the beginning, we had a lot of discussion about this. At a certain moment I realised that it was useless to impose my conditions and I let go of my conditions a little. That went well, because the design teachers took over' (coach, TDT 3). 
TDT 4 came to a similar leader-follower relationship, but without constructive conflict. This was because the coach and design teachers acknowledged their different ideas from the start and distributed influence accordingly.

\section{Summary of Phase 1}

Team leaders created opportunities for distributed leadership through pragmatic and strategic distributions. The boundaries of TDT empowerment became apparent through team leaders' presence in TDT meetings, and through certain decisions made by team leaders. Design teachers and coaches established leader-follower relationships in their TDTs through opportunistic distributions. Team learning - information sharing and constructive conflict - contributed to the establishment of these relationships.

\subsubsection{Phase 2: Content development}

TDTs 1 to 4 had finished developing their vision and were starting to develop content. TDT 5 had not yet reached this phase and was still engaged in vision development at the time of data collection. TDT 5 was therefore not taken into consideration in this phase.

\section{Formal leaders - Creating opportunities}

Team leaders of TDTs 1 to 4 observed that the TDT members had acquired additional leadership expertise and delegated more influence to them, which indicates an incremental distribution. This quote illustrates this: 'My role was most notable during the vision design. Since the teachers have started to develop content for the programme, I can step back more' (team leader, TDT 1 and 2).

\section{Formal leaders - Bounded empowerment}

Although team leaders delegated more influence to TDT members in this phase, TDT members still faced boundaries to their empowerment. The design teachers in TDT 2 explained that their team leader tried to 'create a balance between delegation and having control'. This was also the case in TDTs 1, 3 and 4. In general, team leaders attended fewer TDT meetings but continued to make decisions and to monitor the TDTs' progress.

Regarding decision-making, the team leader of TDTs 1 and 2 decided when the TDTs could start implementing the innovation. The TDT members accepted the team leader's decision, as this quote indicates: 'The team leader participated in meetings to hear about our progress. Then she decided that TDT 1 could start implementing and that TDT 2 could not yet start... That was it, the decision was made. Nobody debated that decision' (coach, TDT 1 and 2). Additionally, in TDT 4 the team leader decided on the experimentation with content during classes. The design teachers wanted to have two teachers involved in the experiment, but the team leader decided to deploy only 
one teacher. The design teachers accepted this because the team leader explained that he 'must justify the deployment of teachers, and has to make sure that the deployment is effective' (design teachers, TDT 4).

Regarding monitoring, in TDT 3 the team leader monitored the content development phase to make sure that the innovation's scope as agreed on in the vision development phase was followed.

\section{TDT members - Establishing informal leader-follower relationships}

TDT members relatively ad hoc established new leader-follower relationships in which design teachers took on a leader role and the leader role of coaches was reduced (opportunistic distributions). Again, information sharing played a role in establishing these leader-follower relationships. For instance, in TDTs 1 and 2, design teachers claimed and were granted leader roles because they knew more about the content of course materials than the coach, which they showed through information sharing. The coach described this change in leader-follower relationships as follows: 'At the start you intensively try to make the design teachers adopt a vision.... When they adopt that vision, my influence decreases, and the materials' development by the design teachers becomes a matter of course' (coach, TDT 1 and 2). Similarly, in TDTs 3 and 4, coaches granted design teachers more influence because they had acquired more expertise in innovating. This quote illustrates this:

'At the start, the design teachers need a lot of coaching. This need diminished slowly during the innovation trajectory.... For years, innovation was not really necessary because schools bought a lot of existing educational materials. Therefore, innovation became a bit of a lost competency of teachers that is now coming back...' (coach, TDT 4).

These new leader-follower relationships pointed towards the emergence of cultural distributions in TDTs 1 to 4 in which influence increasingly was distributed in natural ways. For example, in TDT 1, design teachers autonomously developed materials without explicitly distributing leadership. Similarly, in TDT 3, one design teacher coordinated other teachers' tasks and the other design teacher monitored the quality of newly developed materials, without explicitly claiming and granting these leader roles. However, data on cultural distributions were limited because no TDTs had entirely reached this stage when data were collected.

In their leader roles, design teachers stimulated other teachers' engagement in team learning to overcome the challenge of how to gain support from the entire teacher team (TDTs 2, 3 and 4). To do this, design teachers initiated information processing with the entire team, by putting the educational innovation on the agenda of team 
meetings. For instance, design teachers in TDT 2 organised brainstorming sessions with the entire teacher team:

'During team meetings, we share our ideas and ask the team what they think about those ideas. For example, we have split the team into two halves for brainstorming. One week we brainstorm with one half, the other week with the other half. So, we do not decide ourselves on what we are going to do, but consult with other teachers' (design teacher, TDT 2).

In addition to these team meetings, design teachers invited individual teachers to join TDT meetings to engage in information processing (in TDTs 2 and 3):

'Once every two weeks we invite one teacher. We discuss our ideas with that teacher and how we can combine materials for next year.... So, we share our ideas, but also ask the other teacher's opinion, what that teacher wants, and whether the teacher thinks our ideas fit into the programme...' (design teacher, TDT 2).

\section{Summary of Phase 2}

Team leaders delegated more influence to TDT members through an incremental distribution. The bounded empowerment of TDTs became apparent through formal leaders' decision-making and monitoring. The TDT members generally agreed with these boundaries. Members established new leader-follower relationships in TDTs through information sharing. TDT members also engaged in information processing to increase the involvement of other teachers of the entire teacher team.

\subsection{Conclusion and discussion}

Although distributed leadership is often seen as an effective way of meeting complex demands, the literature provides limited insights into how distributed leadership can be established in teacher teams. Therefore, the goal of this study was to provide insight into how formal leaders' and teachers' actions and interactions affect the establishment of distributed leadership in VET teacher design teams (TDTs) working on educational innovations.

With regard to research question one, we found that team leaders created opportunities for distributed leadership through pragmatic, strategic and incremental distributions. Moreover, they also set boundaries for distributed leadership by continuing to exercise influence during the educational innovation. Team leaders not only influenced the vision development by being present during TDT meetings, they also made important decisions regarding the educational innovation's scope and monitored the progress. 
With regard to research question two, we found that the team learning process of information sharing helped TDT members to decide who is an expert in certain aspects of the educational innovation. Acknowledging an individual's expertise resulted in granting leadership to that individual. If TDT members were not convinced of an individual's expertise or had different ideas, constructive conflict helped to reach agreement among TDT members on the leader-follower relationship. Additionally, in their informal leader roles, TDT members stimulated other teachers' engagement in team learning. They stimulated other teachers to engage in information processing with the TDT members to increase support from these teachers and to obtain insights into their perspectives.

In addition to these results related to the research questions, we found that the distributed leadership structures that were established in TDTs were dynamic, because different leader-follower relationships emerged in different phases of the educational innovation. For instance, coaches had informal leader roles in all the TDTs during the vision development phase, while they stepped back as informal leaders in most TDTs during the content development phase.

We discuss these findings step by step below, by first discussing the formal leaders' actions, then team members' actions and interactions, and then the dynamic character of distributed leadership.

\subsubsection{Formal leaders' actions}

Our finding that formal leaders created opportunities for distributed leadership that allowed team members to establish leader-follower relationships among themselves indicates the importance of taking formal leaders' actions into consideration. This finding supports previous studies that argue that formal leaders delegate distributed leadership (Hairon \& Goh, 2015), and that they decide who can fulfil leadership roles (Tian et al., 2016). The framework of MacBeath (2005) enabled us to add new insights to these previous studies by showing what specific actions formal leaders intentionally took to create these opportunities.

Additionally, by showing that formal leaders also set boundaries for distributed leadership, our results seem to imply that distributed leadership structures cannot co-exist alongside formal leadership structures in hybrid leadership configurations. Instead, in line with scholars such as Hairon and Goh (2015) and Hatcher (2005), we argue that distributed leadership structures continue to be influenced by leaders in formalised hierarchical positions. Therefore, a cultural distribution as described by MacBeath (2005) may not be realistic for teacher teams. Although team members may distribute informal influence increasingly spontaneously, the formal leader will ultimately determine the scope of this spontaneous distribution. A hybrid leadership configuration, in which formal leaders have actual power and teachers exercise leadership within fixed boundaries, therefore seems more realistic. 
Hatcher (2005) uses the following fitting quote to illustrate this 'I participate, we participate, but they decide over what kind of issue we can decide' (Wainwright, 2003, p. 193 in Hatcher, 2005, p. 259).

There are multiple possible explanations why formal leaders set boundaries on distributed leadership. First, formal leaders (team leaders) need to account for their own actions and for the team's performance to their own formal leader, such as the school leaders or board members. Second, the school's context can also play a role: schools must meet accountability demands that are usually determined by national authorities. Therefore, formal leaders want to continue to exercise control over performance (Gronn, 2009; Runhaar \& Runhaar, 2012). To increase our understanding of the formal leaders' role, we suggest that future research should focus on how and why formal leaders promote or inhibit distributed leadership.

\subsubsection{Team members' actions}

We have provided a detailed insight into what interactive processes contributed to the emergence of leader-follower relationships in teams, by showing the role of team learning, and particularly of information sharing and constructive conflict. This insight was needed, because although the importance of interactions and collaborative dialogue were emphasized in previous research (e.g. Scribner et al., 2007; Woods, 2016), a clear analysis of what these interactions and collaborative dialogue encompass was missing.

Additionally, we have found support for the work of Chatalalsingh and Reeves (2014), who argue that team members can act as 'team-learning leaders', because the results showed that informal leaders (design teachers) enabled team learning in their team by involving other teachers in information processing.

The learning processes in this study are derived from the team learning literature. Because more learning processes are identified in the team learning literature than are included in our study (see for instance Decuyper et al., 2010), we believe that the role of team learning should be examined further. Future research on distributed leadership in teams could build on the existing team learning literature, so that we can acquire greater insight into the contribution of other team learning processes to the allocation of leader and follower roles within teams, and into why and how informal leaders promote specific learning processes in teams.

\subsubsection{The dynamic character of distributed leadership.}

We found that distributed leadership has a dynamic character. As previously argued by Gronn (2009), the way in which distributed leadership was established in TDTs changed over time, depending on the available and acquired expertise of the team members. For instance, team leaders gave more influence to TDT members as they gained leadership expertise. Related to time, the context also seems to play a central 
role in this dynamic character, as the relevance of available and acquired expertise in TDTs depended on the tasks that TDTs were working on. Some expertise was not relevant at the start of the innovation and became relevant in later phases. The bounded empowerment provided by team leaders was also dynamic, because team leaders attended fewer TDT meetings when they believed that the relevant expertise was available in the TDT.

Overall, these findings show that distributed leadership does not imply that everybody is a leader, which is also emphasised by Harris and DeFlaminis (2016). Who is a leader will depend not only on a person's expertise, but also on time and the task context.

\subsubsection{Limitations and future research}

The framework of MacBeath (2005) proved to be useful for examining the establishment of distributed leadership in the TDT's of this study, because it allowed for including both formal leaders' and teachers' actions. However, a limitation of the framework is that possible leader-follower relationships, or distributions of leadership tasks, that may emerge during the opportunistic and cultural distribution are not clearly defined. The framework of distributed leadership of Leithwood, Day, Sammons, Harris, and Hopkins (2006) is more specific in this respect by describing four ways in which informal leaders can distribute leadership tasks: planful alignment, spontaneous alignment, spontaneous misalignment, and anarchic misalignment. We therefore suggest that future research integrates the frameworks of Leithwood et al. (2006) and MacBeath (2005). Integrating these frameworks has several advantages. First, the integration can lead to a more consistent conceptualisation of distributed leadership. Second, this integration may contribute to distinguishing distributed leadership from related concepts that are sometimes used interchangeably, such as shared leadership and collaborative leadership (e.g. Hallinger \& Heck, 2010; D. Wang, Waldman, \& Zhang, 2014). Third, a more specific framework allows for more detailed empirical examinations of the development of distributed leadership.

Moreover, given the explorative character of our study, we distinguished between two successive phases in educational innovation: vision development and content development. This distinction made it possible to explore changes in distributed leadership. However, more innovation phases are identified in the instructional design literature, as for example described in the analysis-designdevelopment-implementation-evaluation (ADDIE) framework (Gustafson \& Branch, 2006). It is possible that the establishment and dynamics of distributed leadership depend on these phases. Therefore, we recommend that future research takes these innovation phases into account. Teams could be selected that have been through all the phases, or data could be collected after each phase. 
Additionally, while organisational changes such as educational innovations are faced with content, process and contextual challenges (Devos, Buelens, \& Bouckenooghe, 2007), we only explored the process challenges faced by the TDTs. For instance, we explored how team learning contributed to creating support from the whole team. However, the TDTs also faced difficulties in the alignment between educational programmes and the labour market and in meeting the VET college's policy regulations, which are content challenges, and with the facilitation in time by their VET college, which is a contextual challenge. Given our focus on the process of establishing distributed leadership, we did not collect data on content and context challenges. Therefore, we recommend that future research focuses on all three types of challenges and examines how these affect distributed leadership and educational innovations.

Furthermore, in addition to time and context, Gronn (2009) also argues that leader-follower relationships are influenced by the membership-bound configuration of these relationships. We were unable to provide any insight into this membershipbound configuration because all the TDTs in this study had the same configuration. It is however possible that dynamic configurations affect distributed leadership structures in teams. Therefore, more research in other teacher teams with dynamic membership is needed to increase our understanding of the dynamics of distributed leadership.

Lastly, retrospective self-reported data were collected, which could result in subjective and biased reports. This issue is partly addressed by collecting data from different actors and comparing their reports. Additionally, because design teachers were asked to reflect on their team processes together in the group interviews, they were able to respond to other teachers' comments. This increased the chance of retrieving actual team processes not influenced by subjective interpretations (Barbour, 2007). However, all actors may have been unaware of specific leadership distributions, roles or team learning processes, or may have failed to recall specific processes. Therefore, it would be interesting if future research were to combine self-reports with observations and to gather data at multiple points in time during educational innovations.

\subsubsection{Practical implications}

Although it is generally assumed that distributed leadership can help teams during educational innovations, such as VET teacher teams' implementation of CBE, distributed leadership needs to have the opportunity to emerge in schools. Team leaders play an important role in delegating influence so that distributed leadership can emerge in teacher teams. Distributed leadership can then be shaped within teams through team members' engagement in team learning. For instance, by sharing information with each other, teachers can prove that they are experienced and claim leader roles. In this way, informal leaders can emerge and co-exist within the team, and together develop and implement new materials. However, team members need to be 
aware that team leaders will place constraints on distributed leadership. Team leaders will determine the scope of distributed leadership and continue to exercise influence themselves. Given the dynamic character of distributed leadership, it is important that team leaders and informal teacher leaders together explore how both forms of influence can reinforce each other within schools. 


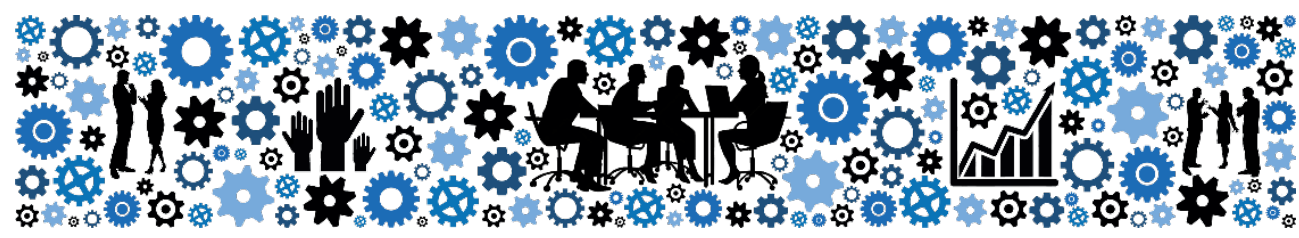

Chapter 6

General conclusion and discussion 


\subsection{Introduction}

The goal of this dissertation was to examine to what extent and how VET colleges offer an organisational context that fosters teachers' engagement in team learning. The relationships between three organisational characteristics - team-oriented HRM, team leaders' leadership style, and opportunities for distributed leadership - and teachers' engagement in team learning were examined in the preceding chapters.

Chapter 2 examined to what extent team-oriented HR practices are positively related to teachers' engagement in team learning and their team's performance. Chapter 3 focused on exploring how differences in team leaders' enactment of teamoriented HRM leads to differences in teachers' engagement in team learning. In Chapter 4, the association between a team leader's transformational leadership style and teachers' engagement in team learning was examined by assessing underlying mechanisms. Chapter 5 examined how team leaders create opportunities and boundaries for distributed leadership and the role that team learning plays in establishing informal leader-follower relationships in teacher teams.

Based on the insights provided by these chapters, the central research question of this dissertation is answered in this final chapter:

To what extent and how does the organisational context, in terms of team-oriented HRM, team leaders' leadership style, and opportunities for distributed leadership, stimulate teachers' engagement in team learning?

In this chapter, the main conclusions are first presented (Section 6.2). These conclusions are followed by a discussion of the theoretical contributions and implications for future research (Section 6.3), the methodological strengths and limitations (Section 6.4), and the practical implications of this dissertation (Section 6.5). This chapter concludes with take-home messages for scholars and VET colleges (Section 6.6).

\subsection{Main conclusions}

This dissertation shows that the organisational context in which VET teacher teams are embedded seems to play an important role in stimulating teachers' engagement in team learning. By focusing on the organisational context as a stimulus for engagement in team learning, this dissertation forms a significant contribution to existing knowledge on team learning, because previous research has tended to focus primarily on teamlevel antecedents and has largely overlooked the organisational context.

The preceding chapters show that the presence of team-oriented HRM, team leaders' enactment of team-oriented HRM, team leaders' transformational leadership style and team leaders' provision of opportunities for distributed leadership all seem to stimulate engagement in team learning. These findings imply that engagement in team 
learning is not only the responsibility of teachers, but also of VET colleges and team leaders. By creating a supportive environment that aims to stimulate teachers to feel and act as part of a real team, and by facilitating intensive collaboration, VET colleges and their team leaders can therefore play a crucial role in increasing teachers' engagement in team learning. To what extent and how VET colleges and team leaders can do this is discussed in more detail below, based on the central findings of the preceding chapters.

\subsubsection{A symbiotic relationship between team-oriented HRM and team leaders' behaviour}

The first central finding that needs to be highlighted is the symbiotic relationship between team-oriented HRM and team leaders' behaviour in stimulating teachers' engagement in team learning. This symbiotic relationship implies that team leaders need supportive team-oriented HR practices to stimulate and motivate their teachers to engage in team learning, but also that they influence the effectiveness of these HR practices through their own behaviour. So, although Chapter 2 shows the extent to which there is a positive relationship between team-oriented HRM and teachers' engagement in team learning, Chapter 3 shows how team-oriented HRM seems to affect teachers' engagement: the crucial link being team leaders' enactment of team-oriented HRM. The findings reported in Chapter 3 show that team leaders who adapt their enactment of team-oriented HRM to their team's needs, tasks and challenges seem to be more effective in stimulating engagement in team learning than team leaders who do not take their team's needs, tasks and challenges into account. This implies that the extent to which team-oriented HRM is effective in stimulating team learning can vary within one VET college, because team leaders can differ in their enactment.

Although this idea of a symbiotic relationship is central to research in private sector organisations (Purcell \& Hutchinson, 2007), it is notable that this idea also seems to apply to the VET context of this dissertation. For public sector organisations, such as VET colleges, it is often argued that line managers (i.e. team leaders) have limited discretionary room to implement $\mathrm{HR}$ practices as they see fit, because the implementation is to a large extent determined by government regulations and organisational demands (Knies \& Leisink, 2013). However, this is not true for the implementation of team-oriented HRM in VET colleges. As Chapter 3 shows, it is only for the enactment of the HR practice of recruitment that team leaders have little discretionary room; they have plenty of discretionary room in their enactment of team development, team evaluation and teamwork facilitation. It is therefore important to take team leaders' behaviour during their enactment of HRM into account if we are to gain insight into how VET teachers' team learning can be effectively fostered through team-oriented HRM. 


\subsubsection{Leadership ambidexterity}

The second central finding is that team leaders' ambidextrous leadership style seems to be crucial for stimulating teachers' engagement in team learning. In the discussion section of Chapter 3, leadership ambidexterity is defined as a leader's ability to adapt his or her leadership style to the team's situation (Bucic et al., 2010). Positive relationships between team leaders' ambidextrous leadership style and teachers' engagement in team learning were found in Chapters 3 and 5. Both chapters show that team leaders who gradually change their leadership style from being more controlling and directive (i.e. a transactional leadership style) to being more stimulating and empowering (i.e. a transformational leadership style) seem to effectively stimulate engagement in team learning. For instance, in Chapter 5 team leaders explained that they gave incrementally increasing responsibilities to teachers when they believed that teachers were ready to take on these responsibilities. Consequently, these increased responsibilities led to more engagement in team learning.

These findings that point towards the need for an ambidextrous team leader confirm the studies of Bucic et al. (2010) and Koeslag-Kreunen et al. (2017), who found that characteristics of both a transformational and transactional leadership style can contribute to team learning. The findings are also aligned with the review study of Rosing et al. (2011), who argued that leaders need to switch between 'opening leader behaviours' (similar to transformational leadership) and 'closing leader behaviours' (similar to transactional leadership) during innovation tasks, for example designing, redesigning and implementing $\mathrm{CBE}$. This is because innovation tasks require both that leaders stimulate followers to explore through experimentation and to take risks, and that they stimulate followers to adhere to rules and avoid risk.

By pointing out the importance of ambidextrous leadership, the findings presented in Chapters 3 and 5 may seem inconsistent with the findings presented in Chapter 4, which specifically show that a transformational leadership style is positively related to teachers' engagement in team learning. However, the opposite is true, because transformational leadership is regarded as an extension of transactional leadership (Bass, 1999; Bucic et al., 2010). Chapter 4 therefore focuses on this extension, and shows how a transformational leadership style can foster engagement in team learning, by emphasising the crucial role of giving teachers the opportunity to participate in decision-making.

\subsubsection{Team empowerment and distributed leadership as catalysts}

The findings reported in Chapters 3, 4 and 5 give detailed insights into how teachers' engagement in team learning can be stimulated, by showing that - when team leaders empower teachers by delegating decision-making and granting increased responsibilities - this seems to result in more engagement in team learning. Therefore, 
the third central finding is that team empowerment and the creation of opportunities for distributed leadership can serve as a catalyst for team learning.

However, the relationship between team empowerment or opportunities for distributed leadership and team learning seems to be complex, because giving increased responsibilities does not automatically result in more engagement in team learning. Chapter 3 shows that, to foster engagement in team learning, team leaders need to stimulate, coach and monitor teachers to take their responsibilities, so that teachers know how and why they need to take responsibility. These findings therefore imply that it is not only important that team leaders give increased responsibilities to teachers, but that they also continue to exercise control by giving direction. Therefore, as is explained in Section 6.2.2, ambidextrous team leaders seem to be needed who show characteristics of a transactional and transformational leadership style, to ensure that empowerment and opportunities for distributed leadership act as catalysts for engagement in team learning.

How empowerment and opportunities for distributed leadership can act as catalysts for team learning is shown in Chapters 4 and 5. Chapter 4 shows that the opportunity to participate in decision-making seems to foster teachers' feelings of being part of a real team, as it is positively related to teachers' perceived task interdependency and affective team commitment. Consequently, teachers who feel more that they are part of a real team are more proactive in improving their team's performance and engage more in team learning, compared with teachers who feel less part of a real team. Chapter 5 shows that, when teachers are granted opportunities to establish leader-follower relationships in their team, they engage in team learning to establish informal leader and follower roles. Moreover, once these informal leader and follower roles have been established, teachers with informal leader roles stimulate other teachers' engagement in team learning because they feel responsible for the team's collective task. As such, Chapters 4 and 5 have in common that they show that, when teachers take additional responsibilities, this seems to stimulate teachers' engagement in team learning.

\subsubsection{A tailor-made approach to stimulating team learning}

Overall, this dissertation shows that there can be a positive relationship between the organisational context of VET colleges and teachers' engagement in team learning. This relationship has proved to be complex, as the central findings show that a symbiotic relationship between team-oriented HRM and team leaders' behaviour, an ambidextrous leadership style of team leaders, and empowerment of teachers - when adapted to the team's needs, tasks and challenges - all seem to foster teachers' engagement in team learning. A 'one-size-fits-all' approach to stimulating teachers' engagement in team learning therefore seems impossible: teacher teams have different needs and work on different tasks and challenges, and so require different supportive 
approaches. Therefore, it is concluded that VET colleges should adopt a tailor-made approach to stimulate teachers' engagement in team learning.

This tailor-made approach can be manifested through a flexible team-oriented HRM system. This implies that team leaders need to have the discretionary room to enact team-oriented HRM in ways that are aligned with their team's needs, tasks and challenges. For example, team leaders may need to be visibly directive and stimulating during teamwork facilitation in teams when teachers are not used to taking the initiative. The tailor-made approach can also be manifested in the ways in which team leaders empower their teacher teams. Although the literature usually connects empowerment with a transformational leadership style, characteristics of a transactional leadership style are possibly a prerequisite for successful team empowerment: teams that are new to participating in decision-making and exercising leadership tasks are likely to benefit from clear directions and deadlines set by their team leader so that they know why they are being given extra responsibilities and what is expected of them.

\subsection{Theoretical contributions and implications for future research}

The findings of this dissertation offer several theoretical contributions and implications for future research, as discussed below.

\subsubsection{Real teams and team learning}

The finding that engagement in team learning seems to be higher in VET teams in which teachers feel and act more as a real team means that simply combining teachers in formal teams is not enough to foster team learning. With this finding, this dissertation agrees with recent insights that not all formal teacher teams are real teams, and that social bonding, such as affective team commitment, and task interdependence seem crucial for team learning to occur (Vangrieken et al., 2016).

The central role of affective team commitment, which is here used interchangeably with collective team identification, has previously been shown in research on team learning outside the educational context (Edmondson et al., 2007; Van der Vegt \& Bunderson, 2005), but so far has only gained limited attention in the context of teacher teams. Because affective team commitment is a central indicator of the extent to which a teacher team is a real team, it is recommended that future research continues to include this variable in studies on teachers' team learning. Additionally, it is suggested that more team-oriented attitudes of teachers are included in future research, such as teachers' willingness to collaborate and their openness towards each other. When these variables are included, the mechanisms through which teachers feel connected to their team are further unravelled and their engagement in team learning can be explained further. 
Moreover, Chapter 4 shows that teachers who proactively try to improve their team's performance report higher engagement in team learning. Because team member proactivity has not been included as a possible antecedent of team learning in previous studies (Decuyper et al., 2010), it is regarded as a relatively new antecedent that deserves to be included in future research.

\subsubsection{Team-oriented HRM and team learning}

A significant contribution of this dissertation is the focus on team-oriented HRM as an organisational-level antecedent of team learning. With this focus, this dissertation contributes to bridging the gap between the team learning literature and HRM literature and offers new insights into HRM research in the educational context.

\section{Bridging the gap between team learning literature and HRM literature}

Chapters 2 and 3 show to what extent and how team-oriented HRM seems to affect teachers' engagement in team learning. These insights are new, because so far the team learning literature has not focused on HRM. Although previous team learning research has included the presence of knowledge management systems as possible organisational-level antecedents of team learning (Decuyper et al., 2010; Gibson \& Vermeulen, 2003; Zellmer-Bruhn \& Gibson, 2006), the facilitation of knowledge sharing is just one aspect of the HRM system. Here, a broader perspective is applied by focusing on multiple team-oriented HR practices. Moreover, this dissertation introduces team learning as a theoretical concept into the HRM literature, which until now has only focused on knowledge acquisition and sharing, as is previously discussed in Chapters 2 and 3 (Chuang et al., 2013; Jiang et al., 2013).

Given the potential of team-oriented HRM, it is recommended that future research continues to bridge the gap between the team learning literature and HRM literature. Both strands of research could learn from each other and build on each other's theory and research. For instance, because only the team learning process of information processing was included in Chapter 2, it would be interesting for future research to unravel information processing into the distinct processes of information sharing, co-construction and constructive conflict. This will make it possible to examine relationships between these more specific team learning processes and different teamoriented HR practices. These insights can help in further determining what aspects a team-oriented HRM system should consist of.

\section{HRM research in the educational context}

It is important to take multiple HR practices into account when examining HRM in the educational context, because Chapters 2 and 3 show that team-oriented HR practices in VET colleges differ in their relationship with team learning. It is therefore recommended that future research on HRM in the educational context continues to 
focus on multiple HR practices and HRM systems. So far, such a focus is often absent because contemporary research on HRM in the educational context tends to focus on single HR practices, such as professional development (DeArmond et al., 2010; Runhaar \& Sanders, 2016), which makes it impossible to compare the effectiveness of different HR practices. This recommendation is particularly relevant for research in the VET context, because VET colleges are increasingly investing in team development and implementing more comprehensive HRM systems, as was discussed in Chapter 1 (Runhaar \& Sanders, 2013).

When examining multiple HR practices and HRM systems in the educational context, it is recommended that distinct HR practices are not examined as a single bundle of practices, but as separate yet dependent practices that exist alongside each other, as was done in Chapters 2 and 3. This approach makes it possible to compare HR practices and determine their unique effects. Moreover, this approach is increasingly adopted in HRM research in other work contexts, because scholars are increasingly aware of the possible distinct effects of separate HR practices (Jiang et al., 2012).

Furthermore, because Chapter 3 shows a symbiotic relationship between team-oriented HRM and team leaders' behaviour, it is recommended to take the role of line managers (i.e. team leaders) into account when examining HRM in the educational context. As is discussed in Section 6.2.1, team leaders in VET colleges seem to have the discretionary room to enact team-oriented HRM and can differ in their enactment. It is therefore interesting to further examine the outcomes of possible differences in team leaders' enactment. While examining these differences, it is recommended to include team leaders' leadership styles, as was discussed in Chapter 3. This is needed because leadership styles are still largely overlooked in the HRM literature in general, but seem to influence the effectiveness of HRM (Vermeeren et al., 2014). Therefore, more research should be conducted on whether team leaders adapt their leadership style during their enactment of team-oriented HR practices to the needs, tasks and challenges of their team, and what the outcomes of this adaptation are with regard to team learning and team performance.

\subsubsection{Transformational leadership and teachers' engagement in team learning}

The findings of Chapter 4 show that team leaders' transformational leadership style is both directly and indirectly positively related to teachers' engagement in team learning processes. The finding of direct relationships in addition to indirect relationships in research models often implies that there are also other, unidentified, mediators at play that were not included in the analysis (Zhao, Lynch, \& Chen, 2010). It is therefore likely that more variables mediate between transformational leadership and teachers' engagement in team learning. A possible mediator in VET teacher teams that is not included in this dissertation is psychological safety, which has been shown to mediate the association between transformational leadership and team learning in nursery 
teams (Raes et al., 2013). Another variable that might mediate this relationship is group potency or group efficacy, which refers to the team's confidence in its own capacity (Decuyper et al., 2010). Group potency is shown to be positively associated with team learning (Van den Bossche et al., 2006; Vangrieken et al., 2016), and is likely to be affected by a transformational leadership style of team leaders, because these leaders act as mentors and provide support to teams, which could increase the team's confidence in itself. It is therefore recommended that the underlying mechanisms in the relationships between transformational leadership and team learning processes are further examined in upcoming studies.

Moreover, it is interesting to further examine the empowerment component of transformational leadership as this is a potential catalyst for team learning. It is recommended that future research examines during which tasks and challenges empowerment is fitting for teacher teams. Additionally, because Chapters 3 and 5 show that an incremental development towards team empowerment seems more successful than a relatively abrupt change towards empowerment, future research could examine in greater detail how such an incremental approach can be utilised by team leaders.

\subsubsection{Distributed leadership and team learning}

Chapter 5 suggests a reciprocal relationship between distributed leadership in VET teacher teams and engagement in team learning: team learning processes contribute to the establishment of informal leader-follower relationships, and teachers with informal leader roles stimulate other teachers' engagement in team learning. This finding is valuable for the team learning and distributed leadership literature. First, this indication of a reciprocal relationship supports the assumed circular relationship between team learning and its outcomes (Decuyper et al., 2010): team learning can lead to outcomes that can serve as input for engagement in new team learning processes. Second, the finding increases our understanding of the emergent nature of distributed leadership and the role that team learning plays in this. This insight is needed, because empirical research on distributed leadership remains limited (Tian et al., 2016), which implies that, so far, its emergent nature and antecedents and outcomes remain largely unexplored.

However, the insights into the reciprocal relationship provided in this dissertation are limited. For instance, it remains unclear whether the team learning processes initiated by informal leaders contribute to the emergence of new leaderfollower relationships that, in turn, foster new engagement team learning. Such a reciprocal relationship would indicate a gain spiral (Hobfoll, 1989). It is therefore recommended that future research examines the possible emergence of a gain spiral. 


\subsubsection{Team learning and team performance}

Chapter 2 shows that VET teachers' engagement in team learning is positively related to their performance. Although positive relationships between team learning and team performance have been shown in other work contexts (e.g. Leicher \& Mulder, 2016; Van Woerkom \& Croon, 2009; Widmann et al., 2016), the contribution of this dissertation lies in showing that this positive association also applies to the VET context.

Because team performance is measured in quite abstract terms, it is recommended that future research in the VET context examines the relationships between team learning and more concrete performance indicators of designing, redesigning and implementing CBE. Wijnia et al. (2016) recently did this, by showing that VET teachers' engagement in team learning is positively related to their CBE implementation. In their study, however, it remains unclear how team learning is related to different aspects of CBE implementation. CBE implementation for instance implies that learning activities take place in authentic situations, that the competencedevelopment of students is assessed before, during and after the learning process, and that core vocational problems are central to the design and redesign of curricula (Wesselink, 2010). Research that distinguishes between these aspects of CBE implementation and examines in-depth how team learning contributes to each of these aspects could provide more detailed insight into the relationship between VET teams' learning and specific team performance indicators.

Moreover, only the direct relationship between team learning and team performance was measured in this dissertation, while some authors have shown that team learning contributes to team performance indirectly, via the achievement of mutually shared cognitions (Van den Bossche, Gijselaers, Segers, Woltjer, \& Kirschner, 2011; Van den Bossche et al., 2006; Vangrieken et al., 2016). It is therefore recommended that future research on VET teacher teams also examines this indirect association by including concrete measures for mutually shared cognitions on different aspects of CBE.

\subsection{Methodological strengths and limitations}

It is considered a strength of this dissertation that a combination of quantitative and qualitative research designs was used to gain insights into fostering factors for VET teachers' engagement in team learning. The advantage of the quantitative research designs of Chapters 2 and 4 is that it is possible to examine to what extent organisational characteristics are related to teachers' engagement in team learning (both chapters) and team performance (only Chapter 2), and to obtain insights into how the organisational characteristics are related to engagement in team learning by examining underlying mechanisms. This was done by using large samples of teachers and teacher teams of VET colleges that were spread across the Netherlands, which allowed for multilevel analysis. Moreover, the advantage of the qualitative research designs of 
Chapters 3 and 5 is that they make it possible to explore in-depth how team leaders' enactment of team-oriented HRM (Chapter 3) and teachers' empowerment through the creation of opportunities for distributed leadership (Chapter 5) are related to teachers' engagement in team learning (both chapters) and teachers' establishment of informal leader-follower relationships (only Chapter 5). These qualitative studies were executed in multiple teams from one VET college per study. This approach allowed a specific focus on team leaders' enactment of team-oriented HRM and empowerment because other contextual characteristics, such as the intended team-oriented HRM strategy of a VET college, were constant factors for all participating teacher teams.

Nevertheless, the quantitative and qualitative research designs have some methodological limitations that need to be taken into account when interpreting the findings. Specific limitations per study, such as the disadvantages of specific research methods, are discussed in the limitations sections of the preceding chapters. This section therefore elaborates on four overarching limitations.

The first limitation concerns the absence of mixed method designs in each study. Although it is considered a strength that fostering factors for team learning were assessed quantitatively and qualitatively, combining these research methods in mixed method designs would have increased the strength of this dissertation further. For instance, interviews with teachers in the study of Chapter 2 could have provided indepth insights into why their perception of the presence of team-oriented HRM seems to increase their affective team commitment and engagement in information processing. Additionally, longitudinal quantitative data on the relationship between the establishment of distributed leadership and engagement in team learning could offer more insights into the possible reciprocal relationship between these concepts. Despite the possible advantages of mixed method designs, these designs seem to be relatively rare in research on team learning, HRM and leadership. Scholars are therefore advised to use mixed method designs in future research.

A second limitation that specifically applies to Chapters 2 and 4 is the use of quantitative data solely based on teachers' perceptions. Although teachers' perceptions will most likely directly influence their behaviours, these chapters would have benefited from the inclusion of team leaders' perceptions as well. This would make it possible to compare teachers' perceptions with team leaders' perceptions and calculate the agreement between these perceptions in each teacher team. It would then for instance be possible to examine whether more team learning occurs in teams in which there is more agreement between teachers and team leaders on the team leaders' leadership style. Both teachers' and team leaders' perceptions were included in the qualitative studies of Chapters 3 and 5, which made it possible to compare their perceptions and focus on their agreement. These comparisons led to interesting results, for example that there was misalignment in some teacher teams between how team leaders view their enactment of team-oriented HRM and how teachers perceive this 
enactment. This misalignment seemed to negatively affect teachers' team learning (Chapter 3). Therefore, it is recommended that future quantitative and qualitative research includes the perceptions of different types of actors, so that the complex relationships between fostering factors and teachers' team learning can be further explained.

A third limitation that is addressed in the previous chapters but needs to be elaborated on is the use of cross-sectional data in Chapters 2 and 4. Although the quantitative data for this dissertation were collected through a longitudinal research design that consisted of three waves of data collection, only one wave was used to assess the research models in each chapter: wave 2 data was used for the research model of Chapter 2 and wave 1 data was used for the research model of Chapter 4. Only one wave per research model was used because the longitudinal research design of the interlinked research project (see Text box 1.3 in Chapter 1) did not result in a suitable longitudinal dataset for the research goals of this dissertation. There was a one-year gap between the data collection for each wave in the longitudinal research design, and the total data collection was spread over three years. This design had two disadvantages in terms of creating a suitable longitudinal dataset. First, several teams stopped participating during this three-year period, either because of a heavy workload or because teams ceased to exist. Second, not all teachers participated in all three waves within the teams that participated in all the waves, for example due to staff turnover. Due to team and teacher dropout, only 360 of the 1,146 teachers who participated in wave 1 also participated in waves 2 and 3 (31\%). Consequently, the samples that remained for the longitudinal testing of the research models were too small, and only one wave per research model was used. A disadvantage of this cross-sectional approach is that it is impossible to determine causality between the variables (Field, 2013). So, although the conceptual models (Figures 2.1 and 4.1) and measurement models (Figures 2.2 and 4.2) suggest causal directions in the relationships between variables, the results should be interpreted with care. Furthermore, the cross-sectional designs prevent the study of possible circular relationships between team learning and its outcomes. To assess causality and circularity, improved longitudinal designs are needed in future research that are more resistant to team and teacher dropout, for instance by starting with very large samples and completing data collection within a shorter time period than the three-year period of the interlinked research project.

The fourth and final aspect that needs to be discussed is the use of non-random sampling in all chapters. For the qualitative research designs in Chapters 3 and 5, nonrandom purposive sampling was a strength and necessity because it allowed for the selection of cases (VET colleges and teacher teams within these colleges) that met relevant selection criteria (Kumar, 2011). In Chapter 3, for instance, purposive sampling enabled the selection of a VET college with a team-oriented HRM system where the implementation of this system was devolved to team leaders. This purposive 
sampling therefore increased the chance of finding meaningful results. However, for the quantitative research designs of Chapters 2 and 4, non-random convenience sampling was used rather than a random sampling strategy. A random sampling strategy would have given each VET teacher team in the Netherlands an equal chance of being included in the research, which would have increased the generalisability of the results and decreased sampling bias (Kumar, 2011). However, this was not possible as there was no dataset that included all VET teacher teams from which a random sample could be drawn. Instead, to increase generalisability and decrease sampling bias, much effort was put into the realisation of the convenience sample. All Dutch VET colleges were contacted and asked to provide contact details of their team leaders, and all the team leaders for whom contact details were obtained were requested to participate with their teams. Although this resulted in the participation of more than 100 teams in the interlinked research project, many team leaders were not reached or did not respond. Their teams therefore did not have the chance to participate.

\subsection{Practical implications}

As is explained in Chapter 1, given the central role of VET teacher teams in determining the quality of CBE programmes, it is important that VET colleges invest in the development of their teacher teams. Currently, VET colleges do this by investing in formal development trajectories for teams and team members (Association of VET Colleges, 2016a; MB015, 2015). This dissertation offers insights into how VET colleges can expand their investment in teams and team members, by stimulating teachers to feel and act as a real team and engage in team learning.

\subsubsection{Team-oriented HRM}

To increase teachers' involvement in their team and their engagement in team learning, it is recommended that VET colleges develop visible team-oriented HRM systems. It is important to send a consistent message through all team-oriented HR practices, so that teachers know what behaviours are expected and rewarded.

This implies that, in addition to team professionalisation through formal development trajectories, which is often part of VET colleges' HRM (Association of VET Colleges, 2016a; MB015, 2015), additional HR practices need to be implemented or further developed. First, when recruiting new team members, recruitment committees should more explicitly select candidates based on their motivation and ability to collaborate and interact with colleagues, in addition to expertise. This would allow teams to be created that consist of teachers who are team-oriented. Second, collaboration and engagement in team learning are emphasized as central parts of VET teachers' competence profile by the Association of VET Colleges (2015). It is therefore recommended that teachers' collaboration and engagement in team learning are structurally discussed during individual teacher evaluations to emphasize the 
importance of team involvement, and not only when problems have occurred. Additionally, during evaluations, not only individual teachers, but teams should also be structurally discussed. Team evaluation should not only focus on student numbers and evaluation reports, as often seems to be the case, but also on the team's collaboration and engagement in team learning. Only when collaboration and team learning are a structural part of evaluations will teachers understand what is expected of them. Third, teacher teams should be facilitated in time and space to work on educational innovations and projects, so that they can collectively develop ideas and solutions. Although the facilitation of team meetings is common, enough specific time should be reserved during these meetings or other meetings for collaboration on innovations and projects so that teachers feel the urgency to collaborate.

\subsubsection{Team leaders' enactment of team-oriented HRM}

Because line managers, or team leaders, play a crucial role in implementing a consistent and visible team-oriented HRM system, VET colleges should be aware that differences in this consistency and visibility can emerge between teacher teams as team leaders can differ in their enactment of HRM. It is therefore recommended that VET colleges take concrete steps to ensure that team leaders enact consistent and visible team-oriented HRM systems. To begin with, VET colleges should monitor and evaluate team leaders' enactment. Monitoring and evaluation not only provide insight into effective ways of enacting team-oriented HRM in teacher teams by team leaders, they also offer the opportunity to intervene in teams where the team leaders' enactment of team-oriented HRM is ineffective. Interventions might be needed, because VET team leaders are sometimes promoted teachers with no managerial background and experience in HRM enactment. Possible interventions are the deployment of coaches from the HR department to support team leaders in their HRM enactment, the establishment of peer coaching meetings in which team leaders can share and discuss their experiences in enacting HRM with each other, and the inclusion of HRM enactment in team leaders' professionalisation trajectories. Finally, as a means to emphasize the importance of team leaders' professionalisation regarding their HRM roles, HRM enactment should be included in existing or newly developed competence profiles of team leaders.

\subsubsection{Team leaders' empowerment and distributed leadership}

Although VET colleges increasingly acknowledge leadership as a crucial factor in activating and stimulating teachers and teams (Association of VET Colleges, 2016a), much remains unclear about what the role of leaders should encompass (MB015, 2015). This dissertation concludes that there is no blueprint for an effective leadership style. Instead, which leadership style is effective seems to depend on the team's needs, tasks and challenges. This implies that team leaders should be stimulated and supported to take their team's needs, tasks and challenges into account and adapt their 
leadership style to their estimation of their team's situation. The use of a competence profile for team leaders that, in addition to HRM enactment, emphasizes the need for ambidextrous leadership competencies may contribute to team leaders' professionalisation in this respect. Moreover, by learning from coaches or role models, and by participating in peer coaching meetings and professionalisation trajectories, team leaders can develop the necessary competencies to correctly assess the team's needs, tasks and challenges and to act accordingly. In peer coaching meetings, team leaders can for instance co-construct shared interpretations of team tasks and challenges during which empowerment seems an appropriate way of providing teachers with the professional space to act, and shared mental models can be developed on how to shape this empowerment.

Furthermore, given the findings of this dissertation, it is recommended that team leaders take an incremental approach when empowering teacher teams. Teachers need time to learn how to take on their new responsibilities and to establish informal leader-follower relationships in their team. The involvement of team leaders remains important during this time: they can monitor the progress and intervene when needed. For instance, team leaders can stimulate teachers' involvement in the team by giving them clear tasks and deadlines. In this way, it becomes clear to teachers that their team involvement is needed and they may start to act more as real teams. Consequently, more team learning may occur regarding their responsibilities, tasks and roles in the team (Zoethout, Wesselink, Runhaar, \& Mulder, 2017). Once teachers have proven themselves willing to and capable of taking on extra responsibilities and establishing leader and follower roles, team leaders can step back as visible leaders and devolve more responsibilities to the team.

\subsection{Take-home messages}

To conclude this dissertation, two take-home messages are formulated, one for scholars and one for VET colleges.

\section{Take-home message for scholars}

Scholars who are interested in teams and team learning research are advised to take the organisational context in which teams are embedded into consideration, because it seems to affect engagement in team learning. Although managers' leadership style is included in many studies on team learning, the organisation's HRM system, the symbiotic relationship between this HRM system and managers' behaviour, and opportunities for distributed leadership have so far been largely overlooked. Including these contextual characteristics in future research is essential for a further understanding of engagement in team learning. 
Take-home message for VET colleges

To increase teacher team performance, it seems important that teachers engage in team learning. Stimulating teachers' engagement in team learning is therefore crucial, and VET colleges have a responsibility in this. By investing in the implementation or further development of a flexible team-oriented HRM system and in the selection and development of highly competent team leaders, VET colleges can create environments that urge, stimulate and support teachers to feel and act more as a real team and to engage more in team learning. 


\section{References}

Alfes, K., Truss, C., Soane, E. C., Rees, C., \& Gatenby, M. (2013). The relationship between line manager behavior, perceived HRM practices, and individual performance: Examining the mediating role of engagement. Human Resource Management, 52(6), 839-859. doi: 10.1002/hrm.21512

Anderson, N. R., \& West, M. A. (1998). Measuring climate for work group innovation: Development and validation of the team climate inventory. Journal of Organizational Behavior, 19(3), 235-258. doi: 10.1002/(sici)10991379(199805)19:3<235::aid-job837>3.0.co;2-c

Appelbaum, E., Bailey, T., Berg, P., \& Kalleberg, A. L. (2001). Do high performance work systems pay off? In S. Vallas (Ed.), The transformation of work (Vol. 10, pp. 85107). Oxford: Elsevier Science.

Association of VET Colleges. (2009). Professioneel Statuut MBO [Professional Statute VET]. De Bilt: Association of VET Colleges.

Association of VET Colleges. (2015). Het kwalificatiedossier van de docent mbo [The qualification file of the VET teacher]. De Bilt: Association of VET Colleges.

Association of VET Colleges. (2016a). Agenda opleiding en professionalisering onderwijsgevenden in het mbo [Agenda for education and professionalization of teachers in VET]. Woerden: Association of VET Colleges.

Association of VET Colleges. (2016b). CAO MBO 2016-2017 [Collective labour agreement VET 2016-2017]. Woerden: Association of VET Colleges.

Association of VET Colleges. (2017). This is VET in the Netherlands. De Bilt: Association of VET Colleges. Retrieved from https://www.mboraad.nl/sites/default/files/170410-mbo-raad-vd-englishrgbscherm.pdf.

Avolio, B. J., \& Gibbons, T. C. (1988). Developing transformational leaders: A life span approach. In J. A. Conger \& R. N. Kanungo (Eds.), Charismatic leadership: The elusive factor in organizational effectiveness (pp. 276-308). San Francisco: Jossey-Bass Inc., Publishers.

Barber, M., \& Mourshed, M. (2007). How the world's best-performing schools come out on top. London: McKinsey \& Company.

Barbour, R. S. (2007). Doing focus groups. London: SAGE Publications Ltd.

Bass, B. M. (1997). Does the transactional-transformational leadership paradigm transcend organizational and national boundaries? American Psychologist, 52(2), 130-139. doi: 10.1037/0003-066x.52.2.130

Bass, B. M. (1999). Two decades of research and development in transformational leadership. European Journal of Work and Organizational Psychology, 8(1), 932. doi: 10.1080/135943299398410

Bass, B. M., Avolio, B. J., Jung, D. I., \& Berson, Y. (2003). Predicting unit performance by assessing transformational and transactional leadership. Journal of Applied Psychology, 88(2), 207-218. doi: 10.1037/0021-9010.88.2.207

Blau, P. M. (1964). Exchange and power in social life. New York: Wiley.

Bolden, R. (2011). Distributed leadership in organizations: A review of theory and research. International Journal of Management Reviews, 13(3), 251-269. doi: 10.1111/j.1468-2370.2011.00306.x 
Boselie, P., Dietz, G., \& Boon, C. (2005). Commonalities and contradictions in HRM and performance research. Human Resource Management Journal, 15(3), 67-94. doi: 10.1111/j.1748-8583.2005.tb00154.x

Bowen, D. E., \& Ostroff, C. (2004). Understanding HRM-firm performance linkages: The role of the "strength" of the HRM system. Academy of Management Review, 29(2), 203-221. doi: 10.2307/20159029

Braun, V., \& Clarke, V. (2006). Using thematic analysis in psychology. Qualitative Research in Psychology, 3(2), 77-101. doi: 10.1191/1478088706qp063oa

Bucic, T., Robinson, L., \& Ramburuth, P. (2010). Effects of leadership style on team learning. Journal of Workplace Learning, 22(4), 228-248. doi: $10.1108 / 13665621011040680$

Bush, T., \& Glover, D. (2012). Distributed leadership in action: Leading highperforming leadership teams in English schools. School Leadership \& Management, 32(1), 21-36. doi: 10.1080/13632434.2011.642354

Byrne, B. M. (2012). Structural equation modeling with Mplus. New York: Routledge.

Campion, M. A., Medsker, G. J., \& Higgs, A. C. (1993). Relations between work group characteristics and effectiveness: Implications for designing effective work groups. Personnel Psychology, 46(4), 823-847. doi: 10.1111/j.17446570.1993.tb01571.x

CBS. (2017). Leerlingen, deelnemers en studenten [pupils, participants and students]. Retrieved from http://statline.cbs.nl/Statweb/publication/?DM=SLNL\&PA=37220\&D1=7191\&D2=0\&D3=110-115\&HDR=G1,T\&STB=G2\&VW=T

Chan, D. (2009). So why ask me? Are self-reported data really that bad? In C. E. Lance \& R. J. Vandeberg (Eds.), Statistical and methodological myths and urban legends (pp. 309-336). London: Routledge.

Chatalalsingh, C., \& Reeves, S. (2014). Leading team learning: What makes interprofessional teams learn to work well? Journal of Interprofessional Care, 28(6), 513-518. doi: 10.3109/13561820.2014.900001

Chen, G., Kirkman, B. L., Kanfer, R., Allen, D., \& Rosen, B. (2007). A multilevel study of leadership, empowerment, and performance in teams. Journal of Applied Psychology, 92(2), 331-346. doi: 10.1037/0021-9010.92.2.331

Chuang, C. H., Jackson, S. E., \& Jiang, Y. (2013). Can knowledge-intensive teamwork be managed? Examining the roles of HRM systems, leadership, and tacit knowledge. Journal of Management, 42(2), 524-554. doi: $10.1177 / 0149206313478189$

Cohen, S. G., \& Bailey, D. E. (1997). What makes teams work: Group effectiveness research from the shop floor to the executive suite. Journal of Management, 23(3), 239-290. doi: 10.1016/S0149-2063(97)90034-9

Crawford, M. (2012). Solo and distributed leadership definitions and dilemmas. Educational Management Administration \& Leadership, 40(5), 610-620. doi: $10.1177 / 1741143212451175$

Crossan, M. M., Lane, H. W., \& White, R. E. (1999). An organizational learning framework: From intuition to institution. Academy of Management Review, 24(3), 522-537.

Day, D. V., Gronn, P., \& Salas, E. (2004). Leadership capacity in teams. The Leadership Quarterly, 15(6), 857-880. doi: 10.1016/j.leaqua.2004.09.001 
De Bruijn, E., Billett, S., \& Onstenk, J. (2017). Vocational education in the Netherlands. In E. De Bruijn, S. Billet, \& J. Onstenk (Eds.), Enhancing teaching and learning in the Dutch vocational education system: Reforms enacted. Cham: Springer.

De Dreu, C. K., \& West, M. A. (2001). Minority dissent and team innovation: The importance of participation in decision making. Journal of Applied Psychology, 86(6), 1191-1201. doi: 10.1037/0021-9010.86.6.1191

De Hoogh, A., Den Hartog, D., \& Koopman, P. (2004). De ontwikkeling van de CLIO: Een vragenlijst voor charismatisch leiderschap in organisaties [The development of CLIO: A questionnaire for charismatic leadership in organizations]. Gedrag en Organisatie, 17(5), 354-381.

DeArmond, M., Gross, B., \& Goldhaber, D. (2010). Is it better to be good or lucky? Decentralized teacher selection in 10 elementary schools. Educational Administration Quarterly, 46(3), 322-362. doi: 10.1177/0013161X10365824

Decuyper, S., Dochy, F., \& Van den Bossche, P. (2010). Grasping the dynamic complexity of team learning: An integrative model for effective team learning in organisations. Educational Research Review, 5(2), 111-133. doi: 10.1016/j.edurev.2010.02.002

DeRue, D. S., \& Ashford, S. J. (2010). Who will lead and who will follow? A social process of leadership identity construction in organizations. Academy of Management Review, 35(4), 627-647. doi: 10.5465/amr.2010.53503267

Devos, G., Buelens, M., \& Bouckenooghe, D. (2007). Contribution of content, context, and process to understanding openness to organizational change: Two experimental simulation studies. The Journal of Social Psychology, 147(6), 607-630. doi: 10.3200/SOCP.147.6.607-630

Dochy, F., Gijbels, D., Raes, E., \& Kyndt, E. (2014). Team learning in education and professional organisations. In S. Billett, C. Harteis, \& H. Gruber (Eds.), International handbook of research in professional and practice-based learning (pp. 987-1020). Dordrecht: Springer.

Drach-Zahavy, A., \& Somech, A. (2001). Understanding team innovation: The role of team processes and structures. Group Dynamics: Theory, Research, and Practice, 5(2), 111-123. doi: 10.1037//1089-2699.5.2.111

Edmondson, A. C. (1999). Psychological safety and learning behavior in work teams. Administrative Science Quarterly, 44(2), 350-383. doi: 10.2307/2666999

Edmondson, A. C. (2002). The local and variegated nature of learning in organizations: A group-level perspective. Organization Science, 13(2), 128-146. doi: 10.1287 /orsc. 13.2 .128 .530

Edmondson, A. C., Dillon, J. R., \& Roloff, K. S. (2007). Three perspectives on team learning: Outcome improvement, task mastery, and group process. The Academy of Management Annals, 1(1), 269-314. doi: 10.1080/078559811

Egodawatte, G., McDougall, D., \& Stoilescu, D. (2011). The effects of teacher collaboration in grade 9 applied mathematics. Educational Research for Policy and Practice, 10(3), 189-209. doi: 10.1007/s10671-011-9104-y

Ellinger, A. D. (2005). Contextual factors influencing informal learning in a workplace setting: The case of "reinventing itself company". Human Resource Development Quarterly, 16(3), 389-415.

Evers, A. T., Van der Heijden, B. I. J. M., Kreijns, K., \& Gerrichhauzen, J. T. G. (2011). Organisational factors and teachers' professional development in Dutch 
secondary schools. Journal of European Industrial Training, 35(1), 24-44. doi: 10.1108/03090591111095727

Field, A. (2013). Discovering statistics using IBM SPSS statistics (4th ed.). London: SAGE Publications Ltd.

Flinchbaugh, C., Li, P., Luth, M. T., \& Chadwick, C. (2016). Team-level high involvement work practices: Investigating the role of knowledge sharing and perspective taking. Human Resource Management Journal, 26(2), 134-150. doi: 10.1111/1748-8583.12098

Fuller, A., \& Unwin, L. (2004). Expansive learning environments. Integrating organizational and personal development. In H. Rainbird, A. Fuller, \& A. Munro (Eds.), Workplace learning in context (pp. 126-144). London: Routledge.

Fuller, A., \& Unwin, L. (2011). Workplace learning and the organization. In M. Malloch, L. Cairns, K. Evans, \& B. O'Conner (Eds.), The SAGE handbook of workplace learning (pp. 46-59). Los Angeles: Sage.

Gardner, T. M., Wright, P. M., \& Moynihan, L. M. (2011). The impact of motivation, empowerment, and skill-enhancing practices on aggregate voluntary turnover: The mediating effect of collective affective commitment. Personnel Psychology, 64(2), 315-350. doi: 10.1111/j.1744-6570.2011.01212.x

Geijsel, F. P., Sleegers, P., Stoel, R. D., \& Krüger, M. L. (2009). The effect of teacher psychological and school organizational and leadership factors on teachers' professional learning in Dutch schools. The Elementary School Journal, 109(4), 406-427. doi: 10.1086/593940

Geijsel, F. P., Sleegers, P., \& Van Den Berg, R. (1999). Transformational leadership and the implementation of large-scale innovation programs. Journal of Educational Administration, 37(4), 309-328. doi: 10.1108/09578239910285561

Gewirtz, S., \& Ball, S. (2000). From 'Welfarism' to 'New Managerialism': Shifting discourses of school headship in the education marketplace. Discourse: Studies in the Cultural Politics of Education, 21(3), 253-268. doi: $10.1080 / 713661162$

Gibbs, G. (2007). Analyzing qualitative data. London: SAGE Publications Ltd.

Gibson, C., \& Vermeulen, F. (2003). A healthy divide: Subgroups as a stimulus for team learning behavior. Administrative Science Quarterly, 48(2), 202-239.

Griffin, M. A., Neal, A., \& Parker, S. K. (2007). A new model of work role performance: Positive behavior in uncertain and interdependent contexts. Academy of Management Journal, 50(2), 327-347. doi: 10.5465/amj.2007.24634438

Gronn, P. (2002). Distributed leadership as a unit of analysis. The Leadership Quarterly, 13(4), 423-451. doi: 10.1016/s1048-9843(02)00120-0

Gronn, P. (2009). Leadership configurations. Leadership, 5(3), 381-394. doi: $10.1177 / 1742715009337770$

Gunter, H., Hall, D., \& Bragg, J. (2013). Distributed leadership a study in knowledge production. Educational Management Administration \& Leadership, 1-26. doi: $10.1177 / 1741143213488586$

Gustafson, K. L., \& Branch, R. M. (2006). What is instructional design? In R. A. Reiser \& J. V. Dempsey (Eds.), Trends and issues in instructional design and technology. Upper Saddle River, New Jersey: Merrill Prentice Hall. 
Hailey, V. H., Farndale, E., \& Truss, C. (2005). The HR department's role in organisational performance. Human Resource Management Journal, 15(3), 4966. doi: 10.1111/j.1748-8583.2005.tb00153.x

Hairon, S., \& Goh, J. W. (2015). Pursuing the elusive construct of distributed leadership: Is the search over? Educational Management Administration \& Leadership, 43(5), 693-718. doi: 10.1177/1741143214535745

Hallinger, P., \& Heck, R. H. (2010). Collaborative leadership and school improvement: Understanding the impact on school capacity and student learning. School Leadership \& Management, 30(2), 95-110. doi: 10.1080/13632431003663214

Handelzalts, A. (2009). Collaborative curriculum development in teacher design teams. Doctoral thesis. University of Twente, Enschede.

Harris, A. (2008). Distributed leadership: Developing tomorrow's leaders. London: Routledge.

Harris, A. (2009). Distributed leadership: What we know. In A. Harris (Ed.), Distributed leadership: Different perspectives (pp. 11-21). London: Springer.

Harris, A., \& DeFlaminis, J. (2016). Distributed leadership in practice: Evidence, misconceptions and possibilities. Management in Education, 1-6. doi: $10.1177 / 0892020616656734$

Harris, A., \& Spillane, J. (2008). Distributed leadership through the looking glass. Management in Education, 22(1), 31-34. doi: 10.1177/0892020607085623

Hatcher, R. (2005). The distribution of leadership and power in schools. British Journal of Sociology of Education, 26(2), 253-267. doi: $10.1080 / 0142569042000294200$

Hobfoll, S. E. (1989). Conservation of resources: A new attempt at conceptualizing stress. American Psychologist, 44(3), 513. doi: 10.1037/0003-066x.44.3.513

Hood, C. (1995). The "new public management" in the 1980s: Variations on a theme. Accounting, Organizations and Society, 20(2), 93-109. doi: 10.1016/03613682(93)e0001-w

Hox, J. (2010). Multilevel analysis: Techniques and applications (Second ed.). New York: Routledge.

Hu, L. t., \& Bentler, P. M. (1999). Cutoff criteria for fit indexes in covariance structure analysis: Conventional criteria versus new alternatives. Structural Equation Modeling: A Multidisciplinary Journal, 6(1), 1-55. doi: 10.1080/10705519909540118

Hülsheger, U. R., Anderson, N., \& Salgado, J. F. (2009). Team-level predictors of innovation at work: A comprehensive meta-analysis spanning three decades of research. Journal of Applied Psychology, 94(5), 1128. doi: 10.1037/a0015978

Jackson, S. E., Chuang, C.-H., Harden, E. E., \& Jiang, Y. (2006). Toward developing human resource management systems for knowledge-intensive teamwork. Research in Personnel and Human Resources Management, 25, 27-70. doi: 10.1016/S0742-7301(06)25002-3

Jak, S., \& Evers, A. (2010). Onderzoeksnotitie: Een vernieuwd meetinstrument voor organizational commitment [Research note: A renewed instrument for organizational commitment]. Gedrag en Organisatie, 23(2), 158-171.

Janssen, T. (2016). HRM en prestaties in het primair onderwijs [HRM and performance in primary education]. Doctoral thesis. Rotterdam: Erasmus University Rotterdam. 
Jiang, K., Lepak, D., Hu, J., \& Baer, J. (2012). How does human resource management influence organizational outcomes? A meta-analytic investigation of mediating mechanisms. Academy of Management Journal, 55(6), 1264-1294. doi: 10.5465/amj.2011.0088

Jiang, K., Takeuchi, R., \& Lepak, D. P. (2013). Where do we go from here? New perspectives on the black box in strategic human resource management research. Journal of Management Studies, 50(8), 1448-1480. doi: $10.1111 /$ joms.12057

Johns, G. (2001). In praise of context. Journal of Organizational Behavior, 22(1), 31-42. doi: $10.1002 /$ job.80

Judge, T. A., \& Piccolo, R. F. (2004). Transformational and transactional leadership: A meta-analytic test of their relative validity. Journal of Applied Psychology, 89(5), 755-768. doi: 10.1037/0021-9010.89.5.755

Kaše, R., Paauwe, J., \& Zupan, N. (2009). HR practices, interpersonal relations, and intrafirm knowledge transfer in knowledge-intensive firms: A social network perspective. Human Resource Management, 48(4), 615-639. doi: 10.1002/hrm.20301

Kasl, E., Marsick, V. J., \& Dechant, K. (1997). Teams as learners: A research-based model of team learning. The Journal of Applied Behavioral Science, 33(2), $227-$ 246. doi: $10.1177 / 0021886397332010$

Katz, D., \& Kahn, R. L. (1978). The social psychology of organizations (Second ed.). New York: Wiley.

Kehoe, R. R., \& Wright, P. M. (2013). The impact of high-performance human resource practices on employees' attitudes and behaviors. Journal of Management, 39(2), 366-391. doi: 10.1177/0149206310365901

Kirkman, B. L., \& Rosen, B. (1999). Beyond self-management: Antecedents and consequences of team empowerment. Academy of Management Journal, 42(1), 58-74. doi: $10.2307 / 256874$

Knapp, R. (2010). Collective (team) learning process models: A conceptual review. Human Resource Development Review, 9(3), 285-299. doi: $10.1177 / 1534484310371449$

Knies, E., Boselie, P., Gould-Williams, J., \& Vandenabeele, W. (2014). Special issue of International Journal of Human Resource Management: Strategic human resource management and public sector performance. The International Journal of Human Resource Management, 26(3), 421-424. doi: 10.1080/09585192.2014.980127

Knies, E., \& Leisink, P. (2013). Leadership behavior in public organizations: A study of supervisory support by police and medical center middle managers. Review of Public Personnel Administration, 34(2), 108-127. doi: 10.1177/0734371X13510851

Koeslag-Kreunen, M. G., Van der Klink, M. R., Van den Bossche, P., \& Gijselaers, W. H. (2017). Leadership for team learning: The case of university teacher teams. Higher Education, 1-17. doi: 10.1007/s10734-017-0126-0

Kostopoulos, K. C., Spanos, Y. E., \& Prastacos, G. P. (2013). Structure and function of team learning emergence: A multilevel empirical validation. Journal of Management, 39(6), 1430-1461. doi: 10.1177/0149206311419366

Kumar, R. (2011). Research methodology: A step-by-step guide for beginners. London: SAGE Publications Ltd. 
LeBreton, J. M., \& Senter, J. L. (2007). Answers to 20 questions about interrater reliability and interrater agreement. Organizational Research Methods, 11(4), 815-852. doi: $10.1177 / 1094428106296642$

Leicher, V., \& Mulder, R. H. (2016). Team learning, team performance and safe team climate in elder care nursing. Team Performance Management: An International Journal, 22. doi: 10.1108/TPM-04-2016-0017

Leithwood, K., Day, C., Sammons, P., Harris, A., \& Hopkins, D. (2006). Successful school leadership: What it is and how it influences pupil learning. Nottingham: DfES Publications.

Leithwood, K., \& Jantzi, D. (2005). A review of transformational school leadership research 1996-2005. Leadership and Policy in Schools, 4(3), 177-199. doi: $10.1080 / 15700760500244769$

Leithwood, K., \& Jantzi, D. (2006). Transformational school leadership for large-scale reform: Effects on students, teachers, and their classroom practices. School Effectiveness and School Improvement, 17(2), 201-227. doi: 10.1080/09243450600565829

Leithwood, K., Steinbach, R., \& Ryan, S. (1997). Leadership and team learning in secondary schools. School Leadership \& Management, 17(3), 303-326. doi: $10.1080 / 13632439769863$

Liden, R. C., Wayne, S. J., \& Bradway, L. K. (1997). Task interdependence as a moderator of the relation between group control and performance. Human Relations, 50(2), 169-181. doi: 10.1177/001872679705000204

Liu, S., Hu, J., Li, Y., Wang, Z., \& Lin, X. (2014). Examining the cross-level relationship between shared leadership and learning in teams: Evidence from China. The Leadership Quarterly, 25(2), 282-295. doi: 10.1016/j.leaqua.2013.08.006

Lodders, N. (2013). Teacher learning and innovating together: Exploring collective learning and its relationship to individual learning, transformational leadership and team performance in higher vocational education. Doctoral thesis. Enschede: University of Twente.

Loureiro, A., \& Caria, T. H. (2013). To learn and to construct knowledge in the context of work with adult education: A Portuguese case study. International Journal of Lifelong Education, 32(2), 149-164. doi: 10.1080/02601370.2012.733971

Lubberman, J., Van Rens, C., Hovius, M., \& Wester, M. (2013). Vraag en aanbod van mbo-personeel: Een onderzoek naar beschikbaarheid van informatie [Supply and demand of VET personnel: A study on availability of information]. Nijmegen: ITS, Radboud Universiteit Nijmegen.

Lumby, J. (2013). Distributed leadership: The uses and abuses of power. Educational Management Administration \& Leadership, 41(5), 581-597. doi: $10.1177 / 1741143213489288$

MacBeath, J. (2005). Leadership as distributed: A matter of practice. School Leadership \& Management, 25(4), 349-366. doi: 10.1080/13634230500197165

MB015. (2015). Focus op vakmanschap in bedrijf [Focus on craftmanship in action]. Ede: MB015.

McGovern, P., Gratton, L., Hope-Hailey, V., Stiles, P., \& Truss, C. (1997). Human resource management on the line? Human Resource Management Journal, 7(4), 12-29. doi: 10.1111/j.1748-8583.1997.tb00286.x

Messersmith, J. G., Patel, P. C., Lepak, D. P., \& Gould-Williams, J. S. (2011). Unlocking the black box: Exploring the link between high-performance work systems 
and performance. Journal of Applied Psychology, 96(6), 1105-1118. doi: $10.1037 / \mathrm{a} 0024710$

Ministry of Education. (2011). Actieplan MBO focus op vakmanschap 2011-2015 [Action plan VET 'Focus on craftsmanship 2011-2015]. Den Haag: Retrieved from http://www.rijksoverheid.nl/documenten-enpublicaties/kamerstukken/2011/02/16/actieplan-mbo-focus-opvakmanschap-2011-2015.html.

Ministry of Education. (2017). Stromen in het Nederlandse onderwijs [student flows in Dutch education]. Retrieved from https://www.onderwijsincijfers.nl/kengetallen/sectoroverstijgend/nederlan ds-onderwijsstelsel/stromen-in-het-nederlandse-onderwijs

Moolenaar, N. M., Daly, A. J., \& Sleegers, P. J. (2010). Occupying the principal position: Examining relationships between transformational leadership, social network position, and schools' innovative climate. Educational Administration Quarterly, 46(5), 623-670. doi: 10.1177/0013161X10378689

Mulder, M. (2017). Competence theory and research: A synthesis. In M. Mulder (Ed.), Competence-based vocational and professional education. Bridging the worlds of work and education (pp. 1071-1106). Dordrecht/Singapore: Springer.

Mulder, M., Weigel, T., \& Collins, K. (2007). The concept of competence in the development of vocational education and training in selected EU member states: A critical analysis. Journal of Vocational Education \& Training, 59(1), 67-88. doi: 10.1080/13636820601145630

Mulder, M., \& Winterton, J. (2017). Introduction. In M. Mulder (Ed.), Competence-based vocational and professional education. Bridging the worlds of work and education (pp. 1-43). Dordrecht/Singapore: Springer.

Mulford, B., \& Silins, H. (2003). Leadership for organisational learning and improved student outcomes: What do we know? Cambridge Journal of Education, 33(2), 175-195. doi: 10.1080/03057640302041

Muthén, L. K., \& Muthén, B. O. (1998-2012). Mplus User's Guide (Seventh ed.). Los Angeles: Muthén \& Muthén.

Nehles, A. C., van Riemsdijk, M., Kok, I., \& Looise, J. K. (2006). Implementing human resource management successfully: A first-line management challenge. Management revue, 17(3), 256-273. doi: http://www.jstor.org/stable/41783521

Nishii, L. H., Lepak, D. P., \& Schneider, B. (2008). Employee attributions of the "why" of HR practices: Their effects on employee attitudes and behaviors, and customer satisfaction. Personnel Psychology, 61(3), 503-545. doi: 10.1111/j.1744-6570.2008.00121.x

Nishii, L. H., \& Wright, P. M. (2008). Variability within organizations: implications for strategic human resource management. In D. B. Smith (Ed.), The people make the place: dynamic linkages between individuals and organizations (pp. 225248). Mahwah, NJ: Lawrence Erlbaum.

Oude Groote Beverborg, A., Sleegers, P. J. C., \& van Veen, K. (2015). Fostering teacher learning in VET colleges: Do leadership and teamwork matter? Teaching and Teacher Education, 48, 22-33. doi: 10.1016/j.tate.2015.01.015

Park, S., Henkin, A. B., \& Egley, R. (2005). Teacher team commitment, teamwork and trust: Exploring associations. Journal of Educational Administration, 43(5), 462-479. doi: 10.1108/09578230510615233 
Parker, S. K., \& Collins, C. G. (2010). Taking stock: Integrating and differentiating multiple proactive behaviors. Journal of Management, 36(3), 633-662. doi: $10.1177 / 0149206308321554$

Pearce, C. L. (2004). The future of leadership: Combining vertical and shared leadership to transform knowledge work. Academy of Management Executive, 18(1), 47-57. doi: 10.5465/AME.2004.12690298

Podsakoff, P. M., MacKenzie, S. B., Lee, J. Y., \& Podsakoff, N. P. (2003). Common method biases in behavioral research: A critical review of the literature and recommended remedies. Journal of applied psychology, 88(5), 879-903. doi: 10.1037/0021-9010.88.5.879

Podsakoff, P. M., MacKenzie, S. B., Moorman, R. H., \& Fetter, R. (1990). Transformational leader behaviors and their effects on followers' trust in leader, satisfaction, and organizational citizenship behaviors. The Leadership Quarterly, 1(2), 107-142. doi: 10.1016/1048-9843(90)90009-7

Preacher, K. J., Zyphur, M. J., \& Zhang, Z. (2010). A general multilevel SEM framework for assessing multilevel mediation. Psychological methods, 15(3), 209-233. doi: $10.1037 / a 0020141 . s u p p$

Purcell, J., \& Hutchinson, S. (2007). Front-line managers as agents in the HRMperformance causal chain: Theory, analysis and evidence. Human Resource Management Journal, 17(1), 3-20. doi: 10.1111/j.1748-8583.2007.00022.x

Raes, E., Decuyper, S., Lismont, B., Van den Bossche, P., Kyndt, E., Demeyere, S., \& Dochy, F. (2013). Facilitating team learning through transformational leadership. Instructional Science, 41(2), 287-305. doi: 10.1007/s11251-0129228-3

Raes, E., Decuyper, S., Van den Bossche, P., \& Dochy, F. (2015). An exploratory study of group development and team learning. Human resource development quarterly, 26, 5-30. doi: 10.1002/hrdq.21201

Rainey, H. G. (2014). Understanding and managing public organizations (5th ed.). San Francisco: Jossey-Bass.

Rosing, K., Frese, M., \& Bausch, A. (2011). Explaining the heterogeneity of the leadership-innovation relationship: Ambidextrous leadership. The Leadership Quarterly, 22(5), 956-974. doi: 10.1016/j.leaqua.2011.07.014

Runhaar, P. (2016). How can schools and teachers benefit from human resources management? Conceptualising HRM from content and process perspectives. Educational Management Administration \& Leadership, 45(4), 639-656. doi: $10.1177 / 1741143215623786$

Runhaar, P., Konermann, J., \& Sanders, K. (2013). Teachers' organizational citizenship behaviour: Considering the roles of their work engagement, autonomy and leader-member exchange. Teaching and Teacher Education, 30, 99-108. doi: 10.1016/j.tate.2012.10.008

Runhaar, P., \& Runhaar, H. (2012). HR policies and practices in vocational education and training institutions: Understanding the implementation gap through the lens of discourses. Human Resource Development International, 15(5), 609625. doi: 10.1080/13678868.2012.710108

Runhaar, P., \& Sanders, K. (2013). Implementing human resources management (HRM) within Dutch VET institutions: Examining the fostering and hindering factors. Journal of Vocational Education \& Training, 65(2), 236-255. doi: $10.1080 / 13636820.2013 .783612$ 
Runhaar, P., \& Sanders, K. (2016). Promoting teachers' knowledge sharing. The fostering roles of occupational self-efficacy and human resource management. Educational Management Administration \& Leadership, 44(5), 794-813. doi: $10.1177 / 1741143214564773$

Runhaar, P., Sanders, K., \& Konermann, J. (2013). Teachers' work engagement: Considering interaction with pupils and human resources practices as job resources. Journal of Applied Social Psychology, 43(10), 2017-2030. doi: 10.1111/jasp.12155

Runhaar, P., Sanders, K., \& Yang, H. (2010). Stimulating teachers' reflection and feedback asking: An interplay of self-efficacy, learning goal orientation, and transformational leadership. Teaching and Teacher Education, 26(5), 11541161. doi: 10.1016/j.tate.2010.02.011

Runhaar, P., Ten Brinke, D., Kuijpers, M., Wesselink, R., \& Mulder, M. (2014). Exploring the links between interdependence, team learning and a shared understanding among team members: The case of teachers facing an educational innovation. Human Resource Development International, 17(1), 67-87. doi: 10.1080/13678868.2013.856207

Sanders Jones, J. L., \& Linderman, K. (2014). Process management, innovation and efficiency performance: The moderating effect of competitive intensity. Business Process Management Journal, 20(2), 335-358. doi: 10.1108/BPMJ-032013-0026

Satorra, A., \& Bentler, P. M. (2001). A scaled difference chi-square test statistic for moment structure analysis. Psychometrika, 66(4), 507-514. doi: $10.1007 / \mathrm{bf02296192}$

Schaubroeck, J., Lam, S. S., \& Cha, S. E. (2007). Embracing transformational leadership: Team values and the impact of leader behavior on team performance. Journal of applied psychology, 92(4), 1020-1030. doi: 10.1037/0021-9010.92.4.1020

Scott-Ladd, B., Travaglione, A., \& Marshall, V. (2006). Causal inferences between participation in decision making, task attributes, work effort, rewards, job satisfaction and commitment. Leadership \& Organization Development Journal, 27(5), 399-414. doi: 10.1108/01437730610677990

Scribner, J. P., Sawyer, R. K., Watson, S. T., \& Myers, V. L. (2007). Teacher teams and distributed leadership: A study of group discourse and collaboration. Educational Administration Quarterly, 43(1), 67-100. doi: 10.1177/0013161X06293631

Seibert, S. E., Wang, G., \& Courtright, S. H. (2011). Antecedents and consequences of psychological and team empowerment in organizations: A meta-analytic review. Journal of applied psychology, 96(5), 981-1003. doi: 10.1037/00219010.92.2.331

Silins, H., \& Mulford, B. (2002). Schools as learning organisations: The case for system, teacher and student learning. Journal of Educational Administration, 40(5), 425-446. doi: 10.1108/09578230210440285

Somech, A., \& Ron, I. (2007). Promoting organizational citizenship behavior in schools: The impact of individual and organizational characteristics. Educational Administration Quarterly, 43(1), 38-66. doi: 10.1177/0013161X06291254

Spillane, J. (2005). Distributed leadership. The Educational Forum, 69(2), 143-150. doi: 10.1080/00131720508984678 
Szczesiul, S., \& Huizenga, J. (2014). The burden of leadership: Exploring the principal's role in teacher collaboration. Improving Schools, 17(2), 176-191. doi: $10.1177 / 1365480214534545$

Thoonen, E. E., Sleegers, P. J., Oort, F. J., Peetsma, T. T., \& Geijsel, F. P. (2011). How to improve teaching practices: The role of teacher motivation, organizational factors, and leadership practices. Educational Administration Quarterly, 47(3), 496-536. doi: 10.1177/0013161X11400185

Tian, M., Risku, M., \& Collin, K. (2016). A meta-analysis of distributed leadership from 2002 to 2013: Theory development, empirical evidence and future research focus. Educational Management Administration \& Leadership, 44, 146-164. doi: $10.1177 / 1741143214558576$

Tjosvold, D., Yu, Z., \& Hui, C. (2004). Team learning from mistakes: The contribution of cooperative goals and problem-solving. Journal of Management Studies, 41(7), 1223-1245. doi: 10.1111/j.1467-6486.2004.00473.x

Truijen, K. (2012). Teaming Teachers: Exploring factors that influence effective team functioning in a vocational edcation context. (Doctoral thesis), University of Twente, Enschede.

Tynjälä, P. (2008). Perspectives into learning at the workplace. Educational research review, 3(2), 130-154. doi: 10.1016/j.edurev.2007.12.001

Tynjälä, P. (2013). Toward a 3-P model of workplace learning: A literature review. Vocations and Learning, 6(1), 11-36. doi: 10.1007/s12186-012-9091-z

UWV. (2017). Veel vraag naar jongeren met een mbo-opleiding [There is a great demand for VET-graduates]. Retrieved 3 July, 2017, from https://www.uwv.nl/overuwv/pers/persberichten/2017/veel-vraag-naarjongeren-met-een-mbo-opleiding.aspx

Van den Bossche, P., Gijselaers, W., Segers, M., Woltjer, G., \& Kirschner, P. (2011). Team learning: building shared mental models. Instructional Science, 39(3), 283301. doi: $10.1007 / \mathrm{s} 11251-010-9128-3$

Van den Bossche, P., Gijselaers, W. H., Segers, M., \& Kirschner, P. A. (2006). Social and cognitive factors driving teamwork in collaborative learning environments: Team learning beliefs and behaviors. Small group research, 37(5), 490-521. doi: $10.1177 / 1046496406292938$

Van der Vegt, G. (2008). De relatie tussen expertise diversiteit en teaminnovativiteit: De modererende werking van taakafhankelijkheid en taakflexibiliteit [The relationship between expertise diversity and team innovativeness: The moderating effects of task interdependene and task flexibility]. Gedrag en Organisatie, 21(2), 170-183.

Van der Vegt, G., \& Bunderson, J. S. (2005). Learning and performance in multidisciplinary teams: The importance of collective team identification. Academy of management Journal, 48(3), 532-547. doi: 10.5465/AMJ.2005.17407918

Van Offenbeek, M. (2001). Processes and outcomes of team learning. European Journal of Work and Organizational Psychology, 10(3), 303-317. doi: 10.1080/13594320143000690

Van Woerkom, M., \& Croon, M. (2009). The relationships between team learning activities and team performance. Personnel Review, 38(5), 560-577. doi: 10.1108/00483480910978054 
Van Woerkom, M., \& Van Engen, M. L. (2009). Learning from conflicts? The relations between task and relationship conflicts, team learning and team performance. European Journal of Work and Organizational Psychology, 18(4), 381-404. doi: 10.1080/13594320802569514

Vanblaere, B., \& Devos, G. (2016). Relating school leadership to perceived professional learning community characteristics: A multilevel analysis. Teaching and Teacher Education, 57, 26-38. doi: 10.1016/j.tate.2016.03.003

Vangrieken, K., Dochy, F., \& Raes, E. (2016). Team learning in teacher teams: Team entitativity as a bridge between teams-in-theory and teams-in-practice. European Journal of Psychology of Education, 31(3), 275-298. doi: 10.1007/s10212-015-0279-0

Vangrieken, K., Dochy, F., Raes, E., \& Kyndt, E. (2015). Teacher collaboration: A systematic review. Educational research review, 15, 17-40. doi: 10.1016/j.edurev.2015.04.002

Vermeeren, B., Kuipers, B., \& Steijn, B. (2014). Does leadership style make a difference? Linking HRM, job satisfaction, and organizational performance. Review of Public Personnel Administration, 34(2), 174-195. doi: 10.1177/0734371X13510853

Viera, A. J., \& Garrett, J. M. (2005). Understanding interobserver agreement: The kappa statistic. Family Medicine, 37(5), 360-363.

Wang, D., Waldman, D. A., \& Zhang, Z. (2014). A meta-analysis of shared leadership and team effectiveness. Journal of applied psychology, 99(2), 181-198. doi: 10.5465/ambpp.2013.11215abstract

Wang, G., Oh, I., Courtright, S. H., \& Colbert, A. E. (2011). Transformational leadership and performance across criteria and levels: A meta-analytic review of 25 years of research. Group \& Organization Management, 36(2), 223-270. doi: $10.1177 / 1059601111401017$

Wesselink, R. (2010). Comprehensive competence-based vocational education: The development and use of a curriculum analysis and improvement model. (Doctoral thesis), Wageningen University, Wageningen.

Wesselink, R., de Jong, C., \& Biemans, H. J. (2010). Aspects of competence-based education as footholds to improve the connectivity between learning in school and in the workplace. Vocations and Learning, 3(1), 19-38. doi: 10.1007/s12186-009-9027-4

Widmann, A., Messmann, G., \& Mulder, R. H. (2016). The impact of team learning behaviors on team innovative work behavior: A systematic review. Human Resource Development Review, 15(4), 429-458. doi: $10.1177 / 1534484316673713$

Wijnia, L., Kunst, E., Van Woerkom, M., \& Poell, R. (2016). Team learning and its association with the implementation of competence-based education. Teaching and Teacher Education, 56, 115-126. doi: 10.1016/j.tate.2016.02.006

Wong, S. (2004). Distal and local group learning: Performance trade-offs and tensions. Organization Science, 15(6), 645-656. doi: 10.1287/orsc.1040.0080

Woods, P. A. (2016). Authority, power and distributed leadership. Management in Education, 30(4), 155-160. doi: 10.1177/0892020616665779

Woods, P. A., Bennett, N., Harvey, J. A., \& Wise, C. (2004). Variabilities and dualities in distributed leadership findings from a systematic literature review. 
Educational Management Administration \& Leadership, 32(4), 439-457. doi: $10.1177 / 1741143204046497$

Wright, P. M., \& Nishii, L. H. (2013). Strategic HRM and organizational behaviour: Integrating multiple levels of analysis. In J. Paauwe, D. E. Guest, \& P. M. Wright (Eds.), HRM \& performance: Achievements \& challenges. West Sussex: Wiley.

Zaccaro, S. J., Ely, K., \& Shuffler, M. (2008). The leader's role in group learning. In V. I. Sessa \& M. London (Eds.), Work group learning. Understanding, improving \& assessing how groups learn in organizations (pp. 193-214). New York: Lawrence Elbaum Associates.

Zait, A., \& Bertea, P. E. (2011). Methods for testing discriminant validity. Management \& Marketing Journal, 9(2), 217-224.

Zellmer-Bruhn, M., \& Gibson, C. (2006). Multinational organization context: Implications for team learning and performance. Academy of management Journal, 49(3), 501-518.

Zhao, X., Lynch, J. G., \& Chen, Q. (2010). Reconsidering Baron and Kenny: Myths and truths about mediation analysis. Journal of consumer research, 37(2), 197-206.

Zhu, W., Chew, I. K., \& Spangler, W. D. (2005). CEO transformational leadership and organizational outcomes: The mediating role of human-capital-enhancing human resource management. The Leadership Quarterly, 16(1), 39-52. doi: 10.1016/j.leaqua.2004.06.001

Zoethout, H., Wesselink, R., Runhaar, P., \& Mulder, M. (2017). Using transactivity to understand emergence of team learning. Small group research, 48(2), 190214. doi: $10.1177 / 1046496417691614$ 


\section{English summary}

\section{The necessity of VET teachers' engagement in team learning}

Secondary vocational education and training, here abbreviated as VET, has a central position in the Dutch education system. It is the second largest education sector and qualifies large numbers of students for many professions. To ensure the smooth transition of students to the labour market, VET colleges have implemented competence-based education (CBE) programmes, which are designed to develop relevant professional competencies.

VET colleges continuously work on the quality of their CBE programmes by designing and redesigning curricula and implementing new courses and qualification profiles, so that the CBE programmes continue to meet government and labour market demands. This challenging task is to a large extent the responsibility of teacher teams and requires intensive collaboration between teachers. Teachers for instance collectively need to integrate different courses into new interdisciplinary courses or revise existing courses.

Teachers' engagement in team learning processes is regarded as a crucial factor in accomplishing this challenging task. Team learning is defined as teachers' collective engagement in processes that contribute to building and maintaining mutually shared cognition, leading to increased team performance. This implies that, by engaging in team learning, teachers can achieve a mutually shared cognition on which aspects of their CBE programmes require improvements and on actions they need to take to achieve these improvements.

Team learning is however not always self-evident in teacher teams, because not all formal teacher teams can be characterised as real teams that consist of interdependent individuals who share responsibilities and see themselves and are seen by others as an intact social entity. This is because teachers traditionally have a high degree of autonomy, tend to retain their privacy and autonomy, are not used to frequent collaboration and interaction, and find it difficult to make time for interactions with colleagues.

\section{The focus of this dissertation: stimulating teachers' engagement in team learning} Because engagement in team learning is not always self-evident, this dissertation examines to what extent and how VET colleges can stimulate teachers' engagement in team learning. The focus lies on three organisational characteristics that may stimulate team learning: the presence of team-oriented human resource management (HRM), team leaders' leadership style, and available opportunities for distributed leadership. This focus on organisational characteristics is needed, because previous research on team learning has largely overlooked the possible influence of the organisation in which teams are embedded. 
The first characteristic, team-oriented HRM, refers to a set of HR practices that aim to increase teams' abilities, motivation and opportunities to perform in desired ways, such as engaging in team learning, with the goal to increase team performance. Regarding the second characteristic, team leaders' leadership style, this dissertation focuses on the empowerment component of transformational leadership as a possible stimulation for teachers' engagement in team learning. This empowerment component implies that team leaders try to increase teachers' participation in their team by giving them increased responsibilities and trying to move them beyond their self-interest. The third characteristic, opportunities for distributed leadership, implies that leadership tasks are distributed among those who are best equipped, skilled or positioned to lead in a certain situation, regardless of whether they are in formal leadership positions. Distributed leadership is believed to increase interdependence among team members, and may therefore stimulate engagement in team learning.

To examine the relationships between these three organisational characteristics and teachers' engagement in team learning, the following central research question was formulated:

To what extent and how does the organisational context, in terms of team-oriented HRM, team leaders' leadership style, and opportunities for distributed leadership, stimulate teachers' engagement in team learning?

\section{Central findings per chapter}

To answer the central research question, four studies were conducted. The results of these studies are presented in Chapters 2 to 5. Chapter 2 examines the extent to which there is a positive relationship between team-oriented HRM and teachers' team performance (operationalised as team efficiency and team innovation), via teachers' affective team commitment and engagement in team learning (operationalised here as information processing). Four team-oriented HR practices were examined: recruitment, team development, team evaluation and teamwork facilitation. The relationship was assessed using multilevel structural equation modelling (MSEM) with complex structure analysis, using data from 704 teachers working in 70 teams. It was found that recruitment, team evaluation and teamwork facilitation were positively related to team efficiency and innovation via teachers' affective team commitment and engagement in team learning. Apart from this indirect relationship, teamwork facilitation was also directly positively related to team performance. It is notable however that the HR practice of team development was only directly and positively associated with team innovation and not with team efficiency. Overall, these findings suggest that, when VET colleges implement team-oriented HRM to increase the teams' abilities, motivation and opportunity for teamwork and team learning, teachers feel 
more connected to the team and engage more in team learning, with increased team performance as a result.

Chapter 3 explores in greater depth how team leaders' individual enactment of the four team-oriented HR practices influence teachers' perceptions of these HR practices and their responses in terms of team learning. One Dutch VET college was selected in which a team-oriented HRM system was present and where the enactment was devolved to team leaders. Interviews with four team leaders and group interviews with eleven teachers of these four teams were conducted. Results show that, to effectively stimulate teachers' engagement in team learning, two things about team leaders' enactment seem important. First, there needs to be alignment between how team leaders enact team-oriented HRM and how teachers perceive their team leaders' enactment, which implies that teachers must interpret the team-oriented HR practices as intended by the team leader. Second, there needs to be a fit between team leaders' enactment and the team's needs, tasks and challenges, which implies that team leaders must adapt their enactment to the specific needs of a team and their team's situation. Team leaders who took this into account and adapted their behaviour to their team's tasks and challenges were for instance directive when their teams needed direction, and empowering when teachers were ready to take on responsibility for fulfilling their tasks. Consequently, their teachers engaged more in team learning than teachers of teams in which this fit and team leaders' adaptation were largely absent.

The goal of Chapter 4 was to examine to what extent a positive relationship exists between a team leader's transformational leadership style and teachers' engagement in team learning. Underlying mechanisms in this relationship were assessed by including the possible mediations of teachers' opportunities to participate in decision-making, their affective team commitment, perceived task interdependence, and team member proactivity. The relationships were assessed using MSEM with complex structure analysis, using data from 992 teachers working in 92 teams. The findings suggest that a transformational empowering leadership style of team leaders directly stimulates the team learning processes of information acquisition and information processing, as well as indirectly stimulating information acquisition, boundary crossing and information processing via the included underlying mechanisms. The mediating role of teachers' opportunity to participate in decisionmaking seems to be important here, because the findings suggest that it increases teachers' affective team commitment and perceived task interdependence. Consequently, more committed and interdependent teachers were more proactive in searching for solutions to improve their team's functioning, and therefore engaged more in all team learning processes.

Chapter 5 explores how team leaders create opportunities and constraints for distributed leadership in teacher design teams (TDTs), and how teachers use these opportunities to establish leader-follower relationships by engaging in team learning. 
One Dutch VET college was selected in which teachers who collaborated in TDTs were given opportunities for distributed leadership. Interviews and group interviews with three team leaders and thirteen members of five TDTs were conducted. The results show that team leaders incrementally gave increased responsibilities to TDT members. These TDT members engaged in team learning processes (information sharing and constructive conflict) to establish versatile leader-follower relationships in their TDTs, which changed in accordance with their different tasks. Moreover, teachers with informal leader roles initiated team learning (information processing) with the entire team to work on educational innovations together.

\section{Main conclusions}

Overall, the results that are presented in Chapters 2 to 5 suggest that the organisational context of VET colleges plays an important role in stimulating teachers' engagement in team learning. This implies that not only teachers, but also their VET colleges are responsible for teachers' engagement in team learning. By creating a supportive environment through team-oriented HRM, transformational leadership and opportunities for distributed leadership, teachers seem to feel and act more as part a real team, with higher engagement in team learning as a consequence.

Based on the findings of Chapters 2 to 5 , three central findings of this dissertation are discussed in Chapter 6. First, it is concluded that a symbiotic relationship exists between team-oriented HRM and team leaders' behaviour in stimulating teachers' engagement in team learning: team leaders need team-oriented HR practices to stimulate their teachers to engage in team learning, but at the same time influence the effectiveness of these HR practices through their enactment of these practices. Second, team leaders' ambidextrous leadership style is suggested to be crucial for stimulating teachers' engagement in team learning. This implies that both a transactional leadership style and transformational leadership style contribute to stimulating teachers' engagement in team learning, and that it depends on the team's needs, tasks and challenges which leadership style is needed. Third, team empowerment and opportunities for distributed leadership are concluded to be potential catalysts for engagement in team learning. Empowerment and distributed leadership only seem to be catalysts when teacher teams are ready to take their additional responsibilities and when teachers know why and how they need to take these responsibilities. Team leaders play an important role in meeting these conditions: they can stimulate, coach and monitor teachers in taking their responsibilities and incrementally increase their team's responsibilities.

Given these central findings, it is concluded that it is impossible for VET colleges to take a 'one-size-fits-all' approach to stimulate teachers' engagement in team learning, because teacher teams have different needs and operate in diverse situations that require different supportive approaches. Therefore, to stimulate teachers' 
engagement in team learning, VET colleges should adopt a tailor-made approach that is characterised by a flexible team-oriented HRM system, flexible leadership and team empowerment.

\section{Theoretical contributions and implications for future research}

Several theoretical contributions and implications for future research are discussed in Chapter 6. The contributions and implications that are related to the found relationships between team-oriented HRM, transformational leadership and distributed leadership on the one hand and engagement in team learning on the other hand are summarised here.

A significant contribution made by this dissertation is that the gap between team learning literature and HRM literature is bridged by providing insights into the relationship between team-oriented HRM and engagement in team learning and into the role that team leaders play in this relationship. Moreover, recommendations are given for future research on HRM in the educational context. Because research on HRM in the educational context is still relatively limited, it is suggested that insights from this dissertation and from HRM literature in other work contexts should be incorporated in future studies: multiple HR practices should be studied simultaneously and the role of line managers or team leaders should be taken into account to improve our understanding of the effectiveness of team-oriented HRM in the educational context.

Another contribution is that insights are provided into how team leaders' transactional leadership style may affect teachers' engagement in team learning by unravelling underlying mechanisms. Because the results suggest that unidentified underlying mechanisms may also be at play, it is recommended that future research aims to expose these mechanisms. In addition, it is recommended to examine more indepth how transformational leaders can incrementally empower teams to stimulate engagement in team learning.

The final contribution mentioned here is that this dissertation also bridges the gap between team learning literature and distributed leadership literature. The results regarding the relationship between distributed leadership and team learning suggest a reciprocal relationship and possibly a gain spiral. Future research is needed to obtain a better understanding of this reciprocity.

\section{Practical implications}

Because this dissertation suggests that VET colleges play a central role in stimulating teachers' engagement in team learning, it is recommended in Chapter 6 that these colleges should invest in the development of a supportive environment for teams. Four recommondations are given that may contribute to the development of this enviroment. First, it is suggested that VET colleges invest in the continued development of a consistent and visible team-oriented HRM system, so that teachers know that they are 
expected to act as part of a real team and to engage in team learning. Second, because line managers or team leaders play a crucial role in the implementation of a consistent and visible team-oriented HRM system, it is recommended that VET colleges monitor and evaluate team leaders' enactment of HR practices. Monitoring and evaulation enables VET colleges to gain insights into effective enactments and to intervene when enactments are ineffective. Inverventions could include the development of competence profiles of team leaders, the deployment of coaches for team leaders, the establishment of peer coaching meetings for team leaders, and the inclusion of HRM enactment in team leaders' professionalisation trajectories. Third, similar interventions are suggested for developing the necessary competencies of team leaders for correctly assessing their team's needs, tasks and challenges, and for adapting their leadership style in accordance with their assessment. Fourth, it is recommended that team leaders use an incremental approach to empower teacher teams, because teachers need time to learn why and how to take extra responsibilities and to establish leader-follower relationships. In this way, teachers are given the time to get accustomed to their extra responsibilities and to learn how to behave as informal leaders, with more engagement in team learning as a consequence. 


\section{Nederlandse samenvatting}

\section{De noodzaak van teamleren in mbo-docententeams}

Het middelbaar beroepsonderwijs (mbo) heeft een centrale positie binnen het

Nederlandse onderwijssysteem. Het is de op één na grootste onderwijssector en kwalificeert grote groepen studenten voor uiteenlopende beroepen. Om een soepele overgang van studenten naar de arbeidsmarkt te realiseren, investeren mbo-colleges in het ontwikkelen van relevante professionele competenties van studenten middels beroepsgericht onderwijs.

Mbo-colleges werken continu aan de kwaliteit van beroepsgericht onderwijs. Om ervoor te zorgen dat onderwijsprogramma's blijven aansluiten op eisen en wensen van de overheid en de arbeidsmarkt, worden curricula, vakken en kwalificatieprofielen voortdurend ontwikkeld en herzien. Deze uitdagende taak is grotendeels de verantwoordelijkheid van docententeams en vraagt om intensieve samenwerking tussen docenten. Docenten moeten bijvoorbeeld samen bestaande vakken integreren in nieuwe interdisciplinaire vakken of bestaande vakken herzien.

Om deze uitdagende taak te volbrengen, is het cruciaal dat docenten deelnemen aan teamleerprocessen. Teamleren wordt hier gedefinieerd als de collectieve deelname van docenten aan processen die bijdragen aan de ontwikkeling en het onderhouden van een wederzijds gedeelde cognitie, die leidt tot toenemende teamprestaties. Dit houdt in dat door middel van teamleren, docenten een wederzijds gedeelde cognitie, of consensus, kunnen bereiken over welke onderdelen van hun onderwijsprogramma verbeterd moeten worden en welke acties ze moeten ondernemen om deze verbeteringen te realiseren.

Het is echter niet vanzelfsprekend dat teamleren voorkomt in docententeams. Dit komt mede doordat niet alle formele docententeams te karakteriseren zijn als echte teams, die bestaan uit wederzijds afhankelijke teamleden, die verantwoordelijkheden delen, en zichzelf zien en door anderen worden gezien als een intacte sociale eenheid. Dat niet alle formele docententeams te karakteriseren zijn als echte teams, komt onder andere doordat docenten een hoge mate van autonomie hebben, hun privacy en autonomie willen behouden, niet gewend zijn om regelmatig samen te werken en te interacteren, en het moeilijk vinden om tijd vrij te maken voor interacties met collega's.

\section{De kern van deze dissertatie: het stimuleren van teamleren}

Omdat teamleren niet altijd vanzelfsprekend is, is in deze dissertatie onderzocht in welke mate en op welke wijze mbo-colleges het teamleren van docenten kunnen stimuleren. Hierbij staan drie organisatorische kenmerken centraal, die teamleren mogelijk stimuleren: de aanwezigheid van teamgericht human resource management (HRM), de leiderschapsstijl van teamleiders, en de mogelijkheden voor gespreid leiderschap. De focus op deze kenmerken is nodig, omdat eerder onderzoek naar 
teamleren de mogelijke invloed van de organisaties waarin teams zijn ingebed grotendeels over het hoofd heeft gezien.

Het eerste kenmerk, teamgericht HRM, verwijst naar alle HR-praktijken gericht op het vergroten van de bekwaamheid, motivatie en mogelijkheden van teams om gewenst gedrag te vertonen dat nodig is om teamprestaties te verhogen, zoals teamleren. Wat betreft het tweede kenmerk, de leiderschapsstijl van teamleiders, wordt in deze dissertatie gefocust op empowerment. Empowerment is een eigenschap van een transformationele leiderschapsstijl en kan mogelijk het teamleren van docenten stimuleren. Empowerment houdt in dat teamleiders teamparticipatie van docenten proberen te vergroten door hen meer verantwoordelijkheden te geven en hen verder te laten kijken dan hun eigenbelang. Het derde kenmerk, mogelijkheden voor gespreid leiderschap, houdt in dat leiderschapstaken zijn verdeeld over docenten die het beste uitgerust, bekwaam en gepositioneerd zijn om te leiden in een bepaalde situatie, ongeacht of ze een formele leiderschapspositie bekleden. Er wordt van uitgegaan dat gespreid leiderschap de interdependentie van teamleden vergroot, en daarom teamleren stimuleert.

Om de relatie tussen deze drie organisatorische kenmerken en teamleren van docenten te onderzoeken, is de volgende centrale onderzoeksvraag geformuleerd:

In welke mate en hoe stimuleert de organisatorische context, in termen van teamgericht $H R M$, de leiderschapsstijl van teamleiders en mogelijkheden voor gespreid leiderschap, het teamleren van docenten?

\section{Centrale bevindingen per hoofdstuk}

Om de centrale onderzoeksvraag te kunnen beantwoorden zijn vier studies uitgevoerd. De resultaten van die studies staan beschreven in hoofdstuk 2 tot en met 5 . In hoofdstuk 2 wordt onderzocht in welke mate er een positieve relatie bestaat tussen teamgericht HRM en prestaties van docententeams (teamefficiëntie en teaminnovatie), en of deze relatie wordt gemedieerd door de teambetrokkenheid en het teamleren van docenten (informatieverwerking). Vier teamgerichte HR-praktijken zijn onderzocht: werving en selectie, teamontwikkeling, teamevaluatie en de facilitering van samenwerking. De relaties zijn onderzocht onder 704 docenten, die werkzaam waren in 70 docententeams, door middel van multilevel structural equation modeling (MSEM) met een complex structure analysis. De resultaten tonen dat werving en selectie, teamevaluatie en de facilitering van samenwerking indirect positief gerelateerd waren aan teamefficiëntie en teaminnovatie, en dat deze relaties gemedieerd werden door teambetrokkenheid en informatieverwerking van docenten. Naast deze indirecte relaties was de facilitering van samenwerking ook direct gerelateerd aan teamprestaties. Het is opmerkelijk dat teamontwikkeling alleen direct en positief gerelateerd was aan teaminnovatie en niet aan teamefficiëntie. Over het algemeen 
impliceren deze resultaten dat wanneer mbo-colleges teamgericht HRM implementeren om de bekwaamheid, motivatie en mogelijkheden van teams voor samenwerking en teamleren te vergroten, docenten zich meer verbonden voelen met het team en meer aan teamleren doen, met verhoogde teamprestaties als gevolg.

In hoofdstuk 3 is verkend hoe de uitvoering van teamgericht HRM door teamleiders van invloed is op de percepties van docenten over teamgericht HRM en hun reactie in termen van teamleren. Voor het onderzoek is één mbo-college geselecteerd waar een teamgericht HRM-systeem aanwezig was en waar teamleiders verantwoordelijk waren voor de uitvoering van HRM. Er zijn interviews met vier teamleiders en groepsinterviews met elf docenten van deze vier teams afgenomen. De resultaten tonen aan dat twee aspecten van de uitvoering van teamgericht HRM door teamleiders belangrijk zijn voor het effectief stimuleren van teamleren. Ten eerste moet de uitvoering van teamgericht HRM door teamleiders op één lijn liggen met hoe docenten de uitvoering waarnemen. Met andere woorden, het is belangrijk dat docenten de teamgerichte HR-praktijken op een juiste manier interpreteren, zoals bedoeld door de teamleider. Ten tweede, de uitvoering van teamgericht HRM door teamleiders moet aansluiten bij de behoeften, taken en uitdagingen van docententeams. Dit houdt in dat teamleiders hun uitvoering dienen aan te passen aan de specifieke behoeften van een team en de teamsituatie. Teamleiders die rekening hielden met deze aansluiting en hun gedrag aanpasten aan de taken en uitdagingen van teams, waren bijvoorbeeld sturend wanneer hun docenten behoefte hadden aan sturing, en kenden docenten in toenemende mate verantwoordelijkheden toe, wanneer docenten er klaar voor waren om deze verantwoordelijkheden op zich te nemen. Als gevolg namen deze docenten meer deel aan teamleren dan docenten van teams waar deze aansluiting tussen het gedrag van teamleiders en de specifieke behoeften van een team en de teamsituatie grotendeels afwezig was.

Het doel van hoofdstuk 4 was om te onderzoeken in welke mate er een positieve relatie bestond tussen een transformationele leiderschapsstijl van teamleiders en het teamleren van docenten. Tevens zijn de mediërende effecten van de mogelijkheid voor docenten om deel te nemen aan besluitvorming, teambetrokkenheid, interdependentie tussen docenten en teamgerichte proactiviteit van docenten onderzocht. De relaties zijn onderzocht onder 992 docenten, die werkzaam waren in 92 docententeams, door middel van MSEM met een complex structure analysis. De resultaten impliceren dat een transformationele leiderschapsstijl die gekenmerkt wordt door empowerment direct de teamleerprocessen 'informatieverwerving' en 'informatieverwerking' beïnvloedt, en daarnaast ook indirect 'informatieverwerving', 'boundary crossing' en 'informatieverwerking' stimuleert via de onderzochte mediatoren. De mediërende rol van de mogelijkheid voor docenten om deel te nemen aan besluitvorming bleek belangrijk te zijn. De resultaten suggereren namelijk dat deze mogelijkheid de teambetrokkenheid en interdependentie van docenten verhoogt. Meer 
betrokken docenten en docenten die een hogere mate van interdependentie ervoeren, waren op hun beurt meer proactief in het zoeken naar verbeteringen voor het functioneren van hun team, en namen meer deel aan alle teamleerprocessen.

In hoofdstuk 5 is verkend hoe teamleiders mogelijkheden en beperkingen voor gespreid leiderschap vormgaven in docentontwikkelteams (DOTs), en hoe docenten gebruik maakten van deze mogelijkheden om leider-volger relaties vorm te geven middels teamleren. Voor het onderzoek is één mbo-college geselecteerd waarin docenten die samenwerkten in DOTs leiderschap konden spreiden. Er zijn interviews afgenomen met drie teamleiders en groepsinterviews met dertien leden van vijf DOTs. De resultaten tonen aan dat teamleiders geleidelijk meer verantwoordelijkheden toekenden aan leden van de DOTs. De leden van de DOTs namen deel aan de teamleerprocessen 'informatiedeling' en 'constructief conflict' om dynamische leidervolger relaties te vormen in hun DOTs. Deze relaties veranderden naarmate de taken van de DOTs veranderden. Docenten met een informele leidersrol initieerden daarnaast teamleren (informatieverwerking) in het gehele team om gezamenlijk aan onderwijsinnovaties te werken.

\section{Belangrijkste conclusies}

De resultaten van hoofdstuk 2 tot en met 5 laten zien dat de organisatorische context van mbo-colleges een belangrijke rol lijkt te spelen in het stimuleren van teamleren van docenten. Dit betekent dat niet alleen de docenten maar ook mbo-colleges verantwoordelijk zijn voor de deelname van docenten aan teamleerprocessen. Door een ondersteunende omgeving te creëren, die bestaat uit teamgericht HRM, transformationeel leiderschap en mogelijkheden voor gespreid leiderschap, voelen en gedragen docenten zich meer als een echt team, met een hogere deelname aan teamleerprocessen als gevolg.

Gebaseerd op de bevindingen van hoofdstuk 2 tot en met 5 worden drie centrale bevindingen bediscussieerd in hoofdstuk 6 . Ten eerste wordt in hoofdstuk 6 geconcludeerd dat er een symbiotische relatie bestaat tussen teamgericht HRM en het gedrag van teamleiders, als het gaat om het stimuleren van teamleren: teamleiders hebben teamgerichte HR-praktijken nodig om teamleren te stimuleren, maar beïnvloeden tegelijkertijd de effectiviteit van deze HR-praktijken door hun uitvoering van deze praktijken. Ten tweede wordt geconcludeerd dat een ambidextrous leiderschapsstijl (grofweg vertaald als een 'tweehandige' leiderschapsstijl) van teamleiders cruciaal is voor het stimuleren van teamleren van docenten. Dit betekent dat zowel een transactionele leiderschapsstijl en een transformationele leiderschapsstijl teamleren kunnen stimuleren, en dat een passende leiderschapsstijl afhangt van de behoeften, taken en uitdagingen van een team. Ten derde wordt geconcludeerd dat team empowerment en mogelijkheden voor gespreid leiderschap katalysators voor teamleren kunnen zijn. Empowerment en mogelijkheden voor 
gespreid leiderschap kunnen echter alleen omschreven worden als katalysators wanneer docententeams er klaar voor zijn om meer verantwoordelijkheden op zich te nemen en wanneer docenten weten waarom en hoe ze deze verantwoordelijkheden op zich moeten nemen. Er is een belangrijke rol voor teamleiders weggelegd in het bereiken van deze condities: zij kunnen docenten stimuleren, coachen en monitoren in het nemen van verantwoordelijkheden en geleidelijk het aantal verantwoordelijkheden van het docententeam laten toenemen.

Gezien deze centrale bevindingen, wordt in hoofdstuk 6 tot slot geconcludeerd dat er geen uniforme aanpak mogelijk is voor mbo-colleges om teamleren van docenten te stimuleren. Docententeams hebben verschillende behoeften en zijn in verschillende situaties werkzaam, die vragen om verschillende ondersteunende aanpakken. Om teamleren te stimuleren moeten mbo-colleges daarom maatwerk hanteren door middel van een flexibel teamgericht HRM-systeem, adaptief leiderschap en geleidelijke team empowerment.

\section{Theoretische bijdrage en suggesties voor vervolgonderzoek}

In hoofdstuk 6 worden diverse theoretische bijdrages en suggesties voor vervolgonderzoek bediscussieerd. De belangrijkste bijdrages en suggesties worden hier samengevat.

Een significante bijdrage van deze dissertatie is dat een brug wordt geslagen tussen literatuur over teamleren en literatuur over HRM door inzichten te bieden in de relatie tussen teamgericht HRM en teamleren, en in de rol die teamleiders hierin spelen. Er worden ook suggesties gedaan voor vervolgonderzoek naar HRM in de onderwijscontext. Omdat onderzoek naar HRM in de onderwijscontext nog relatief beperkt is, wordt gesuggereerd dat de inzichten uit deze dissertatie en literatuur over HRM in andere contexten gebruikt moeten worden in toekomstig onderzoek: meerdere HR-praktijken zouden gelijktijdig onderzocht moeten worden en er moet rekening gehouden worden met de rol van teamleiders om ons begrip van effectief teamgericht HRM in het onderwijs te vergroten.

Een andere bijdrage is dat nieuwe inzichten worden geboden in hoe een transformationele leiderschapsstijl van teamleiders het teamleren van docenten kan stimuleren, door onderliggende mechanismen te ontrafelen. Omdat de resultaten suggereren dat ook nog onontdekte mechanismen een rol kunnen spelen, wordt aangeraden dat toekomstig onderzoek zich richt op het identificeren van deze mechanismen. Daarnaast wordt aangeraden om meer diepgravend onderzoek te doen naar hoe transformationele leiders geleidelijk meer verantwoordelijkheden kunnen toekennen aan docenten, zodat teamleren gestimuleerd wordt.

De laatste bijdrage die hier gemeld wordt is dat deze dissertatie ook een brug slaat tussen literatuur over teamleren en literatuur over gespreid leiderschap. De resultaten suggereren een wederkerige relatie tussen gespreid leiderschap en 
teamleren, en mogelijk is er sprake van een gain spiral. Toekomstig onderzoek is nodig om meer inzichten te verkrijgen in deze wederkerigheid.

\section{Praktische implicaties}

Omdat de resultaten van deze dissertatie impliceren dat mbo-colleges een centrale rol spelen in het stimuleren van teamleren van docenten, wordt in hoofdstuk 6 aanbevolen dat deze colleges investeren in de ontwikkeling van stimulerende omgevingen voor teams. Er worden vier suggesties gedaan die kunnen bijdragen aan de ontwikkeling van zo'n omgeving. Ten eerste wordt aanbevolen dat mbo-colleges zouden moeten investeren in de verdere ontwikkeling van een consistent en zichtbaar teamgericht HRM-systeem, zodat docenten weten dat van hen verwacht wordt dat ze zich gedragen als lid van een echt team en aan teamleren deelnemen. Ten tweede, omdat teamleiders een cruciale rol spelen in de implementatie van een consistent en zichtbaar teamgericht HRM-systeem, wordt aangeraden dat mbo-colleges de uitvoering van HR-praktijken door teamleiders monitoren en evalueren. Monitoring en evaluaties helpen mbocolleges om inzichten te verkrijgen in effectieve vormen van uitvoering en om te interveniëren wanneer een uitvoering ineffectief is. Interventies die ingezet kunnen worden, zijn de ontwikkeling van een competentieprofiel van teamleiders, de inzet van coaches voor teamleiders, de oprichting van intervisie-bijeenkomsten waarin teamleiders ervaringen kunnen delen, en de inclusie van de uitvoering van HRM in professionaliseringstrajecten voor teamleiders. Ten derde, gelijksoortige interventies worden aanbevolen voor de ontwikkeling van competenties van teamleiders die nodig zijn voor het correct beoordelen van de behoeften, taken en uitdagingen van hun team, en voor het aanpassen van hun leiderschapsstijl op basis van hun beoordeling. Tot slot wordt teamleiders aangeraden om een geleidelijke aanpak te hanteren in hun empowerment van docententeams, omdat docenten tijd nodig hebben om te leren waarom en hoe ze extra verantwoordelijkheden moeten oppakken en om informele leider-volger relaties op te bouwen. Op deze manier hebben docenten de tijd om te wennen aan hun extra verantwoordelijkheden en rol als informele leider, met mogelijk meer teamleren als gevolg. 


\section{Dankwoord}

Ik heb de afgelopen jaren met plezier aan mijn promotieonderzoek gewerkt. Hoewel promoveren soms een solistische bezigheid is, heb ik gelukkig veel waardevolle steun en betrokkenheid van anderen ervaren. Ik wil dan ook iedereen die de afgelopen jaren betrokken is geweest bij mijn promotieonderzoek ontzettend bedanken, en een aantal van hen in het bijzonder.

Allereerst wil ik mijn co-promotoren, Piety en Renate, en mijn promotor, Martin, bedanken voor hun waardevolle begeleiding en prettige samenwerking. Piety en Renate, als co-promoteren vulden jullie elkaar goed aan. Piety als enthousiaste dagelijks begeleider, die altijd tijd vrij maakte om te brainstormen over alle aspecten van mijn studies en me naast mijn promotieonderzoek ook bij andere interessante projecten betrok. Renate als iemand met oog voor detail, die met een scherpe blik naar mijn ideeën keek en me vaak prikkelde met kritische vragen ('waarom zou een krant jou bellen over jouw onderzoek?'). Ik waardeer het enorm dat jullie snel feedback gaven op mijn stukken en dat ik altijd binnen kon lopen om mijn onderzoek te bespreken. Martin, de vrijheid en verantwoordelijkheid die je me hebt gegeven, hebben me uitgedaagd en droegen bij aan mijn groei als onderzoeker.

Naast het promotieteam wil ik ook de andere collega's van het onderzoeksproject over teamleren bedanken, met name Eva en Hildert. Ik heb onze intensieve en gezellige samenwerking erg gewaardeerd. Eva, analyses, terugkoppelingen, ideeën over studies, successen en frustraties; alles wat komt kijken bij een promotie hebben we uitvoerig met elkaar besproken. Onze vele en lange telefoongesprekken zouden genoeg data bieden voor een op zichzelf staand promotieonderzoek. Hildert, wat was het handig om een kamer te delen met iemand die heel goed wist waar ik mee bezig was. Onze een-tweetjes, soms kort, soms uitmondend in lange discussies, hebben me vaak verder geholpen in mijn onderzoek.

Ook wil ik alle collega's van ECS bedanken voor hun betrokkenheid en de goede sfeer, met name mijn collega's van 'the corner office'. Anahuac, your funny comments on the tasteless Dutch food and on our full agendas, and your jokes about my weird laptop problems ('typical Machiel problems', which sometimes even happened to you), contributed to the great atmosphere. Hildert (nogmaals), je brengt jezelf soms onbedoeld in grappige situaties (zoals de rolstoel tijdens de Fall School, de biercantus in Regensburg), die voor veel onvergetelijke momenten hebben gezorgd. De goede sfeer zorgde ervoor dat ik altijd met plezier naar de WUR ging.

Mijn onderzoek was natuurlijk niet mogelijk geweest zonder de deelname van de mbo instellingen, hun teamleiders en docententeams. Ik wil alle deelnemers dan ook bedanken voor hun commitment. Zij hebben drie keer die toch wel lange vragenlijsten ingevuld en in sommige gevallen ook nog extra tijd vrijgemaakt voor deelname aan 
interviews. Hopelijk hebben onze terugkoppelingen van de resultaten jullie waardevolle inzichten opgeleverd.

Natuurlijk wil ik ook mijn (schoon-)familie en vrienden bedanken, die, hoewel ze het zelf misschien niet beseffen, een belangrijke rol hebben gespeeld. Ik heb tijdens mijn promotietraject genoten van de gezellige momenten samen, waarop ik mijn onderzoek goed kon loslaten en in perspectief kon plaatsen.

Ook wil ik mijn paranimfen, Eva (nogmaals) en Johan, bedanken voor hun enthousiasme en betrokkenheid bij de laatste fase van mijn promotietraject; de verdediging en feestelijke afsluiting!

Ten slotte wil ik mijn lieve Veerle bedanken. Mijn keuze om te gaan promoveren had ook voor jou veel gevolgen. We zijn gaan samenwonen in Utrecht, eerst in jouw kleine, gezellige studiootje (slapen in de keuken en eten in de slaapkamer), daarna in ons burgerlijke rijtjeshuis. Je gaf vaak goede adviezen en door samen leuke dingen te doen, heb je me uit de 'valley of sh*t' gehouden. Zonder jou had ik dit nooit kunnen doen! 


\section{About the author}

Machiel Bouwmans was born on September 25, 1984, in Deurne. He obtained his master's degree in Sociology at the Tilburg University and his master's degree in Political Science at the Radboud University. In 2009, Machiel started his career as a researcher at Ipso Facto Beleidsonderzoek and later at Actis Onderzoek. In 2013, he started his PhD trajectory on the topic of team learning of VET teacher teams at the Wageningen University. Machiel currently works at the Research Group (Lectoraat) Vocational Education at the University of Applied Sciences Utrecht and teaches on the topic of Learning in Organisations at the Department of Education at Utrecht University.

\section{Peer reviewed articles: published and in press}

Bouwmans, M., Runhaar, P., Wesselink, R., \& Mulder, M. (2017). Fostering teachers' team learning: An interplay between transformational leadership and participative decision-making? Teaching and Teacher Education, 65, 71-80. doi: 10.1016/j.tate.2017.03.010

Bouwmans, M., Runhaar, P., Wesselink, R., \& Mulder, M. (2017). Stimulating teachers' team performance through team-oriented HR practices: The roles of affective team commitment and information processing. International Journal of Human Resource Management. doi: 10.1080/09585192.2017.1322626

Bouwmans, M., Runhaar, P., Wesselink, R., \& Mulder, M. (In press). Leadership ambidexterity: Key to stimulating team learning through team-oriented HRM? An explorative study among teacher teams in VET colleges. Educational Management Administration \& Leadership

Bouwmans, M., Runhaar, P., Wesselink, R., \& Mulder, M. (In press). Towards distributed leadership in VET schools: the interplay between formal leaders and team members. Educational Management Administration \& Leadership.

\section{Professional publications related to this dissertation}

Bouwmans, M., \& Runhaar, P. (2014). Teamgericht HRM. Profiel Vakblad, (7), 30.

Bouwmans, M., \& Runhaar, P. (2017). Gespreid leiderschap in een hiërarchische organisatiestructuur. In F. Hulsbos, \& S. van Langevelde (Eds.), Gespreid leiderschap in het onderwijs. Elkaar invloed gunnen voor vernieuwing. Utrecht: Kessels \& Smit Publishers.

Bouwmans, M., \& Runhaar, P. (2017). De invloed van teamgericht HRM op teamleeractiviteiten van docenten. De Nieuwe Meso, (3), 64-70.

Runhaar, P., Bouwmans, M., \& Wesselink, R. (2015). Teamontwikkeling in het mbo: Aandacht voor werkverdeling. Hoe verdelen we de taken? Profiel Vakblad, (1), 14-15.

Zoethout, H., Bouwmans, M., Runhaar, P., \& Wesselink, R. (2016). Eén voor allen, allen voor één. $0 \& 0,29$ (2), 22-26. 


\section{Conference papers and presentations}

Bouwmans, M., Runhaar, P., Wesselink, R., \& Mulder, M. (2015). The influence of teambased HRM on team learning (summary). Paper presented at EAWOP, Oslo.

Bouwmans, M., Runhaar, P., Wesselink, R., \& Mulder, M. (2015). Can HRM stimulate teachers' team learning? Examining the relationship between $H R$ practices and learning activities in the educational context. Paper presented at the Onderwijs Research Dagen (ORD), Leiden.

Bouwmans, M., Runhaar, P., Wesselink, R., \& Mulder, M. (2016). Distributed leadership and team learning in VET teacher teams. Paper presented at the Onderwijs Research Dagen (ORD), Rotterdam.

Bouwmans, M., Runhaar, P., Wesselink, R., \& Mulder, M. (2016). Stimulating teachers' team performance through team-oriented HR practices: Unravelling the role of affective team commitment and team learning. Paper presented at EARLI SIG 14, Regensburg.

Bouwmans, M., Runhaar, P., Wesselink, R., \& Mulder, M. (2016). Towards distributed leadership: From opportunities created by formal leaders to a development through team learning. Paper presented at Competence 2016, Wageningen.

Bouwmans, M., Runhaar, P., Wesselink, R., \& Mulder, M. (2017). Het stimuleren van teamleren door leiderschap. Presentation at the Onderwijs Research Dagen (ORD), Antwerpen. 
in the context of the research school

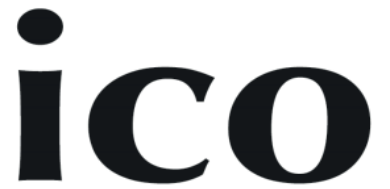

Interuniversity Center for Educational Research

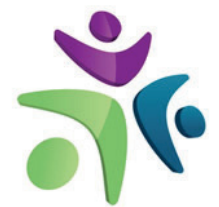

Wageningen School of Social Sciences

Marinus Henri Corné Frans Bouwmans

Wageningen School of Social Sciences (WASS)

Completed Training and Supervision Plan

Name of the learning activity

A) Project related competences

Learning in and for vocations and professions

Advanced studies in HRM

Competence theory research and practice

ICO National fall school

ICO International fall school

\section{B) General research related competences}

WASS Introduction course

ICO Introductory Course

From topic to proposal

Mplus: How to get started?

Longitudinal data analysis: the current best methods

Scientific writing

Start to teach

'Kan HRM teamleren van docenten stimuleren?

Onderzoek naar de relatie tussen HRM praktijken

en leeractiviteiten in onderwijsteams'

'De ontwikkeling van gespreid leiderschap en de rol van teamleren'

'Het stimuleren van teamleren door leiderschap'

'The development of distributed leadership through top-down and bottom-up processes'

'Can HRM stimulate teachers' team learning?

Examining the relationship between HR practices and learning activities in the educational context'

'Can team-oriented HRM stimulate teacher team performance? The role of team commitment and team learning'

\section{Department/Institute}

Year ECTS*

$\begin{array}{lll}\text { ICO } & 2013 & 3 \\ \text { Dutch HRM Network } & 2015 & 6 \\ \text { WASS/ICO } & 2014 & 3 \\ \text { ICO } & 2015 & 1 \\ \text { ICO } & 2014 & 3\end{array}$

WASS
ICO
WASS
Utrecht University
Utrecht University
Wageningen in'to languages
Utrecht University
ORD, Leiden

$2013 \quad 1$

$2014 \quad 5$

20134

$2014 \quad 0.5$

$2015 \quad 1.5$

ORD, Rotterdam

$2016 \quad 1$

ORD, Antwerpen

$2017 \quad 1$

Competence 2016,

Wageningen

EAWOP, Oslo

$2016 \quad 1.8$

$2017 \quad 0.9$

$2015 \quad 1$

20161

$2015 \quad 1$

EARLI SIG 14, Regensburg $2016 \quad 1$ 


\section{C) Career related competences/personal development}

Committee and chair group work

ECS

2013-

- Management team ECS

2017

- $\mathrm{PhD}$ Committee

- $\quad$ ECS research meetings

Teaching activities

- $\quad$ Teaching and supervising master thesis students

- Guest lectures

Total

* One credit according to ECTS is on average equivalent to 28 hours of study load 
The research described in this thesis was financially supported by the Netherlands Organisation for Scientific Research (NWO) [Grant number 411-12-070].

Printed by: Digiforce (www.proefschriftmaken.nl) 

*

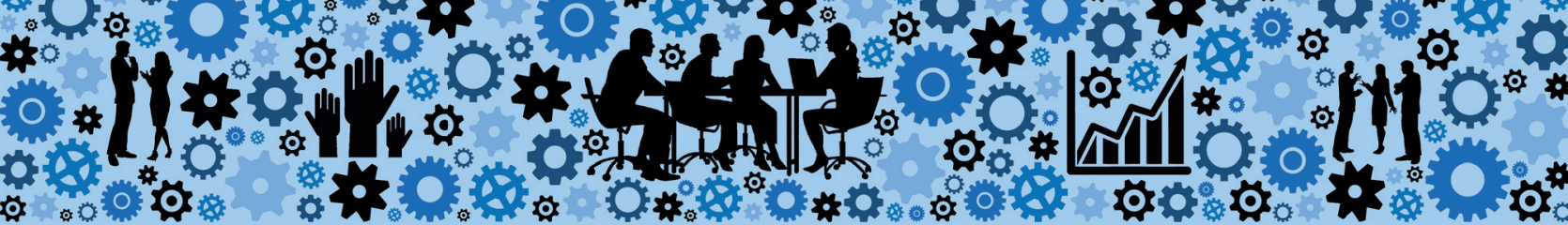




\section{Propositions}

1. Real teacher teams are needed to improve educational quality. (this thesis)

2. Distributed leadership is a utopia. (this thesis)

3. Too much theoretical discussion without empirical research leads to scientific stagnation.

4. Valorisation should be a more central criterion in evaluating scientific contributions.

5. Different types of discourse in social science disciplines prevent scientific progress.

6. An excellent composition does not automatically imply an excellent photograph.

7. Finishing a dissertation requires spending much time away from a laptop.

Propositions belonging to the thesis, entitled

'The role of VET colleges in stimulating teachers' engagement in team learning'

Machiel Bouwmans

Wageningen, 12 January 2018 